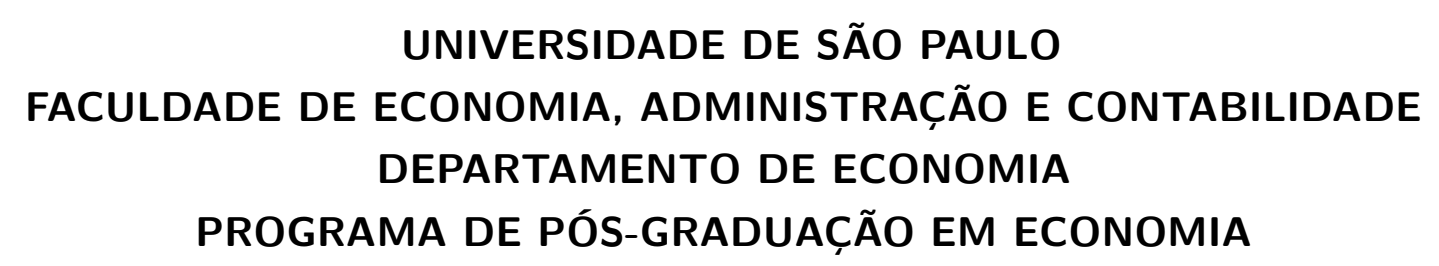

\title{
A Desoneração da Folha Salarial e seu Efeito sobre o Mercado de Trabalho no Brasil
}

Erick Baumgartner

Orientador: Profa. Dra. Renata Del Tedesco Narita

São Paulo - Brasil

2017 
Prof. Dr. Marco Antonio Zago

Reitor da Universidade de São Paulo

Prof. Dr. Adalberto Américo Fischmann

Diretor da Faculdade de Economia, Administração e Contabilidade

Prof. Dr. Eduardo Amaral Haddad

Chefe do Departamento de Economia

Prof. Dr. Ariaster Baumgratz Chimeli

Coordenador do Programa de Pós-Graduação em Economia 


\title{
A Desoneração da Folha Salarial e seu Efeito sobre o Mercado de Trabalho no Brasil
}

\author{
Dissertação apresentada ao Departamento \\ de Economia da Faculdade de Economia, \\ Administração e Contabilidade da Univer- \\ sidade de São Paulo como requisito parcial \\ para a obtenção do título de Mestre em \\ Ciências.
}

Orientador: Profa. Dra. Renata Del Tedesco Narita

Versão Original

São Paulo - Brasil

2017 
FICHA CATALOGRÁFICA

Elaborada pela Seção de Processamento Técnico do SBD/FEA/USP

Baumgartner, Erick

A desoneração da folha salarial e seu efeito sobre o mercado de

trabalho no Brasil / Erick Baumgartner. -- São Paulo, 2017.

$103 \mathrm{p}$.

Dissertação (Mestrado) - Universidade de São Paulo, 2017

Orientador: Renata Del Tedesco Narita.

1. Encargo social 2. Mercado de trabalho 3. Emprego 4. Salários 5. Contribuição previdenciária I. Universidade de São Paulo. Faculdade de Economia, Administração e Contabilidade. II. Título. 


\section{Agradecimentos}

Agradeço à minha família, pelo apoio incondicional aos meus projetos, por mais inusitados que às vezes sejam.

Agradeço à minha orientadora, Renata del Tedesco Narita, pela orientação e por toda a atenção dada no decorrer deste trabalho. Também agradeço aos professores Raphael Bottura Corbi e Paula Carvalho Pereda pelas críticas e sugestões dadas.

Agradeço ainda aos grandes amigos que fiz durante o mestrado. O ambiente que construímos juntos foi, com certeza, um dos grandes motivos para que esse período fosse tão proveitoso. 

"You look at each individual paper published in Economics, and it seems trivial. But you do all this kind of work, not because you expect the individual report that's written to make a difference, but because the overall milieu and the professional consensus that arises about general directions to be taken is of interest. It creates ideas about the world, but they only become influential because they are built on this 'mount of gravel'. You can pick a stone and overlook its importance, but it is contributing to the formation of something bigger". 



\section{Resumo}

Este trabalho usa a alocação discricionária de setores econômicos no regime tributário diferenciado criado pela desoneração da folha salarial para estimar o impacto de um incentivo fiscal e da mudança da base tributária da contribuição previdenciária dos salários para a receita bruta. Com base em um painel de setores econômicos observado na Relação Anual de Informações Sociais (RAIS) entre 2009 e 2014, estimase um Event Study usando os ramos econômicos onde apenas parte dos setores foram desonerados, enquanto outros setores similares mantiveram-se no regime antigo. Os resultados não encontram efeito da política para os salários, assim como para o nível de emprego dos setores desonerados em função de seus produtos (NCM). Para os desonerados por atividade econômica (CNAE), por outro lado, estima-se um efeito positivo de $7,5 \%$ da desoneração sobre o nível de emprego das empresas desoneradas (fora do SIMPLES), que é parcialmente compensado por uma diminuição do emprego dentro do SIMPLES.

Palavras-chaves: Encargo social. Mercado de trabalho. Emprego. Salários. Contribuição previdenciária. 



\section{Abstract}

This work uses the discretionary allocation of economic sectors in the new contribution regime created by the payroll tax relief to estimate the impact of a fiscal incentive and the substitution of the tax base of the social security contribution from payroll to gross revenues. I estimate an Event Study based on data from economic sectors observed between 2009 and 2014 in Relação Anual de Informações Sociais (RAIS), using economic groups where only part of the integrating sectors have been shifted from their tax regime, leaving similar sectors with different contribution schemes. The results do not find any effect on salaries, as well as on the employment level of sectors allocated in the new regime based on their products (NCM). Sectors that received the payroll tax relief based on their economic activity (CNAE), however, show an increase of $7.5 \%$ on their employment level, which is partly offset by a decrease in the employment level of SIMPLES.

Key-words: Social charges. Labor market. Employment. Salaries. Social security contribution 



\section{Lista de ilustrações}

Figura 1 - Event-Studies Trimestrais dos Placebos de Salário - Grande Setor de 2 Dígitos . . . . . . . . . . . . . . . . . . 37

Figura 2 - Event-Studies Trimestrais dos Placebos de Emprego - Grande Setor de 2 Dígitos . . . . . . . . . . . . . . . . . . . . . . 39

Figura 3 - Event-Studies Trimestrais dos Placebos de Emprego - Grande Setor de 3 Dígitos . . . . . . . . . . . . . . . . . . . . . 40 40

Figura 4 - Event-Studies Trimestrais dos Salários Iniciais - Grande Setor de 2 Dígitos 45

Figura 5 - Event-Studies Trimestrais do Emprego no Regime Normal . . . . . . . 50

Figura 6 - Event-Studies Trimestrais do Emprego no SIMPLES . . . . . . . . . . 52

Figura 7 - Event-Studies Trimestrais do Emprego no Total . . . . . . . . . . . . . 54

Figura 8 - Event-Studies Trimestrais do Emprego no Total por Intensidade . . . . 55

Figura 9 - Event-Studies Trimestrais do Emprego no Total em função da MP 77457

Figura 10 - Event-Studies Trimestrais do Emprego no Total - Comparação dos Erros 58

Figura 11 - Event-Studies Trimestrais do Emprego no Total em função da MP 774

- Comparação dos Erros . . . . . . . . . . . . . . . . 58

Figura 12 -Event-Studies Trimestrais do Emprego no Total por Intensidade - Comparação dos Erros . . . . . . . . . . . . . . . . . . . . . . 59 



\section{Lista de tabelas}

Tabela 1 - Histórico da Política de Desoneração . . . . . . . . . . . . . . . . 20

Tabela 2 - Comparação de Produtos Desonerados e Não Desonerados . . . . . . . 21

Tabela 3 - Exemplos de Contribuição Previdenciária . . . . . . . . . . . . . . 21

Tabela 4 - Comparação dos Regimes Tributários . . . . . . . . . . . . . . 23

Tabela 5 - Comparação dos Regimes Tributários . . . . . . . . . . . . . . . 24

Tabela 6 - Renúncia Fiscal e Repasses Governamentais . . . . . . . . . . . . . . 24

Tabela 7 - Distribuição de Setores - Grande Setor de 2 Dígitos . . . . . . . . . . . 32

Tabela 8 - Distribuição de Setores - Grande Setor de 3 Dígitos . . . . . . . . . . . 32

Tabela 9 - Exemplo de Setores Comparáveis . . . . . . . . . . . . . . 33

Tabela 10 - Estimação dos Placebos de Salário para o Grande Setor de 2 Dígitos 36

Tabela 11 -Estimação dos Placebos de Emprego para o Grande Setor de 2 Dígitos 38

Tabela 12 - Estimação dos Placebos de Emprego para o Grande Setor de 3 Dígitos 40

Tabela 13 - Análise do Efeito da Desoneração sobre as Características Setoriais Desonerados por CNAE . . . . . . . . . . . . . . . . 42

Tabela 14 -Estimação dos Salários Iniciais no Regime Normal . . . . . . . . . . . 44

Tabela 15 - Estimação dos Salários Iniciais de Baixa Escolaridade no Regime Nor-

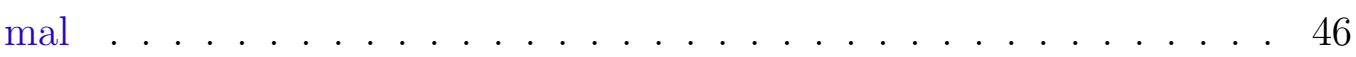

Tabela 16 -Estimação dos Salários no Regime Normal . . . . . . . . . . . . . . . 48

Tabela 17 - Estimação do Nível de Emprego no Regime Normal . . . . . . . . . . . 50

Tabela 18 -Estimação do Nível de Emprego no SIMPLES . . . . . . . . . . . . . . 51

Tabela 19 -Estimação do Nível de Emprego no Total . . . . . . . . . . . . . . 53

Tabela 20 -Separação do Efeito pela Intensidade da Desoneração . . . . . . . . . . 55

Tabela 21 - Separação do Efeito entre Setores Mantidos e Retirados pela MP №774 56

Tabela 22 -Estimação da Proporção de Firmas no SIMPLES . . . . . . . . . . . . 67

Tabela 23 -Estimação do Tamanho das Firmas . . . . . . . . . . . . . . 68

Tabela 24 - Estimação do Nível de Emprego Total dos Desonerados pela CNAE . . 69

Tabela 28 - Lista de Setores Mantidos pela MP 774 e "Analisáveis" . . . . . . . . . 103 



\section{Sumário}

1 Introdução e Revisão da Bibliografia Fundamental . . . . . . . . . . . . . . 17

1.1 A Desoneração da Folha de Pagamentos . . . . . . . . . . . . . . . 17

1.2 Revisão da Bibliografia Fundamental . . . . . . . . . . . . . . . . . . . . . 24

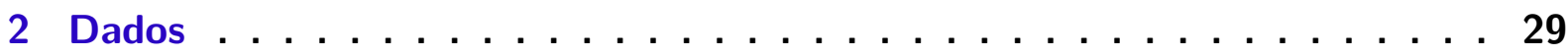

3 Identificação e Metodologia . . . . . . . . . . . . . . . . . . . . . 31

4 Análise dos Resultados . . . . . . . . . . . . . . . . . . . 43

4.1 Efeitos sobre o Nível Salarial . . . . . . . . . . . . . . . . . . . . . . 43

4.2 Efeitos sobre o Nível de Emprego . . . . . . . . . . . . . . . . . . . 49

4.3 Efeitos Diferenciados sobre o Emprego . . . . . . . . . . . . 54

5 Considerações Finais . . . . . . . . . . . . . . . . . . . . 61

Referências ......................... 63

$\begin{array}{ll}\text { Apêndices } & 65\end{array}$

APÊNDICE A Regressões de Saída do SIMPLES . . . . . . . . . . . . . . 67

APÊNDICE B Regressões com Erros Clusterizados . . . . . . . . . . . 69

Anexos

ANEXO A Setores Comparáveis . . . . . . . . . . . . . . 73

A.1 Lista de Setores Comparáveis - 2 Dígitos da CNAE . . . . . . . . . . . 73

A.2 Lista de Setores Comparáveis - 3 Dígitos da CNAE . . . . . . . . . . . . 84

ANEXO B Comparação das Contribuições na CPP e na CPRB . . . . . . . 89

ANEXO C Lista de Setores Analisáveis Mantidos pela MP $774 \ldots$. . . . . . 103 



\section{Introdução e Revisão da Bibliografia Fun- damental}

\subsection{A Desoneração da Folha de Pagamentos}

No dia 2 de agosto de 2011 a presidente da República, Dilma Rousseff, anunciou o início do Plano Brasil Maior, um pacote de medidas do governo federal que criava incentivos para a indústria nacional. Algumas das ações mais emblemáticas de seu governo foram realizadas neste programa, como a continuação do Programa de Sustentação do Investimento, ampliando as linhas de crédito do BNDES, e a criação do REINTEGRA, uma renúncia fiscal dos custos tributários federais das empresas exportadoras de bens manufaturados. Além destas medidas, iniciou-se o processo de desoneração da folha de pagamentos. Até o ano de 2011, a contribuição previdenciária das empresas não vinculadas ao SIMPLES era regida pela Lei 8.212, de 24 de julho de 1991, estipulando a parcela patronal do pagamento à Previdência em $20 \%$ da massa salarial dos empregados. Com o lançamento do Plano Brasil Maior, porém, promulgou-se a Medida Provisória №540, posteriormente convertida na Lei 12.546 que, entre outras medidas, criava a Contribuição Previdenciária sobre a Receita Bruta. Dessa maneira, as empresas dos setores estipulados pela MP passariam a ter uma base diferenciada para a contribuição à Previdência, criando assim dois regimes paralelos de tributação.

Passados seis anos da introdução da nova tributação, a avaliação da mudança da base tributária e, principalmente, da considerável renúncia fiscal que a acompanhou, parece estar longe de ser positiva. Dilma Rousseff declarou ter se equivocado em sua política de desonerações (O Estado de S. Paulo (2017)), e interpreta que os incentivos não tiveram contrapartida em investimentos, sendo absorvidos na taxa de lucro das empresas. O governo Temer parece compartilhar dessa visão, promulgando em 31 de março de 2017 a MP №774, que acaba com a desoneração para quase todos os setores inseridos. Segundo o ministro da Fazenda, Henrique Meirelles, os poucos regimes mantidos no esquema da desoneração são aqueles onde houve efeito da política de incentivos (O Globo (2017)).

A criação da Contribuição Previdenciária sobre a Receita Bruta (CPRB) foi fruto de um debate que já se estendia há muito tempo no contexto brasileiro. Um dos catalisadores da proposta pela desoneração do trabalho foi o aumento da informalidade durante a década de 80. Ulyssea (2005) aponta que, em 1981, a proporção de trabalhadores sem carteira assinada era de $28 \%$. Apesar das turbulências econômicas da chamada "Década Perdida", o nível da informalidade brasileira manteve-se relativamente estável neste patamar. A partir da década de 90, porém, assiste-se a um forte crescimento da taxa de 
trabalhadores informais, chegando a aproximadamente $45 \%$ no ano 2000. Esse período é marcado pela liberalização econômica iniciada pelo governo Collor e pela chamada "Constituição Cidadã", promulgada em 1988 e marcada por seu caráter progressista, levando assim a um aumento dos custos trabalhistas. Bosch, Goñi-Pacchioni e Maloney (2012) realizaram análise onde buscavam responder quais fatores haviam tido maior impacto neste aumento da informalidade. Segundo os autores, $40 \%$ a $50 \%$ desse crescimento é devido à reforma constitucional, enquanto a liberalização econômica possui efeito marginal na taxa de informalidade.

É em meio a esse aumento exacerbado da informalidade no mercado de trabalho e a consequente queda na arrecadação tributária que se inicia o debate quanto aos meios de reversão desta tendência. Um histórico desse debate é apresentado por Paiva e Ansiliero (2009). Os autores apontam o ano de 1995 como o marco em que, pela primeira vez, o valor da arrecadação das contribuições previdenciárias não foi suficiente para o cobrir o pagamento dos benefícios. A partir daí surgiram diversas medidas legais que, na prática, abriam o caminho para a desoneração. A primeira delas é a Emenda Constitucional №20 de 1998, que abria espaço para que contribuições previdenciárias patronais sobre a folha de pagamento pudessem ter alíquotas ou bases de cálculo diferenciadas. Posteriormente surge a EC №41 de 2003, que inclui a possibilidade da substituição da contribuição sobre a folha de pagamentos por "contribuição específica incidente sobre a receita ou faturamento". Ainda no ano de 2008 é enviada ao Congresso a Proposta de Emenda à Constituição (PEC) №233, que determinava a regulamentação da desoneração parcial da contribuição patronal sobre a folha de pagamento, e que acabou por não ser apreciada pelo Congresso.

Por trás desta movimentação legal inicial encontravam-se diferentes propostas sobre a reação a ser tomada em face ao aumento da informalidade. Paiva e Ansiliero (2009) citam diversas frentes neste sentido, como o Fórum Nacional da Previdência Social, concluído em 2007 e que declarou, entre seus consensos, a busca pela desoneração da folha de salários sem aumento da carga tributária, e o Ministério Extraordinário de Assuntos Estratégicos, que em seu trabalho "Diretrizes a respeito da reconstrução das relações entre o trabalho e o capital no Brasil" apresenta a desoneração como elemento de "peso substancial" para a diminuição da informalidade no Brasil.

Paralelamente, a conjuntura econômica do período trazia outros elementos ao debate. A OCDE, em sua publicação "The OECD Jobs Study" OCDE (1994), manifestou-se favoravelmente a medidas neste sentido como solução para as crescentes taxas de desemprego do continente europeu naquele momento. A desoneração da folha de pagamentos representa uma diminuição nos custos de contratação da força de trabalho, reduzindo uma teórica ineficiência trazida pela taxação incidente sobre os salários. Como apontam Ansiliero et al. (2008), esta interpretação sustenta-se na ideia de que a incidência do imposto recai de maneira considerável sobre o empregador. Se não existe possibilidade de 
repasse total da taxa para o trabalhador, uma diminuição da mesma também reduz os custos de contratação, atuando como um incentivo ao emprego. No contexto europeu, em meio à crise econômica de 2008, a impossibilidade de uma desvalorização cambial dentro de uma união monetária levou à defesa da chamada "desvalorização fiscal", uma busca de ganhos de competitividade através da diminuição dos custos dos fatores de produção. Tais diminuições seriam reparadas através de um imposto sobre o valor agregado (IVA), não recaindo sobre as exportações e dando vantagens relativas à produção nacional. No Brasil, os efeitos da crise econômica de 2008 também incentivavam o governo a realizar medidas que buscassem a manutenção do nível de emprego, tornando ainda mais amplo o escopo das reformas tributárias.

Com isso, percebemos um movimento de longo prazo em busca de mudanças do sistema tributário brasileiro visando maior formalização e a garantia de financiamento da previdência e, paralelamente, uma pressão mais imediata neste mesmo sentido buscando a manutenção do nível de emprego e maior competitividade para a indústria nacional. É irônico perceber que enquanto o debate de longo prazo tinha interesse, especificamente, no aumento das contribuições previdenciárias, a desoneração criada a partir de 2011 opta por uma considerável renúncia fiscal, com diminuição dos pagamentos à previdência da grande maioria dos setores afetados. Ainda que a lei estipulasse a compensação, por parte do governo, do montante não repassado à previdência em função da desoneração, os repasses realizados estiveram constantemente abaixo do valor estimado da renúncia.

A mudança tributária foi realizada progressivamente. Seguindo a conversão da MP №540 na Lei 12.546, diversos atos legislativos foram promulgados, ampliando o escopo do novo regime. Enquanto inicialmente apenas um pequeno número de setores havia sido beneficiado, como as empresas de calçados, confecção de artefatos de couro e de tecnologia de informação, ao fim do processo de inclusão, em 2014, a desoneração já afetava 273 dos 670 setores da CNAE no nível "classe" (5 dígitos). A tabela 1 apresenta um resumo dos atos iniciais e dos setores incluídos por eles neste novo regime tributário.

O grande número de atos relacionados à desoneração é apenas um dos diversos indicativos do alto grau de complexidade do regime criado. Foram escolhidos critérios diferentes para alocar setores no novo regime. O primeiro deles é a Tabela de Incidência sobre Produtos Industrializados (TIPI), que utiliza a mesma classificação que a Nomenclatura Comum do Mercosul (NCM). O segundo critério é o código da Classificação Nacional de Atividades Econômicas (CNAE 2.0) da empresa. Além destes, existem casos específicos em que a alocação de um setor econômico se faz em função da definição apresentada em lei, sem nenhuma alusão à CNAE 2.0, como é o caso dos setores de TI e TIC. A diversidade é controversa pois, como apontado em Nota Técnica sobre a Desoneração da Folha Salarial ANFIP (2015), a Constituição Federal, nas emendas relativas à desoneração, especifica: "a lei definirá os setores de atividade econômica para os quais as contribuições incidentes 
Tabela 1 - Histórico da Política de Desoneração

\begin{tabular}{|c|c|c|}
\hline Ato & Lei & Setores Desonerados \\
\hline MP №540 & $12.546 / 2011$ & $\begin{array}{l}\text { Serviços ( call centers e empresas de tecnolo- } \\
\text { gia da informação e comunicação - TI e TIC) } \\
\text { e Indústria (confecções e artefatos de couro) }\end{array}$ \\
\hline MP №563 & $12.715 / 2012$ & $\begin{array}{l}\text { Serviços (design houses e hotéis) e Indús- } \\
\text { tria (móveis, plásticos, têxtil, material elé- } \\
\text { trico, entre outros) }\end{array}$ \\
\hline PLV №18 & $12.715 / 2012$ & $\begin{array}{l}\text { Indústria (brinquedos, medicamentos e fár- } \\
\text { macos, pedras e rochas ornamentais, entre } \\
\text { outros) e Transportes (aéreo, rodoviário co- } \\
\text { letivo e marítimo) }\end{array}$ \\
\hline MP №582 & $12.794 / 2013$ & $\begin{array}{l}\text { Indústria (pescado, vidros, construção me- } \\
\text { tálica, equipamento ferroviário, papel e celu- } \\
\text { lose, entre outros) }\end{array}$ \\
\hline MP №610 & $12.844 / 2013$ & $\begin{array}{l}\text { Serviços (suporte técnico de informática), } \\
\text { Construção (construção civil), Comércio } \\
\text { (comércio varejista), Indústria (borracha, } \\
\text { cobre e suas obras, manutenção e repara- } \\
\text { ção de embarcações, entre outros) e, a partir } \\
\text { de } 2014 \text {, Transportes (rodoviário de carga, } \\
\text { metroferroviário de passageiros, entre outros) }\end{array}$ \\
\hline
\end{tabular}

Nota: Lista de leis que alocaram a desoneração e seus respectivos setores

na forma dos incisos I, b e IV do caput, serão Não Cumulativas, inclusive na hipótese de substituição gradual, total ou parcial, da contribuição incidente na forma do inciso I (do empregador, da empresa e da entidade a ela equiparada na forma da lei) pela incidente sobre a receita ou o faturamento". Logo, há uma orientação clara pela escolha de setores econômicos, e não de produtos. A dificuldade proveniente da utilização da TIPI está na fiscalização das empresas, já que produtos muito parecidos foram alocados em regimes diferentes de tributação, de modo que identificar declarações falsas da venda de produtos desonerados se torna extremamente complicado. A tabela 2 apresenta alguns desses casos.

É importante ressaltar que, para o caso das desonerações por NCM, houve espaço para um benefício diferenciado. A Lei 12.844, de julho de 2013, criou um acréscimo de $1 \%$ no COFINS dos produtos importados que tiverem sido desonerados pela Lei 12.546. A justificativa para esse acréscimo era a equiparação entre o produtor internacional e o nacional, que passara também a contribuir sobre sua receita. Dada a renúncia fiscal da medida, porém, tal medida apenas somou-se aos benefícios trazidos aos produtores desonerados, encarecendo os produtos dos concorrentes internacionais.

Tanto para as empresas alocadas no novo regime através do setor econômico quanto as produtoras de itens desonerados através do TIPI, o cálculo de sua contribuição deve 
Tabela 2 - Comparação de Produtos Desonerados e Não Desonerados

\begin{tabular}{cccc}
\hline \multicolumn{2}{c}{ Desonerados } & \multicolumn{2}{c}{ Não Desonerados } \\
\hline \hline NCM & Descrição & NCM & Descrição \\
\hline 82.01 .40 .00 & Machado & 82.11 .91 .00 & Facas de mesa \\
\hline 82.03 .20 .10 & Alicates & $82 . .11 .93 .10$ & Podadeiras \\
\hline 82.03 .40 .00 & Corta tubos & 82.12 .10 .10 & Navalhas \\
\hline 82.04 .11 .00 & Chave de porca & 82.13 .00 .00 & Tesouras \\
\hline 82.05 .20 .00 & Martelos & 82.14 .10 .00 & Espátulas \\
\hline 83.01 .10 .00 & Cadeados & 82.15 .10 .00 & Colheres, garfos, etc. \\
\hline
\end{tabular}

Nota: Fonte: SPE - Ministério da Fazenda

ser feito de maneira proporcional. Para todas aquelas que têm menos de $5 \%$ de sua receita proveniente de atividades e produtos desonerados, a tributação mantém-se a mesma, contribuindo com $20 \%$ de sua folha de pagamentos. Para as demais, porém, a contribuição se divide proporcionalmente entre os dois regimes, em função da fração da receita auferida em cada um deles. A tabela 3 apresenta o funcionamento desse sistema. No caso (1), a empresa só atua no novo regime, e contribui com $2 \%$ de toda a sua receita bruta. No caso (2), a empresa aufere menos de $5 \%$ de sua receita com produtos e atividades desonerados, e sendo assim, contribui apenas sobre sua folha de pagamento. No caso (3), metade de sua receita é proveniente de desonerados, de modo que 50\% de sua contribuição é calculada sobre sua receita bruta e a outra metade no regime antigo, em função de sua folha de pagamentos.

Tabela 3 - Exemplos de Contribuição Previdenciária

\begin{tabular}{lccc}
\hline $\begin{array}{l}\text { Receita de } \\
\text { Martelos } \\
\text { (Des.) }\end{array}$ & Espátulas & Folha de Pagamento & Contribuição Previdenciária \\
\hline \hline$(1) \mathrm{R} \$ 1000$ & $\mathrm{R} \$ 0$ & $\mathrm{R} \$ 300$ & $\begin{array}{c}\mathrm{R} \$ 20 \\
\left(0,02^{*} 1000\right)\end{array}$ \\
\hline$(2) \mathrm{R} \$ 40$ & $\mathrm{R} \$ 960$ & $\mathrm{R} \$ 300$ & $\begin{array}{c}\mathrm{R} \$ 60 \\
(0,2 * 300)\end{array}$ \\
\hline (3) $\mathrm{R} \$ 500$ & $\mathrm{R} \$ 500$ & $\mathrm{R} \$ 300$ & $\begin{array}{l}\mathrm{R} \$ 40 \\
\end{array}$ \\
\hline
\end{tabular}

Nota: Elaboração do Autor

Sendo levado a cabo primordialmente através de medidas provisórias, o processo é influenciado pela estrutura legislativa, com a constante modificação de propostas governamentais através de emendas parlamentares. Com isso, não parecem haver critérios claros para a escolha dos setores desonerados. Um caso emblemático é a classe 5510-8 da CNAE, "Hotéis e Similares", onde hotéis foram desonerados enquanto motéis e apart hotéis mantiveram-se no antigo regime de tributação. Acompanhando as justificativas dos vetos presidenciais, é recorrente o bloqueio de setores que são posteriormente adicionados 
em um próximo ato legislativo, o que também poderia indicar a disputa entre executivo e legislativo. Um evento sintomático dessa disputa é a devolução, por parte de Renan Calheiros, presidente do Senado na ocasião, da MP №669, de 2015, que tratava do aumento das alíquotas da CPRB. O pressuposto para a utilização de medidas provisórias é a urgência e a relevância da matéria tratada, sendo claramente inadequada para uma reestruturação do regime tributário. Ainda assim, dada a aceitação de inúmeras MPs anteriores relacionadas à desoneração, tal devolução é representativa da deterioração do relacionamento entre os dois poderes.

Outro exemplo da falta de clareza nos objetivos da medida é o capítulo 19 da Tabela de Incidência sobre Produtos Industrializados (TIPI), referente a "preparações a base de cereais, farinhas, amidos, féculas ou leite; produtos de pastelaria", que foi completamente desonerado pela Lei 12.794 de setembro de 2012. Em 2014, porém, a Lei 13.043 excluiu do regime de desoneração especificamente o produto 1901.20.00, "Misturas e pastas para a preparação de produtos de padaria, pastelaria e da indústria de bolachas e biscoitos, da posição 19.05" (além da denominação 1901.90.90, referente a "outros"). O caso se torna ainda mais curioso com a Lei 13.161 de 2015, que recoloca o produto entre os desonerados. O grau extremo de especificação de escolhas como esta contrasta com a discricionariedade com que os setores foram incluídos no esquema de desoneração, tornando ainda mais indispensáveis as (não apresentadas) justificativas para a seleção dos setores e produtos do novo regime.

Inicialmente, as alíquotas do novo regime foram estipuladas em 2,5\% ou 1,5\% da receita bruta, de acordo com o setor de atividade. A Lei 12.715 de 2012, porém, diminuiu as mesmas para $2 \%$ e $1 \%$, respectivamente. Para as empresas alocadas na alíquota de $2 \%$, a tabela 4 apresenta a comparação entre a contribuição no regime anterior e aquela com base na CPRB.

Como podemos ver, a desoneração diminuiu a contribuição previdenciária de todos os setores apresentados. O mesmo ocorre para os setores com a alíquota de 1\%, como apresenta a tabela 5. Em ambos os cados, subsetores pontuais inseridos nos grupos apresentados apresentam um grau menor de desoneração, ou mesmo, em casos específicos, oneração em relação ao regime anterior. A comparação em um nível mais agregado é apresentada no Anexo 2. Ainda assim, casos como esse são uma exceção, e na maior parte dos setores, a desoneração representa uma diminuição tributária considerável.

Dado o montante da renúncia fiscal trazido pela desoneração, um dos grandes problemas criados pelo novo regime tributário foi o tamanho dos repasses necessários para cobrir o vácuo de arrecadação da previdência. O inciso IV do art. 9º da Lei №12.546 explicita que a União deve compensar o Fundo do Regime Geral de Previdência Social por essas perdas. A tabela 6 apresenta a renúncia fiscal e os repasses governamentais entre 2012 e 2014. 
Tabela 4 - Comparação dos Regimes Tributários

\begin{tabular}{|c|c|c|c|c|}
\hline CNAE 2.0 & Atividade Econômica & $\begin{array}{l}\text { Contribuição de } \\
1 \% \text { sobre a Receita } \\
\text { Bruta (Líquida } \\
\text { de Exportações) - } \\
\text { CPRB }\end{array}$ & $\begin{array}{l}\text { Contribuição de } 20 \% \\
\text { sobre a Folha de } \mathrm{Pa}- \\
\text { gamentos - CPP }\end{array}$ & $\frac{C P R B}{C P P}$ \\
\hline 4120.4 & Construção de edifícios & $1.886,3$ & $3.583,9$ & $52,6 \%$ \\
\hline 421 & $\begin{array}{l}\text { Construção de rodovias, ferrovias, } \\
\text { obras urbanas e obras-de-arte espe- } \\
\text { ciais }\end{array}$ & $1.358,7$ & $2.228,1$ & $61,0 \%$ \\
\hline 422 & $\begin{array}{l}\text { Obras de infra-estrutura para } \\
\text { energia elétrica, telecomunicações, } \\
\text { água, esgoto e transporte por dutos }\end{array}$ & 364,1 & 874,0 & $41,7 \%$ \\
\hline 429 & $\begin{array}{l}\text { Construção de outras obras de } \\
\text { infra-estrutura }\end{array}$ & 914,4 & $1.537,8$ & $59,5 \%$ \\
\hline 431 & Demolição e preparação do terreno & 195,2 & 350,5 & $55,7 \%$ \\
\hline 4321.5 & Instalações elétricas & 176,3 & 469,4 & $37,5 \%$ \\
\hline 4322.3 & $\begin{array}{l}\text { Instalações hidráulicas, de sist. ven- } \\
\text { tilação e refrigeração }\end{array}$ & 88,2 & 170,7 & $51,7 \%$ \\
\hline 4329.1 & $\begin{array}{l}\text { Obras de instal. em construções não } \\
\text { especific. anteriormente }\end{array}$ & 136,0 & 284,0 & $47,9 \%$ \\
\hline 4330.4 & Obras de acabamento & 95,6 & 215,2 & $44,4 \%$ \\
\hline 4391.6 & Obras de fundações & 57,9 & 118,8 & $48,7 \%$ \\
\hline 4399.1 & $\begin{array}{l}\text { Serviços especializados para cons- } \\
\text { trução não especificados }\end{array}$ & 169,9 & 377,5 & $45,0 \%$ \\
\hline 4912.4 & $\begin{array}{l}\text { Transporte metroferroviário de pas- } \\
\text { sageiros }\end{array}$ & 96,8 & 418,8 & $23,1 \%$ \\
\hline 4921.3 & $\begin{array}{l}\text { Transporte rodoviário coletivo, mu- } \\
\text { nicipal e região metropol. }\end{array}$ & 640,2 & $1.857,7$ & $34,5 \%$ \\
\hline 4922.1 & $\begin{array}{l}\text { Transporte rodov. coletivo, inter- } \\
\text { mun., interest., internac. }\end{array}$ & 263,1 & 553,9 & $47,5 \%$ \\
\hline 6201.5 & $\begin{array}{l}\text { Desenvolvimento de programas de } \\
\text { computador sob encomenda }\end{array}$ & 377,7 & $1.000,8$ & $37,7 \%$ \\
\hline 6202.3 & $\begin{array}{l}\text { Desenv. e licenciamento de progr. } \\
\text { computador customizáveis }\end{array}$ & 101,1 & 244,1 & $41,4 \%$ \\
\hline 6203.1 & $\begin{array}{l}\text { Desenv. e licenciamento progr. com- } \\
\text { putador não customizáveis }\end{array}$ & 154,6 & 382,0 & $40,5 \%$ \\
\hline 6204.0 & $\begin{array}{l}\text { Consultoria em tecnologia da infor- } \\
\text { mação }\end{array}$ & 364,8 & 864,0 & $42,2 \%$ \\
\hline 6209.1 & $\begin{array}{l}\text { Suporte técnico, manut. e outros } \\
\text { serviços tecnol. informação }\end{array}$ & 279,8 & 511,4 & $54,7 \%$ \\
\hline 6311.9 & $\begin{array}{l}\text { Tratamento dados, provedores apli- } \\
\text { cação e hospedagem internet }\end{array}$ & 174,5 & 414,7 & $42,1 \%$ \\
\hline 8220.2 & Atividades de teleatendimento & 290,9 & $1.104,5$ & $26,3 \%$ \\
\hline 5510.8 .01 & Hotéis & 248,3 & 496,1 & $50,1 \%$ \\
\hline
\end{tabular}

Nota: Comparação das contribuições, em milhões de reais, que seriam devidas no regime da Contribuição Previdenciária Patronal (CPP) e na Contribuição Previdenciário sobre a Receita Bruta (CPRB) com alíquota de 1\%. Fonte: ANFIP (2015) 
Tabela 5 - Comparação dos Regimes Tributários

\begin{tabular}{|c|c|c|c|c|}
\hline CNAE 2.0 & Atividade Econômica & $\begin{array}{l}\text { Contribuição de } \\
2 \% \text { sobre a Receita } \\
\text { Bruta (Líquida } \\
\text { de Exportações) - } \\
\text { CPRB }\end{array}$ & $\begin{array}{l}\text { Contribuição de } 20 \% \\
\text { sobre a Folha de Pa- } \\
\text { gamentos - CPP }\end{array}$ & $\frac{C P R B}{C P P}$ \\
\hline $\mathrm{A}$ & $\begin{array}{l}\text { Agricultura, pecuária, produção flo- } \\
\text { restal, pesca e aqüicultura }\end{array}$ & 170,5 & 490,5 & $34,8 \%$ \\
\hline B & Indústrias extrativas & 105,6 & 254,1 & $41,5 \%$ \\
\hline $\mathrm{C}$ & Indústrias de transformação & $16.514,4$ & $29.303,8$ & $56,4 \%$ \\
\hline $\mathrm{E}$ & $\begin{array}{l}\text { Água, esgoto, atividades de gestão } \\
\text { de resíduos e descontaminação }\end{array}$ & 18,0 & 32,2 & $55,8 \%$ \\
\hline G & $\begin{array}{l}\text { Comércio; reparação de veículos au- } \\
\text { tomotores e motocicletas }\end{array}$ & $3.434,8$ & $5.462,5$ & $62,9 \%$ \\
\hline $\mathrm{H}$ & Transporte, armazenagem e correio & $2.237,1$ & $5.130,6$ & $43,6 \%$ \\
\hline $\mathrm{J}$ & Informação e comunicação & 454,3 & $1.515,7$ & $30,0 \%$ \\
\hline
\end{tabular}

Tabela 6 - Renúncia Fiscal e Repasses Governamentais

\begin{tabular}{lccc}
\hline Descrição & 2012 & 2013 & 2014 \\
\hline \hline (1) Setores com Alíquota CPRB de 2\% & $1.685,83$ & $5.849,63$ & $10.506,06$ \\
\hline (2) Setores com Alíquota CPRB de 1\% & $5.385,04$ & $13.187,69$ & $21.020,31$ \\
\hline (3) Soma - (1) + (2) & $7.070,87$ & $19.037,32$ & $31.526,37$ \\
\hline (4) Valores compensados pelo Orçamento Fiscal & $1.790,00$ & $9.019,70$ & $18.052,00$ \\
\hline (5) Valor da perda para a Previdência Social - (3) - (4) & $5.280,87$ & $10.017,62$ & $13.474,37$ \\
\hline
\end{tabular}

Nota: Cálculo da renúncia fiscal oriunda da desoneração da folha salarial, dos repasses compensatórios efetivamente realizados pelo governo federal e do valor não transferido à Previdência. Fonte: ANFIP (2015)

O descasamento entre os repasses governamentais e o valor estimado de renúncia da previdência, aliado à deterioração das contas públicas, levou o governo a promulgar a Lei 13.161, de agosto de 2015, que aumentou as alíquotas da CPRB e tornou a desoneração da folha salarial opcional, de modo que, a partir de dezembro de 2015, as empresas estipuladas na Lei 12.546 podem escolher se se mantém no novo regime tributário ou voltam a pagar a contribuição previdenciária apenas em função de sua folha de pagamentos.

\subsection{Revisão da Bibliografia Fundamental}

A literatura sobre a incidência do imposto sobre a folha de pagamento (payroll tax) aponta para certa heterogeneidade nos países em desenvolvimento. Ao encarecer os custos de contratação, é possível que medidas como essa acabem por contribuir para o aumento do desemprego. Isso só ocorreria, porém, se não fosse possível repassar os custos tributários ao trabalhador, já que do contrário não há efeito sobre a demanda por trabalho, 
pois os empregadores simplesmente incluiriam o payroll tax entre seus custos, diminuindo os salários de maneira correspondente. A vigência de um salário mínimo ou a presença de rigidez salarial são alguns dos fatores que poderiam levar a um efeito de impostos como esse no nível de emprego.

Gruber (1995) analisa o caso chileno, onde a privatização da Seguridade Social diminuiu o payroll tax em 25\%, em média, num intervalo de 6 anos. O autor aponta para um repasse total da desoneração para os salários, sem aumento das taxas de emprego. No mesmo sentido, Gruber e Krueger (1991) utilizam variações temporais e espaciais na legislação e nos custos de seguros de saúde oferecidos pelo empregador para estimar a proporção do custo repassada aos trabalhadores. Os autores estimam que a maior parte dos custos é repassada pelo empregador na forma de menores salários, sem grande efeito no nível de emprego.

Por outro lado, Kugler e Kugler (2003) analisam a variação no imposto sobre a folha de pagamento na Colômbia durante as décadas de 80 e 90. É importante ressaltar que, enquanto o estudo referente ao Chile tratava de uma grande diminuição do imposto sobre a folha de pagamento, o caso colombiano é de aumento das contribuições. Sendo assim, diferenças em seus resultados também podem ser entendidas como uma assimetria. Como destacam os autores, é possível que os salários sejam rígidos "para baixo", em função do salário mínimo, por exemplo, enquanto essa rigidez pode se mostrar inexistente quando o imposto diminui, como foi o caso no Chile. O artigo estima que um aumento de $10 \%$ no payroll tax estaria relacionado a uma diminuição de $4 \%$ a $5 \%$ no emprego formal, assim como uma queda de 1,4\% a 2,3\% nos salários. Os resultados de Heckman et al. (2004), com dados cross-section da américa latina, apontam para um repasse de um terço do payroll tax para os salários. Gruber (1995) ressalta, porém, que estudos de incidência tributária com uma cross-section de países podem apresentar viés de variável omitida. Salários mais altos podem estar correlacionados com impostos mais altos para financiar benefícios sociais mais generosos, por exemplo.

Para o caso brasileiro, alguns estudos já analisaram o possível impacto da estrutura tributária sobre a informalidade e o emprego. Fernandes e Menezes-Filho (2002) analisam o aumento dos encargos sociais trazido pela Constituição de 1988, apontando para uma influência pequena sobre o emprego, sendo maior o impacto sobre o salário. Fernandes, Gremaud e Narita (2004) implementam um modelo de equilíbrio geral e estimam que, no caso de uma desoneração dos ganhos do trabalho neutra do ponto de vista fiscal, o emprego formal mantém-se no mesmo patamar. Simulando uma redução da carga tributária total em 10\%, porém, os autores estimam um aumento de 5,3\% no emprego formal. Ulyssea e Reis (2006) também implementam um modelo de equilíbrio geral, porém, diferentemente do trabalho anterior, modelam explicitamente o comportamento do setor informal e utilizam curvas de salário específicas para cada setor. Os autores esti- 
mam um efeito considerável da desoneração no emprego formal, de modo que no maior corte tributário simulado, onde os encargos trabalhistas vão de $27,5 \%$ a 10\%, a proporção de trabalhadores formais sobe de 39,6\% para 47,8\%. Mesmo na menor diminuição dos encargos, porém, uma taxa de $25 \%$ levaria os trabalhadores formais a representar 41,3\% dos ocupados. Os autores apontam que uma possível causa para a grande diferença de seus resultados e daqueles de Fernandes, Gremaud e Narita (2004) é o período utilizado na pesquisa, já que os mesmos se valeram da década de 1980, período de hiperinflação onde houve flexibilidade consideravelmente mais elevada dos salários, enquanto a quase totalidade dos dados de Ulyssea e Reis (2006) se refere ao período pós-Real.

Já no período posterior à desoneração da folha salarial, Dallava (2014) e Scherer (2015) realizaram trabalhos empíricos buscando estimar o efeito da política no emprego e salário dos trabalhadores formais. Dallava (2014) utiliza-se do fato de que, num mesmo setor da CNAE, alguns subsetores foram desonerados enquanto outros mantiveram a tributação sobre a folha de pagamento. Tomando os setores desonerados como o grupo de tratamento e os não desonerados como o controle, a autora estima o efeito da mudança em cada seção da CNAE dos setores desonerados em 2011 por Difference-in-Differences, encontrando um efeito significativo apenas na seção "Comunicação e Informação", tanto para o emprego quanto para o salário. Scherer (2015) também analisa apenas os setores desonerados em 2011 através de um modelo Diff-in-Diff, porém possui mais dados referentes ao período posterior à desoneração e baseia sua identificação nas empresas aderentes ao SIMPLES, sistema de tributação simplificada para micro e médias empresas no Brasil, que já estipulava anteriormente a contribuição patronal sobre o faturamento bruto. Sendo assim, as empresas do SIMPLES são utilizadas como grupo de controle. O estudo encontra um efeito positivo de $14 \%$ a $16 \%$ no emprego formal e cerca de $2 \%$ nos salários. Por usar empresas menores como grupo de tratamento, as análises do autor primeiramente restringem os dados às empresas de até 50 trabalhadores. Ao estimar o efeito utilizando a amostra completa, a estimativa é de que a desoneração afeta o emprego positivamente em $4,6 \%$.

Ao utilizar apenas a primeira rodada de desonerações, realizada em 2011, os estudos citados limitam-se a uma pequena parcela do total de setores desonerados. Para o caso de Scherer (2015), ainda é possível que haja endogeneidade entre tratamento e controle, já que a adesão ao SIMPLES é voluntária (desde que abaixo do limite de faturamento), e talvez tenha sido feita justamente pela possibilidade de tributação sobre a receita bruta. Desse modo, a oferta da receita bruta como base tributária ao grupo de tratamento pode levar empresas do SIMPLES a migrar para a tributação comum, já que há vantagem em relação ao regime anterior devido à renúncia fiscal e não há mais um limite de receita bruta estipulado para manter seu regime tributário.

No caso de Dallava (2014), a seção "Informação e Comunicação", onde a autora 
encontra efeito significativo da desoneração, é a referente às empresas de Tecnologia da Informação. Para esse caso, porém, a divisão 62, "Atividades de Serviços de Tecnologia da Informação"foi completamente desonerada. Sendo assim, são utilizadas as empresas da divisão 63, "Atividades de Prestação de Serviços de Informação", como contrafactuais. Especificamente, os setores não desonerados nessa divisão seriam "Agências de Notícias"e "Outras Atividades de Prestação de Serviços de Informação Não Especificadas Anteriormente", o que pode representar um distanciamento dos setores de TI, sendo um possível problema para a legitimidade desses setores como controles. 



\section{Dados}

A base de dados utilizada é a Relação Anual de Informações Sociais (RAIS). O trabalho utiliza a versão identificada da RAIS, dos anos de 2009 a 2014. Ainda que as observações disponíves neste meio sejam anuais, a informação referente ao mês de entrada e o mês de saída do emprego de cada trabalhador torna possível a criação de um painel mensal de setores da CNAE, com o nível de emprego, o número de contratações, de demissões e variáveis explicativas dos mesmos, como a idade média dos trabalhadores, nível educacional e gênero. Para a análise do nível salarial, além da variável normal, que indica o rendimento médio dos trabalhadores, criou-se uma variação da amostra contendo apenas os trabalhadores contratados no mês de observação, de modo a identificar o salário de entrada dos mesmos. 



\section{Identificação e Metodologia}

Com o objetivo de estimar o efeito da desoneração da folha de pagamentos sobre variáveis como o nível de emprego e de salário do mercado de trabalho brasileiro, é necessário debater qual seria melhor maneira de captar uma relação causal entre a mudança do regime tributário e as variáveis dependentes.

Sendo assim, o histórico do processo legislativo que culminou na desoneração da folha salarial, apresentado neste trabalho, parece demonstrar que, em grande parte dos casos, setores muito similares foram alocados em regimes tributários diferentes, com alguns mantendo-se na antiga Contribuição Previdenciária Patronal (CPP), incidente sobre a folha salarial, e outros sendo alocados na nova Contribuição Previdenciária sobre a Receita Bruta (CPRB). Esse fato sustenta a escolha do nível setorial como unidade de observação, possibilitando a busca de setores similares alocados na tributação antiga para a criação de contrafactuais dos setores desonerados.

Um primeiro passo para o delineamento da similaridade dos setores é a utilização da Classificação Nacional de Atividades Econômicas (CNAE) 2.0. A CNAE determina um número de 7 dígitos para cada setor econômico existente, denominando-os "subclasses", e agrega os mais próximos em função dos dígitos iniciais de suas classificações. Sendo assim, a nomenclatura é dividida em 5 níveis, com 21 seções, 87 divisões (correspondentes aos 2 primeiros dígitos da CNAE), 285 grupos (3 primeiros dígitos), 672 classes ( 5 primeiros dígitos) e 1318 subclasses (os 7 dígitos da CNAE).

Com isso, a nomenclatura da CNAE cria um critério objetivo de agrupamento de setores similares, possibilitando a criação de contrafactuais dentro de um grupo de setores desonerados e não desonerados. Note que, se o grupo correspondente aos setores similares for composto unicamente por setores desonerados ou por não desonerados, não é possível encontrar setores similares em ambas as situações de tributação para esse grupo econômico. Neste caso, assumimos que não há um bom contrafactual (ou, caso haja apenas controles, não houve tratamento para esse grupo econômico), e os setores desse grupos não são utilizados na estimação.

O procedimento ideal, dada a maior similaridade entre os setores, seria utilizar as subclasses (setores de 7 dígitos) como unidade de observação, agrupando-as em função das classes (5 dígitos). A desoneração da folha, porém, foi feita primordialmente em função das CNAEs de 5 dígitos, com poucos casos de desoneração específica de uma subclasse. Além disso, no caso das desonerações por NCM, a correspondência entre NCM e CNAE 2.0 disponibilizada pelo IBGE também é feita com relação à classe da CNAE, com 5 dígitos. Especificamente, só há 9 subclasses desoneradas e 14 subclasses não desoneradas 
que poderiam ser utilizadas em nossa estimação (de um total de 1318), se essa fosse a estratégia de identificação.

Procedemos então com a utilização das classes, de 5 dígitos, como unidade de observação. Para agrupá-las em conjuntos similares, analisamos duas possibilidades diferentes: os grupos (de 3 dígitos) e as divisões (de 2 dígitos). As tabelas 7 e 8 apresentam a distribuição de setores para os dois casos. Um setor é considerado "analisável" se possui tanto desonerados quanto não desonerados em um "Grande Setor", como denominamos o grupo de setores similares, representado pelos "grupos" ou "divisões".

Tabela 7 - Distribuição de Setores - Grande Setor de 2 Dígitos

\begin{tabular}{cccc}
\hline & Não Desonerados & Desonerados & Total \\
\hline Não Analisáveis & 239 & 117 & 356 \\
Analisáveis & 139 & 156 & 295 \\
Total & 378 & 273 & 651 \\
\hline
\end{tabular}

Nota: Divisão das classes (5 primeiros dígitos) da CNAE entre as pertencentes a uma divisão (2 primeiros dígitos) contendo tanto setores desonerados quanto não desonerados (e logo, analisáveis) e as pertencentes a divisões sem ambos os casos (não analisáveis)

Tabela 8 - Distribuição de Setores - Grande Setor de 3 Dígitos

\begin{tabular}{cccc}
\hline & Não Desonerados & Desonerados & Total \\
\hline Não Analisáveis & 312 & 214 & 526 \\
Analisáveis & 66 & 59 & 125 \\
Total & 378 & 273 & 651 \\
\hline
\end{tabular}

Nota: Divisão das classes ( 5 primeiros dígitos) da CNAE entre as pertencentes a um grupo (3 primeiros dígitos) contendo tanto setores desonerados quanto não desonerados (e logo, analisáveis) e as pertencentes a divisões sem ambos os casos (não analisáveis)

A distribuição dos setores apresentada já desconsidera os setores que não possuíam trabalhadores em algum momento do intervalo de tempo de estudo. A limitação do estudo aos setores que apresentavam trabalhadores em todo o período analisado, porém, não leva necessariamente a problemas relacionados ao atrito de amostras em painel, já que um setor pequeno o suficiente a ponto de não possuir nenhum trabalhador ativo em algum período do tempo não é efetivamente representativo da economia brasileira. Com isso, 21 setores foram retirados previamente. Como podemos ver, se agruparmos setores similares em um Grande Setor de 2 dígitos, teremos 156 setores desonerados e 139 setores não desonerados em um grupo comparável. Para o caso do Grande Setor de 3 dígitos, temos 59 desonerados e 66 controles.

Dada a grande quantidade de setores para ambas as especificações, tabelas explicitando as classes "analisáveis" para cada caso foram disponibilizadas no Anexo 1, e parecem agrupar ramos econômicos similares. Um exemplo dos setores econômicos delineados por esta estratégia é dado na tabela 9. 
Tabela 9 - Exemplo de Setores Comparáveis

\begin{tabular}{|c|c|c|c|c|}
\hline Divisão & Descrição & Desonerado & Classe (CNAE 5 díg.) & Descrição \\
\hline \multirow{5}{*}{16} & \multirow{5}{*}{$\begin{array}{l}\text { Fabricação de produtos } \\
\text { de madeira }\end{array}$} & Não & 16102 & Desdobramento de madeira \\
\hline & & Não & 16218 & $\begin{array}{l}\text { Fabricacao de madeira lami- } \\
\text { nada e de chapas de ma- } \\
\text { deira compensada, prensada } \\
\text { e aglomerada }\end{array}$ \\
\hline & & Sim & 16226 & $\begin{array}{l}\text { Fabricação de estruturas de } \\
\text { madeira e de artigos de car- } \\
\text { pintaria para construção }\end{array}$ \\
\hline & & Sim & 16234 & $\begin{array}{l}\text { Fabricação de artefatos de } \\
\text { tanoaria e de embalagens de } \\
\text { madeira }\end{array}$ \\
\hline & & Sim & 16293 & $\begin{array}{l}\text { Fabricação de artefatos de } \\
\text { madeira, palha, cortica, } \\
\text { vime e material trançado } \\
\text { não especificados anterior- } \\
\text { mente, exceto móveis }\end{array}$ \\
\hline
\end{tabular}

\footnotetext{
Nota: Exemplo de de classes da CNAE onde existem tanto tratados quanto controles dentro de uma mesma divisão (2 dígitos),
} possibilitando a análise contrafactual

Com base nessa estratégia de identificação, estimamos o impacto da desoneração no mercado de trabalho brasileiro através de um modelo Difference-in-Differences, utilizando uma amostra de setores analisáveis da CNAE. Permitimos a heterogeneidade dos efeitos da desoneração no tempo através de um event study, à maneira estruturada em Autor (2003). O modelo será especificado da seguinte maneira:

$$
Y_{s t}=\gamma_{s}+\alpha_{t}+\sum_{\tau=-T}^{-2} \beta_{\tau} D_{\tau s t}+\sum_{\tau=0}^{T} \beta_{\tau} D_{\tau s t}+\omega X_{s t}+\rho_{s} t+u_{s t}
$$

Onde os subscritos $s$ e $t$ denotam setor e tempo, respectivamente, sendo os dados observados mensalmente. $Y$ identificará as possíveis variáveis afetadas pela desoneração, com foco em duas variações: o logaritmo do nível de emprego e do nível salarial em cada setor. $\gamma_{s}$ denota o efeito fixo de setor, enquanto $\alpha_{t}$ denota o efeito fixo de tempo. $X_{s t}$ representa uma matrix de variáveis explicativas e $\rho_{s}$ indica a tendência temporal linear do setor $s$. $D_{\tau s t}$ é uma dummy igual a 1 se a desoneração do setor $s$ está $\tau$ períodos distante do mês observado, sendo meses anteriores à desoneração quando $\tau<0$ e posteriores quando $\tau>0$. Sendo assim, para um setor desonerado no mês $\theta_{s}$, temos:

$$
D_{\tau s t}=\mathbb{1}_{\left[t-\theta_{s}=\tau\right]}
$$

Para $\tau=T$, a dummy será igual a 1 para todos os períodos $T$ ou mais meses posteriores à desoneração do setor. O mesmo ocorre para $\tau=-T$, quando a dummy é ativada para todos os $T$ ou mais meses após a medida, ou seja: 


$$
\beta_{\tau}=\left\{\begin{array}{l}
\bar{\beta}, \forall \tau \geq T \\
\underline{\beta}, \forall \tau \leq-T
\end{array}\right.
$$

Para evitar colinearidade perfeita, tomamos $\tau=-1$ como a distância base da desoneração. A especificação acima, além de captar idiossincrasias temporais no efeito da política sobre o mercado de trabalho, permite-nos também realizar um teste sobre a validade da utilização dos setores não desonerados como um contrafactual. Caso nossa premissa seja válida, espera-se que nossas estimativas não encontrem efeito para o período anterior à reforma, ou seja:

$$
\beta_{\tau}=0 \forall \tau<0
$$

Uma outra possibilidade seria captar um efeito antecipatório da reforma, ao estilo do comportamento observado na queda de Ashenfelter (Ashenfelter (1978)). Modificações tributárias exigem um período mínimo de 3 meses de adaptação antes que passem a valer efetivamente. Além disso, grande parte das medidas provisórias usadas na desoneração foi alvo de emendas parlamentares, o que por vezes levou a um período maior de espera entre a promulgação da medida (e dos respectivos setores desonerados) e a vigência das novas regras. Com isso, um efeito anterior à medida não seria descartado. Ainda assim, tal antecipação só seria esperada para os meses imediatamente anteriores à reforma.

A necessidade de acompanhar informações mensais do mercado de trabalho, dado que é nesse espaço de tempo que a lei se modifica, aliado ao longo espaço de tempo em que a desoneração foi realizada, faz com que tenhamos um grande número de observações para cada setor. Bertrand, Duflo e Mullainathan (2002) ressalta que, nesse caso, uma possível correlação serial nos leva a subestimar os erros padrão. Além disso, é possível que haja correlação dos erros dentro de um mesmo segmento econômico, dado que, provavelmente, são afetados de maneira similar pela conjuntura econômica. Bertrand, Duflo e Mullainathan (2002) e Cameron e Miller (2015) apontam para a clusterização dos erros em função dos clusters como um todo (e não apenas nos clusters-ano) como uma maneira de correção desse viés.

A inserção de tendências temporais no modelo é apontada em Angrist e Pischke (2008) como uma forma de análise de robustez, comparando seus resultados com aqueles do modelo sem tendências temporais específicas. Besley e Burgess (2004) é um exemplo de um estudo onde as tendências temporais foram utilizadas nesse sentido. A interpretação dos coeficientes do tratamento é modificada nesse caso, já que passam a demonstrar desvios com relação à tendência temporal dos setores. Dessa maneira, é inclusive possível que a inclusão das tendências recupere a validade dos contrafactuais na estimação, permitindo que o comportamento da variável dependente seja similar entre setores de um 
mesmo grupo econômico sem as diferenças de longo prazo. Os autores ressaltam a necessidade de um número grande de períodos para a realização dessa análise, o que certamente é o caso neste estudo. Sendo assim, reportamos nossos resultados sempre em 3 variações diferentes, indo da mais simples, sem nenhum controle, à mais complexa, controlando pela proporção de pessoas com ensino médio completo, com ensino superior completo, do gênero masculino e por um polinômio de segundo grau da idade média do setor, além das tendências temporais lineares.

O fato de possuirmos mais de um possível critério de proximidade para a formação dos contrafactuais torna necessária uma análise preliminar da melhor maneira de realizar o pareamento. Dado o maior número de observações no Grande Setor de 2 Dígitos, essa seria a análise preferível, e logo, apresentamos os placebos estimados no modelo apresentado $\left(\beta_{-T}, \ldots, \beta_{-2}\right)$ para o nível salarial e para o nível de emprego, discutindo a escolha do critério para os setores de comparação. As regressões são realizadas para todos os setores desonerados, e dividindo-os entre os desonerados por NCM e por CNAE.

Os placebos para o nível salarial são apresentados na tabela 10. A RAIS nos possibilita a criação de diferentes observações para a análise dos salários, e esta diversidade será utilizada na análise dos resultados. No momento, porém, nos restringimos ao log do nível salarial de entrada, que é provavelmente a parcela dos salários mais diretamente afetada por mudanças na demanda por trabalho. Restringimos nossa amostra aos salários das pessoas contratadas em cada mês da amostra, e para manter a amostra balanceada, mantemos apenas os setores que realizaram no mínimo 100 contratações em cada mês. Ao realizar a análise, porém, teremos outras especificações, incluindo assim um maior número de setores. 
Tabela 10 - Estimação dos Placebos de Salário para o Grande Setor de 2 Dígitos

Variável dependente: Log(Salário Inicial)

\begin{tabular}{|c|c|c|c|c|c|c|c|c|c|}
\hline \multirow[b]{2}{*}{9 ou mais trimestres antes } & \multicolumn{3}{|c|}{ Todos os Setores } & \multicolumn{3}{|c|}{ Desonerados por CNAE } & \multicolumn{3}{|c|}{ Desonerados por NCM } \\
\hline & $\begin{array}{c}0.0240 \\
{[-.000, .051]}\end{array}$ & $\begin{array}{c}0.0108 \\
{[-.010, .029]}\end{array}$ & $\begin{array}{c}0.0095 \\
{[-.024, .042]}\end{array}$ & $\begin{array}{c}0.0175 \\
{[-.018, .056]}\end{array}$ & $\begin{array}{c}0.0076 \\
{[-.033, .037]}\end{array}$ & $\begin{array}{c}0.0250 \\
{[-.013, .107]}\end{array}$ & $\begin{array}{c}0.0290 \\
{[-.006, .066]}\end{array}$ & $\begin{array}{c}0.0141 \\
{[-.010, .036]}\end{array}$ & $\begin{array}{c}0.0088 \\
{[-.040, .058]}\end{array}$ \\
\hline 8 trimestres antes & $\begin{array}{c}0.0352^{* *} \\
{[.009, .061]}\end{array}$ & $\begin{array}{c}0.0213 \\
{[-.002, .040]}\end{array}$ & $\begin{array}{c}0.0195 \\
{[-.012, .048]}\end{array}$ & $\begin{array}{c}0.0477 \\
{[-.018, .100]}\end{array}$ & $\begin{array}{c}0.0299^{*} \\
{[.000, .046]}\end{array}$ & $\begin{array}{c}0.0411 \\
{[-.008, .117]}\end{array}$ & $\begin{array}{c}0.0280 \\
{[-.009, .060]}\end{array}$ & $\begin{array}{c}0.0184 \\
{[-.008, .043]}\end{array}$ & $\begin{array}{c}0.0150 \\
{[-.030, .061]}\end{array}$ \\
\hline 7 trimestres antes & $\begin{array}{c}0.0220 \\
{[-.002, .049]}\end{array}$ & $\begin{array}{c}0.0073 \\
{[-.012, .027]}\end{array}$ & $\begin{array}{c}0.0058 \\
{[-.024, .036]}\end{array}$ & $\begin{array}{c}0.0070 \\
{[-.020, .034]}\end{array}$ & $\begin{array}{c}-0.003 \\
{[-.053, .035]}\end{array}$ & $\begin{array}{c}0.0064 \\
{[-.070, .080]}\end{array}$ & $\begin{array}{c}0.0290 \\
{[-.002, .061]}\end{array}$ & $\begin{array}{c}0.0168 \\
{[-.004, .035]}\end{array}$ & $\begin{array}{c}0.0133 \\
{[-.024, .051]}\end{array}$ \\
\hline 6 trimestres antes & $\begin{array}{c}0.0046 \\
{[-.018, .027]}\end{array}$ & $\begin{array}{c}0.0003 \\
{[-.030, .024]}\end{array}$ & $\begin{array}{c}0.0000 \\
-.039, .032]\end{array}$ & $\begin{array}{c}-0.001 \\
{[-.027, .022]}\end{array}$ & $\begin{array}{c}-0.005 \\
{[-.076, .032]}\end{array}$ & $\begin{array}{c}0.0034 \\
{[-.086, .060]}\end{array}$ & $\begin{array}{c}0.0116 \\
{[-.019, .043]}\end{array}$ & $\begin{array}{c}0.0021 \\
{[-.026, .026]}\end{array}$ & $\begin{array}{c}0.0000 \\
{[-.046, .044]}\end{array}$ \\
\hline 5 trimestres antes & $\begin{array}{c}0.0247^{*} \\
{[.001, .051]}\end{array}$ & $\begin{array}{c}0.0120 \\
{[-.008, .032]}\end{array}$ & $\begin{array}{c}0.0101 \\
{[-.016, .036]}\end{array}$ & $\begin{array}{c}0.0167 \\
{[-.028, .055]}\end{array}$ & $\begin{array}{c}-0.001 \\
-.049, .023]\end{array}$ & $\begin{array}{c}0.0045 \\
{[-.059, .041]}\end{array}$ & $\begin{array}{c}0.0364^{*} \\
{[.002, .068]}\end{array}$ & $\begin{array}{c}0.0268^{*} \\
{[.000, .049]}\end{array}$ & $\begin{array}{c}0.0237 \\
{[-.016, .056]}\end{array}$ \\
\hline 4 trimestres antes & $\begin{array}{c}0.0254 \\
{[-.002, .052]}\end{array}$ & $\begin{array}{c}0.0150 \\
{[-.007, .033]}\end{array}$ & $\begin{array}{c}0.0141 \\
-.009, .033]\end{array}$ & $\begin{array}{c}0.0325 \\
{[-.016, .065]}\end{array}$ & $\begin{array}{c}0.0139 \\
{[-.031, .038]}\end{array}$ & $\begin{array}{c}0.0187 \\
{[-.014, .038]}\end{array}$ & $\begin{array}{c}0.0280 \\
{[-.012, .063]}\end{array}$ & $\begin{array}{c}0.0141 \\
{[-.013, .038]}\end{array}$ & $\begin{array}{c}0.0126 \\
{[-.023, .043]}\end{array}$ \\
\hline 3 trimestres antes & $\begin{array}{c}0.0196 \\
-.002, .041]\end{array}$ & $\begin{array}{c}0.0043 \\
{[-.015, .020]}\end{array}$ & $\begin{array}{c}0.0036 \\
{[-.016, .021]}\end{array}$ & $\begin{array}{c}0.0064 \\
{[-.045, .034]}\end{array}$ & $\begin{array}{c}-0.010 \\
{[-.047, .015]}\end{array}$ & $\begin{array}{c}-0.007 \\
{[-.034, .010]}\end{array}$ & $\begin{array}{c}0.0265 \\
{[-.003, .057]}\end{array}$ & $\begin{array}{c}0.0134 \\
{[-.009, .033]}\end{array}$ & $\begin{array}{c}0.0128 \\
{[-.014, .038]}\end{array}$ \\
\hline 2 trimestres antes & $\begin{array}{c}0.0155 \\
{[-.002, .032]}\end{array}$ & $\begin{array}{c}0.0130 \\
{[-.009, .029]}\end{array}$ & $\begin{array}{c}0.0144 \\
-.009, .031]\end{array}$ & $\begin{array}{c}0.0184 \\
{[-.032, .062]}\end{array}$ & $\begin{array}{c}0.0236 \\
{[-.011, .045]}\end{array}$ & $\begin{array}{c}0.0256 \\
{[-.015, .055]}\end{array}$ & $\begin{array}{c}0.0185 \\
{[-.010, .046]}\end{array}$ & $\begin{array}{c}0.0065 \\
{[-.019, .028]}\end{array}$ & $\begin{array}{c}0.0073 \\
{[-.022, .032]}\end{array}$ \\
\hline Noventena & $\begin{array}{c}0.0094 \\
{[-.012, .033]}\end{array}$ & $\begin{array}{c}-0.005 \\
{[-.023, .009]}\end{array}$ & $\begin{array}{c}-0.005 \\
{[-.024, .010]}\end{array}$ & $\begin{array}{c}0.0164 \\
{[-.051, .052]}\end{array}$ & $\begin{array}{c}0.0186 \\
{[-.010, .036]}\end{array}$ & $\begin{array}{c}0.0197 \\
{[-.009, .038]}\end{array}$ & $\begin{array}{c}0.0106 \\
{[-.018, .041]}\end{array}$ & $\begin{array}{c}-0.011 \\
{[-.038, .012]}\end{array}$ & {$\left[\begin{array}{c}-0.012 \\
-.043, .014]\end{array}\right.$} \\
\hline Clusters & 23 & 23 & 23 & 10 & 10 & 10 & 54 & 54 & 54 \\
\hline Efeito Fixo Mensal & Sim & Sim & Sim & Sim & Sim & Sim & Sim & Sim & Sim \\
\hline Efeito Fixo Setorial & Sim & Sim & Sim & Sim & Sim & Sim & Sim & Sim & Sim \\
\hline Controles & Não & Sim & Sim & Não & Sim & Sim & Não & Sim & Sim \\
\hline Tendência Linear Setorial & Não & Não & Sim & Não & Não & Sim & Não & Não & Sim \\
\hline Observações & 13032 & 13032 & 13032 & 4968 & 4968 & 4968 & 8136 & 8136 & 8136 \\
\hline$R^{2}$ & .6375 & .7748 & .8040 & .6874 & .8035 & .8240 & .6141 & .7639 & .7974 \\
\hline Setores & 181 & 181 & 181 & 69 & 69 & 69 & 113 & 113 & 113 \\
\hline
\end{tabular}

Nota: Intervalos de Confiança a $10 \%$ de WCBST nos colchetes. ${ }^{* * *} \mathrm{p}<0.01,{ }^{* *} \mathrm{p}<0.05,{ }^{*} \mathrm{p}<0.1$. Coeficientes estimados na regressão de um Event Study do nível salarial em função da desoneração. O período base é sempre o mês imediatamente anterior ao início da vigência do novo regime tributário. A variável "Noventena"refere-se ao período entre a promulgação da lei ou MP da desoneração e sua efetiva vigência. Os bootstraps são realizados com 1000 repetições e pesos Rademacher, como proposto em Cameron, Gelbach e Miller (2008) 
Figura 1 -Event-Studies Trimestrais dos Placebos de Salário - Grande Setor de 2 Dígitos

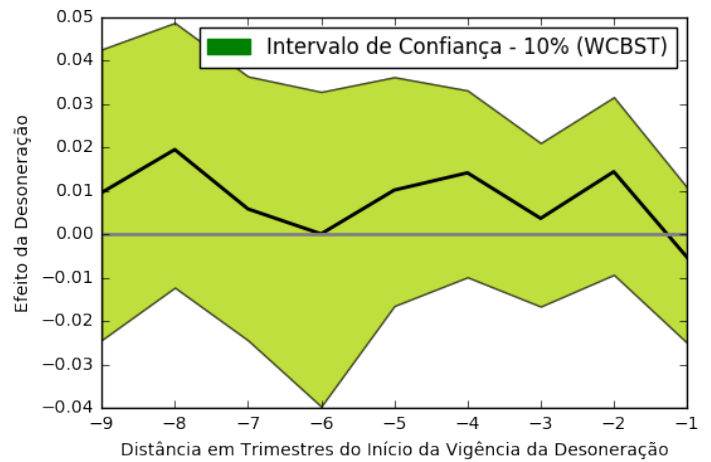

Amostra Completa

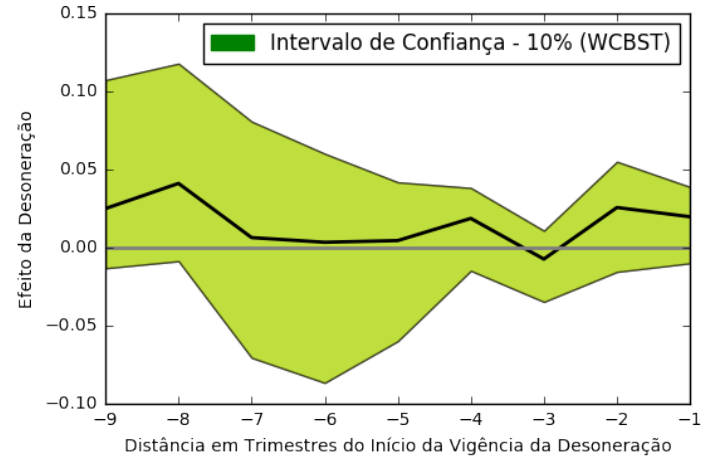

Somente CNAE

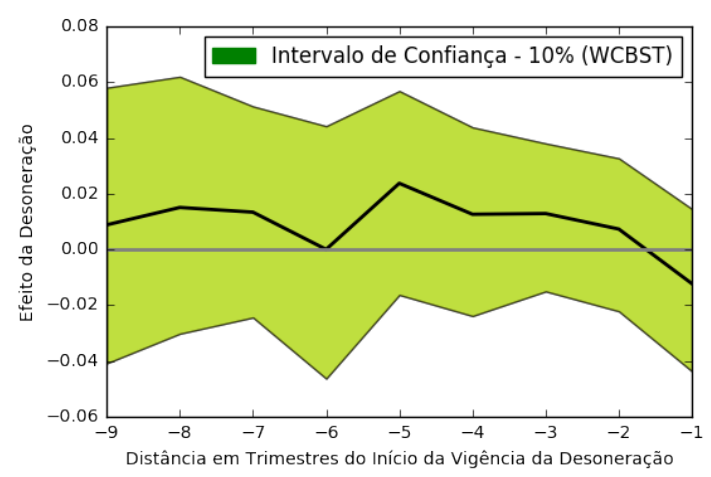

Somente NCM

Nota: Gráficos referentes aos Event Studies das regressões na tabela 10. Apresenta a distribuição dos efeitos estimados da desoneração no decorrer do tempo, assim como seus respectivos intervalos de confiança a $10 \%$

Há ocorrência de placebos significantes, e mesmo dividindo a amostra entre os desonerados por CNAE e por NCM, ainda vemos efeito anterior à medida para ambas as amostras. Ainda assim, os efeitos perdem significância com a inserção dos controles e da tendência linear setorial. Realizamos agora o mesmo procedimento para o nível de emprego. As regressões são apresentadas na tabela 11. 
Tabela 11 - Estimação dos Placebos de Emprego para o Grande Setor de 2 Dígitos

\begin{tabular}{|c|c|c|c|c|c|c|c|c|c|}
\hline \multirow{3}{*}{9 ou mais trimestres antes } & \multicolumn{3}{|c|}{ Todos os Setores } & \multicolumn{3}{|c|}{$\begin{array}{c}\text { Variável dependente: Log(Trabalhadores) } \\
\text { Desonerados por CNAE }\end{array}$} & \multicolumn{3}{|c|}{ Desonerados por NCM } \\
\hline & 0.0008 & 0.0259 & 0.0151 & -0.004 & 0.0148 & -0.020 & -0.014 & 0.0054 & 0.0296 \\
\hline & {$[-.044, .044]$} & {$[-.022, .070]$} & {$[-.022, .052]$} & {$[-.140, .081]$} & {$[-.140, .108]$} & {$[-.085, .035]$} & {$[-.061, .038]$} & {$[-.044, .064]$} & {$[-.028, .083]$} \\
\hline \multirow[t]{2}{*}{8 trimestres antes } & 0.0130 & 0.0236 & 0.0122 & -0.022 & -0.007 & -0.020 & 0.0143 & 0.0145 & 0.0257 \\
\hline & {$[-.021, .046]$} & {$[-.009, .054]$} & {$[-.018, .044]$} & {$[-.143, .071]$} & {$[-.122, .071]$} & {$[-.094, .057]$} & {$[-.029, .057]$} & {$[-.023, .057]$} & {$[-.019, .067]$} \\
\hline \multirow[t]{2}{*}{7 trimestres antes } & 0.0171 & 0.0246 & 0.0134 & -0.024 & -0.010 & -0.025 & 0.0219 & 0.0185 & 0.0279 \\
\hline & {$[-.014, .048]$} & {$[-.004, .051]$} & {$[-.013, .042]$} & {$[-.133, .067]$} & {$[-.109, .060]$} & {$[-.100, .044]$} & {$[-.016, .061]$} & {$[-.015, .056]$} & {$[-.011, .064]$} \\
\hline \multirow[t]{2}{*}{6 trimestres antes } & 0.0260 & 0.0281 & 0.0172 & -0.013 & -0.001 & -0.019 & 0.0275 & 0.0195 & 0.0274 \\
\hline & {$[-.007, .058]$} & {$[-.001, .056]$} & {$[-.006, .039]$} & {$[-.122, .073]$} & {$[-.094, .054]$} & {$[-.098, .037]$} & {$[-.013, .069]$} & {$[-.012, .056]$} & {$[-.006, .060]$} \\
\hline \multirow[t]{2}{*}{5 trimestres antes } & 0.0276 & $0.0258^{*}$ & 0.0166 & -0.006 & -0.000 & -0.019 & 0.0289 & 0.0202 & 0.0253 \\
\hline & {$[-.001, .054]$} & {$[.001, .048]$} & {$[-.002, .034]$} & {$[-.103, .081]$} & {$[-.081, .064]$} & {$[-.092, .052]$} & {$[-.006, .063]$} & {$[-.007, .052]$} & {$[-.002, .050]$} \\
\hline \multirow[t]{2}{*}{4 trimestres antes } & 0.0155 & 0.0159 & 0.0094 & -0.022 & -0.016 & -0.028 & 0.0223 & 0.0153 & 0.0212 \\
\hline & {$[-.010, .040]$} & {$[-.006, .037]$} & {$[-.007, .025]$} & {$[-.097, .040]$} & {$[-.079, .024]$} & {$[-.087, .015]$} & {$[-.006, .053]$} & {$[-.008, .042]$} & {$[-.000, .044]$} \\
\hline \multirow[t]{2}{*}{3 trimestres antes } & 0.0113 & 0.0140 & 0.0095 & -0.017 & -0.012 & -0.017 & 0.0192 & 0.0172 & $0.0211^{*}$ \\
\hline & {$[-.006, .028]$} & {$[-.001, .029]$} & {$[-.004, .023]$} & {$[-.058, .030]$} & {$[-.046, .016]$} & {$[-.053, .015]$} & {$[-.003, .042]$} & {$[-.002, .038]$} & {$[.001, .041]$} \\
\hline \multirow[t]{2}{*}{2 trimestres antes } & 0.0103 & $0.0113^{*}$ & 0.0091* & 0.0015 & 0.0034 & 0.0087 & 0.0095 & 0.0081 & $0.0111 *$ \\
\hline & {$[-.000, .020]$} & {$[.000, .021]$} & {$[.001, .016]$} & {$[-.023, .023]$} & {$[-.022, .022]$} & {$[-.019, .025]$} & {$[-.003, .022]$} & {$[-.001, .018]$} & {$[.000, .022]$} \\
\hline \multirow[t]{2}{*}{ Noventena } & 0.0045 & $0.0042^{*}$ & 0.0031 & 0.0054 & 0.0055 & 0.0053 & 0.0038 & $0.0051^{*}$ & $0.0061^{*}$ \\
\hline & {$[-.001, .010]$} & {$[.000, .007]$} & {$[-.000, .006]$} & {$[-.009, .016]$} & {$[-.005, .014]$} & {$[-.007, .014]$} & {$[-.001, .009]$} & {$[.000, .010]$} & {$[.000, .012]$} \\
\hline
\end{tabular}

\begin{tabular}{|c|c|c|c|c|c|c|c|c|c|}
\hline Clusters & 28 & 28 & 28 & 12 & 12 & 12 & 17 & 17 & 17 \\
\hline Efeito Fixo Mensal & Sim & Sim & Sim & Sim & Sim & Sim & Sim & Sim & Sim \\
\hline Efeito Fixo Setorial & Sim & Sim & Sim & Sim & Sim & Sim & Sim & Sim & Sim \\
\hline Controles & Não & Sim & Sim & Não & Sim & Sim & Não & Sim & Sim \\
\hline Tendência Linear Setorial & Não & Não & Sim & Não & Não & Sim & Não & Não & Sim \\
\hline Observações & 21240 & 21240 & 21240 & 7488 & 7488 & 7488 & 14040 & 14040 & 14040 \\
\hline$R^{2}$ & .1665 & .2883 & .7778 & .2093 & .2435 & .8203 & .1552 & .4070 & .7496 \\
\hline Setores & 295 & 295 & 295 & 104 & 104 & 104 & 195 & 195 & 195 \\
\hline
\end{tabular}

Nota: Intervalos de Confiança a $10 \%$ de WCBST nos colchetes. ${ }^{* * *} \mathrm{p}<0.01,{ }^{* *} \mathrm{p}<0.05,{ }^{*} \mathrm{p}<0.1$. Coeficientes estimados na regressão de um Event Study do nível salarial em função da desoneração. O período base é sempre o mês imediatamente anterior ao início da vigência do novo regime tributário. A variável "Noventena"refere-se ao período entre a promulgação da lei ou MP da desoneração e sua efetiva vigência. Os bootstraps são realizados com 1000 repetições e pesos Rademacher, como proposto em Cameron, Gelbach e Miller (2008) 
Figura 2 - Event-Studies Trimestrais dos Placebos de Emprego - Grande Setor de 2 Dígitos

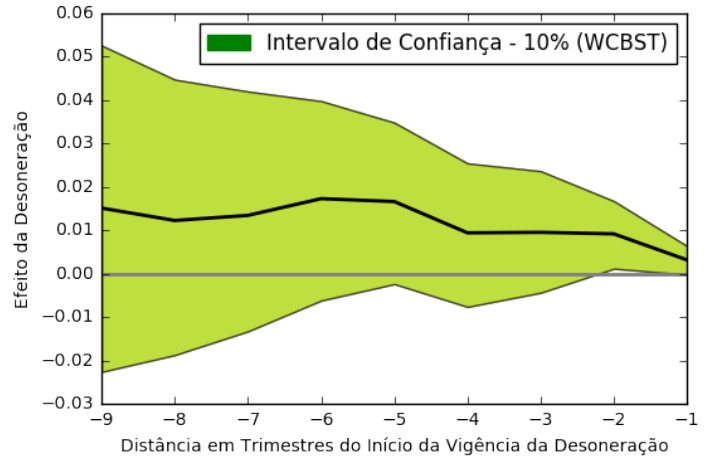

Amostra Completa

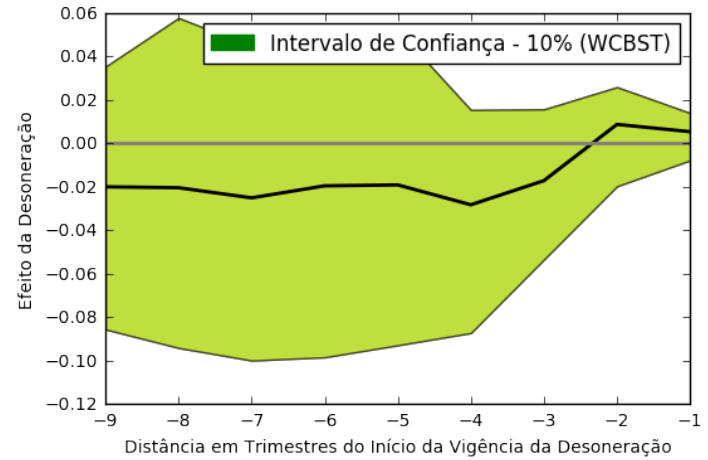

Somente CNAE

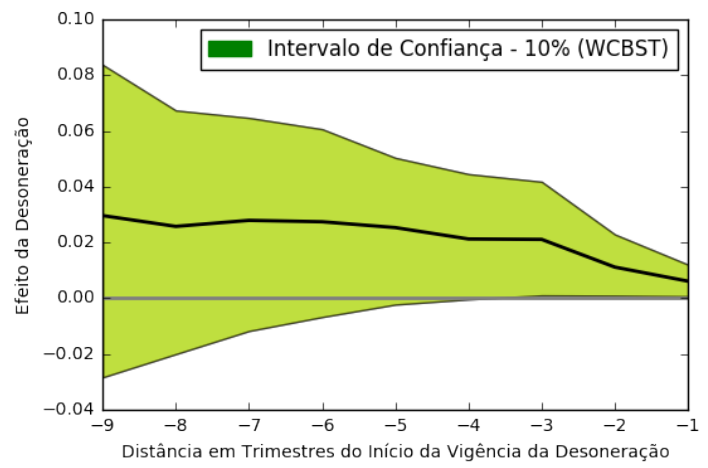

Somente NCM

Nota: Gráficos referentes aos Event Studies das regressões na tabela 11. Apresenta a distribuição dos efeitos estimados da desoneração no decorrer do tempo, assim como seus respectivos intervalos de confiança a $10 \%$

A análise dos placebos estimados nos aponta para possíveis problemas no uso deste nível de similaridade dos dígitos da CNAE como pareamento. Encontramos efeito significante para os placebos estimados no modelo que reúne todas as desonerações, mesmo após a adição dos controles e da tendência linear. Ao separarmos os setores entre os desonerados por CNAE e por NCM, porém, vemos que todo o problema de pareamento encontra-se nos alocados por NCM. Nas três especificações apresentadas, os desonerados por CNAE apresentam placebos não significantes e próximos de zero. Sendo assim, a análise para o Grande Setor de 2 Dígitos (Divisão) será realizada apenas com os setores "analisáveis"em função da CNAE, excluindo os setores referentes à desoneração por NCM.

Dada a impossibilidade deste pareamento para o NCM, procedemos à análise dos placebos para esse grupo no Grande Setor de 3 Dígitos (Grupo), que é apresentada na tabela 12 .

De modo análogo aos desonerados pela CNAE no Grande Setor de 2 Dígitos, nenhum coeficiente mostra-se significante. Para este grupo, porém, alguns dos coeficientes ainda apresentam valores diferentes de zero, o que poderia apontar um pareamente aquém do ideal. 
Tabela 12 - Estimação dos Placebos de Emprego para o Grande Setor de 3 Dígitos

\begin{tabular}{|c|c|c|c|}
\hline \multirow[b]{2}{*}{9 ou mais trimestres antes } & \multicolumn{3}{|c|}{$\begin{array}{c}\text { Variável dependente: Log(Trabalhadores) } \\
\text { Desonerados por NCM }\end{array}$} \\
\hline & $\begin{array}{c}-0.038 \\
{[-.086, .012]}\end{array}$ & {$\left[\begin{array}{c}-0.013 \\
{[-.052, .027]}\end{array}\right.$} & $\begin{array}{c}0.0316 \\
{[-.083, .146]}\end{array}$ \\
\hline 8 trimestres antes & $\begin{array}{c}0.0065 \\
{[-.024, .037]}\end{array}$ & {$\left[\begin{array}{c}0.0101 \\
-.018, .039]\end{array}\right.$} & {$\left[\begin{array}{c}0.0424 \\
-.054, .137]\end{array}\right.$} \\
\hline 7 trimestres antes & $\begin{array}{c}0.0111 \\
{[-.020, .043]}\end{array}$ & $\begin{array}{c}0.0121 \\
{[-.015, .040]}\end{array}$ & $\begin{array}{c}0.0393 \\
{[-.048, .122]}\end{array}$ \\
\hline 6 trimestres antes & $\begin{array}{c}0.0134 \\
{[-.018, .046]}\end{array}$ & {$\left[\begin{array}{c}0.0111 \\
{[-.019, .041]}\end{array}\right.$} & $\begin{array}{c}0.0339 \\
{[-.042, .103]}\end{array}$ \\
\hline 5 trimestres antes & $\begin{array}{c}0.0183 \\
{[-.009, .047]}\end{array}$ & $\begin{array}{c}0.0152 \\
{[-.019, .049]}\end{array}$ & $\begin{array}{c}0.0335 \\
{[-.039, .100]}\end{array}$ \\
\hline 4 trimestres antes & $\begin{array}{c}0.0126 \\
{[-.010, .038]}\end{array}$ & {$\left[\begin{array}{c}0.0053 \\
{[-.011, .024]}\end{array}\right.$} & $\begin{array}{c}0.0232 \\
{[-.017, .063]}\end{array}$ \\
\hline 3 trimestres antes & $\begin{array}{c}0.0141 \\
{[-.003, .033]}\end{array}$ & $\begin{array}{c}0.0082 \\
{[-.007, .025]}\end{array}$ & $\begin{array}{c}0.0205 \\
{[-.009, .049]}\end{array}$ \\
\hline 2 trimestres antes & $\begin{array}{c}0.0060 \\
{[-.008, .021]}\end{array}$ & $\begin{array}{c}0.0070 \\
{[-.009, .023]}\end{array}$ & $\begin{array}{c}0.0136 \\
{[-.006, .033]}\end{array}$ \\
\hline Noventena & $\begin{array}{c}0.0036 \\
{[-.001, .008]}\end{array}$ & $\begin{array}{c}0.0031 \\
{[-.004, .009]}\end{array}$ & $\begin{array}{c}0.0061 \\
{[-.001, .013]}\end{array}$ \\
\hline Clusters & 19 & 19 & 19 \\
\hline Efeito Fixo Mensal & Sim & Sim & Sim \\
\hline Efeito Fixo Setorial & Sim & Sim & Sim \\
\hline Controles & Não & Sim & Sim \\
\hline Tendência Linear Setorial & Não & Não & Sim \\
\hline Observações & 4968 & 4968 & 4968 \\
\hline$R^{2}$ & .1784 & .3454 & .6847 \\
\hline Setores & 69 & 69 & 69 \\
\hline
\end{tabular}

Nota: Intervalos de Confiança a $10 \%$ de WCBST nos colchetes. ${ }^{* * *}$ $\mathrm{p}<0.01,{ }^{* *} \mathrm{p}<0.05,{ }^{*} \mathrm{p}<0.1$. Coeficientes estimados na regressão de um Event Study do nível salarial em função da desoneração. O período base é sempre o mês imediatamente anterior ao início da vigência do novo regime tributário. A variável "Noventena"refere-se ao período entre a promulgação da lei ou MP da desoneração e sua efetiva vigência. Os bootstraps são realizados com 1000 repetições e pesos Rademacher, como proposto em Cameron, Gelbach e Miller (2008)

Figura 3 - Event-Studies Trimestrais dos Placebos de Emprego - Grande Setor de 3 Dígitos

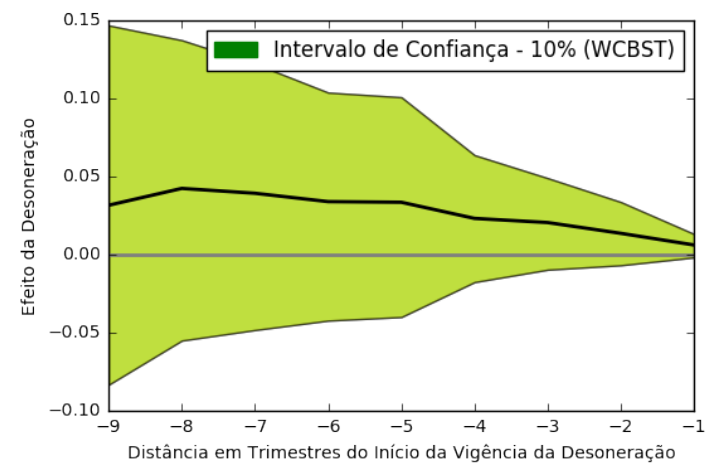

Somente NCM

Nota: Gráficos referentes aos Event Studies das regressões na tabela 11. Apresenta a distribuição dos efeitos estimados da desoneração no decorrer do tempo, assim como seus respectivos intervalos de confiança a $10 \%$ 
Ao dividir a amostra, diminuimos consideravelmente o número de setores e de clusters analisados. A clusterização é proposta em Bertrand, Duflo e Mullainathan (2002) e em Cameron e Miller (2015) como correção do problema de correlação serial e dentro dos clusters. Porém, é necessário um número grande de clusters para que as estimações sejam consistentes. Cameron e Miller (2015) falam em um mínimo de 30 clusters, mas como apontado em MacKinnon e Webb (2016), a distribuição do tratamento entre os clusters pode fazer com que o viés só seja corrigido com um número maior de grupos observados. No caso da análise da desoneração por NCM, isso não é mais possível. Para os desonerados por CNAE, a clusterização em função do Grande Setor de 3 dígitos ainda atinge um número maior do que 30. Ainda que esta seja uma premissa razoável, se houver correlação entre os erros numa abrangência maior, isso também viesará a estimação dos mesmos. Sendo assim, procedemos com a correção proposta em Cameron, Gelbach e Miller (2008), permitindo de forma mais abrangente a correlação dos erros, dentro do Grande Setor de 2 dígitos. As estimações feitas a partir de agora para o nível de emprego serão sempre realizadas em função da amostra do Grande Setor de 2 Dígitos para os desonerados pela CNAE e do Grande Setor de 3 Dígitos para os desonerados pelo NCM.

O método de Wild Cluster Bootstrapping-t (WCBST) é utilizado em Cameron, Gelbach e Miller (2008) para a realização de simulações de Monte Carlo e a réplica de estudos, entre os quais o exemplo apresentado em Bertrand, Duflo e Mullainathan (2002). Com isso, o artigo demonstra a adequação do cálculo para a solução do problema de estimação dos erros quando há correlação serial e um pequeno número de clusters, como é o caso neste estudo. Ainda assim, há na literatura outras soluções possíveis, como o Pairs Cluster Bootstrap, indicado em Bertrand, Duflo e Mullainathan (2002) e também analisado em Cameron, Gelbach e Miller (2008), e o Cluster Adjusted t-Statistic. Uma revisão destes métodos é apresentada em Esarey e Menger (2015).

Por fim, antes de iniciar a análise, é importante certificarmo-nos de que é legítima a utilização de nossas variáveis de controle. Se realmente mudou a dinâmica do mercado de trabalho, a desoneração da folha salarial pode também ter interferido nas características dos setores analisados. A diminuição do custo de contratação pode mudar a demanda das empresas com relação às características de seus trabalhadores. Como exemplo, a desoneração muda a relação entre os custos de trabalho e capital, o que poderia desincentivar a modernização e estimular primordialmente a contratação de trabalhadores mais jovens e menos qualificados.

A tabela 13 apresenta regressões placebo em função da desoneração para as variáveis independentes utilizadas, sem e com a inclusão de tendências lineares setoriais. As estimativas são próximas de 0 e não significantes em sua vasta maioria, indicando não haver problemas de endogeneidade com sua inclusão na regressão. 
Tabela 13 - Análise do Efeito da Desoneração sobre as Características Setoriais - Desonerados por CNAE

\begin{tabular}{|c|c|c|c|c|c|c|c|c|}
\hline & \% E.M. Completo & $\%$ E.S. Completo & \% Homens & Idade & \% E.M. Completo & $\%$ E.S. Completo & \% Homens & Idade \\
\hline 9 ou mais trimestres antes & $\begin{array}{c}0.0219 \\
{[-.003, .038]}\end{array}$ & $\begin{array}{c}-0.006 \\
{[-.018, .009]}\end{array}$ & $\begin{array}{c}-0.007 \\
{[-.017, .003]}\end{array}$ & $\begin{array}{l}0.4065^{* * *} \\
{[.132, .870]}\end{array}$ & $\begin{array}{c}-0.001 \\
{[-.019, .012]}\end{array}$ & $\begin{array}{c}0.0101 \\
{[-.001, .026]}\end{array}$ & $\begin{array}{c}0.0021 \\
{[-.013, .017]}\end{array}$ & $\begin{array}{c}-0.055 \\
{[-.457, .414}\end{array}$ \\
\hline 8 trimestres antes & 0.0155 & -0.002 & -0.003 & $0.2046^{* *}$ & 0.0005 & 0.0075 & 0.0017 & -0.094 \\
\hline 7 trimestres antes & $\begin{array}{c}{[-.004, .026]} \\
0.0102 \\
-.013 .023]\end{array}$ & $\begin{array}{c}{[-.009, .011]} \\
0.0023 \\
{[-.007 .021]}\end{array}$ & $\begin{array}{c}{[-.011, .005]} \\
-0.002 \\
{[-.010 .006]}\end{array}$ & $\begin{array}{c}{[.041, .518]} \\
0.1454^{* *} \\
{[035,347]}\end{array}$ & $\begin{array}{c}{[-.018, .014]} \\
-0.002 \\
{[-.026 .014]}\end{array}$ & $\begin{array}{c}{[-.003, .020]} \\
0.0107 \\
-.002,030]\end{array}$ & $\begin{array}{c}{[-.011, .014]} \\
0.0017 \\
{[-.010 .014]}\end{array}$ & $\begin{array}{c}{[-.448, .253} \\
-0.108 \\
{[-.434 . .144}\end{array}$ \\
\hline 6 trimestres antes & $\begin{array}{c}0.0034 \\
{[-.030, .022]}\end{array}$ & $\begin{array}{c}0.0103 \\
{[-.006, .044]}\end{array}$ & $\begin{array}{c}-0.003 \\
{[-.010, .004]}\end{array}$ & $\begin{array}{c}0.0485 \\
{[-.065, .266]}\end{array}$ & $\begin{array}{c}-0.007 \\
{[-.042, .014]}\end{array}$ & $\begin{array}{c}0.0173 \\
{[-.001, .049}\end{array}$ & $\begin{array}{c}-0.000 \\
{[-.011, .010]}\end{array}$ & $\begin{array}{c}-0.163 \\
{[-.407, .074}\end{array}$ \\
\hline 5 trimestres antes & $\begin{array}{c}0.0028 \\
{[-.026, .020]}\end{array}$ & $\begin{array}{c}0.0090 \\
{[-.007, .041]}\end{array}$ & $\begin{array}{c}-0.003 \\
{[-.009, .001]}\end{array}$ & $\begin{array}{c}0.0179 \\
{[-.051, .179]}\end{array}$ & $\begin{array}{c}-0.005 \\
{[-.037, .015]}\end{array}$ & $\begin{array}{c}0.0146 \\
{[-.003, .045]}\end{array}$ & $\begin{array}{c}-0.000 \\
{[-.009, .006]}\end{array}$ & $\begin{array}{c}-0.153 \\
{[-.376, .033}\end{array}$ \\
\hline 4 trimestres antes & $\begin{array}{c}0.0000 \\
{[-.026, .015]}\end{array}$ & $\begin{array}{c}0.0081 \\
{[-.006, .035]}\end{array}$ & $\begin{array}{c}-0.003 \\
{[-.007, .000]}\end{array}$ & $\begin{array}{c}0.0105 \\
{[-.039, .099]}\end{array}$ & $\begin{array}{c}-0.006 \\
{[-.034, .010]}\end{array}$ & $\begin{array}{c}0.0124 \\
{[-.003, .039]}\end{array}$ & $\begin{array}{c}-0.001 \\
{[-.007, .004]}\end{array}$ & $\begin{array}{c}-0.121 \\
{[-.339, .048}\end{array}$ \\
\hline 3 trimestres antes & $\begin{array}{c}0.0027 \\
{[-.015, .013]}\end{array}$ & $\begin{array}{c}0.0030 \\
{[-.007, .022]}\end{array}$ & $\begin{array}{c}-0.001 \\
{[-.004, .000]}\end{array}$ & $\begin{array}{c}0.0129 \\
{[-.012, .045]}\end{array}$ & $\begin{array}{c}-0.001 \\
{[-.021, .010]}\end{array}$ & $\begin{array}{c}0.0060 \\
{[-.005, .024]}\end{array}$ & $\begin{array}{c}-0.000 \\
{[-.004, .003]}\end{array}$ & $\begin{array}{c}-0.079 \\
{[-.229, .016}\end{array}$ \\
\hline 2 trimestres antes & $\begin{array}{c}0.0059^{*} \\
{[.000, .009]}\end{array}$ & $\begin{array}{c}-0.003 \\
{[-.008, .002]}\end{array}$ & $\begin{array}{c}-0.001 \\
{[-.002, .001]}\end{array}$ & $\begin{array}{c}-0.018 \\
{[-.087, .069]}\end{array}$ & $\begin{array}{c}0.0033 \\
{[-.002, .007]}\end{array}$ & $\begin{array}{c}-0.002 \\
{[-.008, .004]}\end{array}$ & {$\left[\begin{array}{c}-0.000 \\
{[-.001, .002]}\end{array}\right.$} & $\begin{array}{c}-0.070 \\
{[-.119, .015}\end{array}$ \\
\hline Noventena & $\begin{array}{c}0.0017 \\
{[-.000, .003]}\end{array}$ & $\begin{array}{c}-0.000 \\
{[-.002, .000]}\end{array}$ & $\begin{array}{c}-0.000 \\
{[-.000, .001]}\end{array}$ & $\begin{array}{c}-0.010 \\
{[-.069, .062]}\end{array}$ & $\begin{array}{c}0.0007 \\
{[-.001, .002]}\end{array}$ & $\begin{array}{c}-0.000 \\
{[-.001, .001]}\end{array}$ & $\begin{array}{c}0.0001 \\
{[-.000, .002]}\end{array}$ & $\begin{array}{c}-0.029 \\
{[-.075, .042}\end{array}$ \\
\hline 1 trimestre depois & $\begin{array}{c}0.0033 \\
{[-.001, .014]}\end{array}$ & $\begin{array}{c}-0.003 \\
{[-.009, .000]}\end{array}$ & $\begin{array}{c}0.0004 \\
{[-.000, .001]}\end{array}$ & $\begin{array}{c}-0.011 \\
{[-.072, .022]}\end{array}$ & $\begin{array}{c}0.0046^{*} \\
{[.000, .015]}\end{array}$ & $\begin{array}{c}-0.004^{*} \\
{[-.010,-.000]}\end{array}$ & $\begin{array}{c}0.0000 \\
{[-.001, .001]}\end{array}$ & $\begin{array}{c}0.0140 \\
{[-.053, .066}\end{array}$ \\
\hline 3 trimestres depois & $\begin{array}{c}-0.001 \\
{[-.009, .010]}\end{array}$ & $\begin{array}{c}-0.001 \\
{[-.012, .004]}\end{array}$ & $\begin{array}{c}-0.000 \\
{[-.004, .003]}\end{array}$ & $\begin{array}{c}-0.105 \\
{[-.254, .038]}\end{array}$ & $\begin{array}{c}0.0038 \\
{[-.002, .014]}\end{array}$ & $\begin{array}{c}-0.004 \\
{[-.016, .002]}\end{array}$ & $\begin{array}{c}-0.001 \\
{[-.005, .002]}\end{array}$ & $\begin{array}{c}-0.001 \\
{[-.196, .253}\end{array}$ \\
\hline 4 trimestres depois & $\begin{array}{c}-0.000 \\
{[-.010, .015]}\end{array}$ & $\begin{array}{c}-0.001 \\
{[-.015, .005]}\end{array}$ & $\begin{array}{c}-0.000 \\
{[-.005, .005]}\end{array}$ & $\begin{array}{c}-0.142 \\
{[-.377, .095]}\end{array}$ & $\begin{array}{c}0.0062 \\
{[-.002, .018]}\end{array}$ & $\begin{array}{c}-0.005 \\
{[-.020, .003]}\end{array}$ & $\begin{array}{c}-0.002 \\
{[-.006, .004]}\end{array}$ & $\begin{array}{c}0.0025 \\
{[-.288, .372}\end{array}$ \\
\hline 5 trimestres depois & $\begin{array}{c}-0.001 \\
{[-.014, .021]}\end{array}$ & $\begin{array}{c}-0.005 \\
{[-.020, .002]}\end{array}$ & $\begin{array}{c}-0.000 \\
{[-.009, .006]}\end{array}$ & $\begin{array}{c}-0.195 \\
{[-.605, .107]}\end{array}$ & $\begin{array}{c}0.0073 \\
{[-.000, .020]}\end{array}$ & $\begin{array}{c}-0.008 \\
{[-.029, .003]}\end{array}$ & {$\left[\begin{array}{c}-0.000 \\
{[-.008, .009]}\end{array}\right.$} & $\begin{array}{c}0.0598 \\
{[-.297, .540}\end{array}$ \\
\hline Clusters & 12 & 12 & 12 & 12 & 12 & 12 & 12 & 12 \\
\hline Efeito Fixo Mensal & Sim & Sim & Sim & Sim & Sim & Sim & Sim & Sim \\
\hline Efeito Fixo Setorial & Sim & Sim & Sim & Sim & Sim & Sim & Sim & Sim \\
\hline Controles & Não & Não & Não & Não & Não & Não & Não & Não \\
\hline Tendência Linear Setorial & Não & Não & Não & Não & Sim & Sim & Sim & Sim \\
\hline Observações & 7488 & 7488 & 7488 & 7488 & 7488 & 7488 & 7488 & 7488 \\
\hline$R^{2}$ & .1943 & .2569 & .2707 & .4147 & .6552 & .5324 & .6982 & .7438 \\
\hline Setores & 104 & 104 & 104 & 104 & 104 & 104 & 104 & 104 \\
\hline
\end{tabular}

Nota: Intervalos de Confiança a $10 \%$ de WCBST nos colchetes. ${ }^{* * *} \mathrm{p}<0.01,{ }^{* *} \mathrm{p}<0.05,{ }^{*} \mathrm{p}<0.1$. Coeficientes estimados na regressão de um Event Study do nível salarial em função da desoneração. O período base é sempre o mês imediatamente anterior ao início da vigência do novo regime tributário. A variável "Noventena"refere-se ao período entre a promulgação da lei ou MP da desoneração e sua efetiva vigência. Os bootstraps são realizados com 1000 repetições e pesos Rademacher, como proposto em Cameron, Gelbach e Miller (2008) 


\section{Análise dos Resultados}

\subsection{Efeitos sobre o Nível Salarial}

A seguir são apresentados os resultados da análise do impacto da desoneração para diferentes especificações do nível salarial. A primeira variável analisada é o salário inicial, onde incluímos apenas os trabalhadores contratados no mês observado. Essa especificação busca focar a análise no grupo que, provavelmente, sofre um efeito mais direto das mudanças nos custos de contratação. Um aumento generalizado da demanda por trabalho pode aumentar os salários ofertados para as novas contratações, mas os salários já negociados podem ter maior rigidez, ajustando-se mais lentamente à nova conjuntura. 
Tabela 14 - Estimação dos Salários Iniciais no Regime Normal

9 ou mais trimestres antes

8 trimestres antes

7 trimestres antes

6 trimestres antes

5 trimestres antes

4 trimestres antes

3 trimestres antes

2 trimestres antes

Noventena

1 trimestre depois

2 trimestres depois

3 trimestres depois

4 trimestres depois

5 ou mais trimestres depois

\section{Clusters}

Efeito Fixo Mensal

Controles

Tendência Linear Setorial

\begin{tabular}{ccc}
\multicolumn{3}{c}{ Todos os Setores } \\
\hline 0.0240 & 0.0108 & 0.0095 \\
{$[-.000, .051]$} & {$[-.010, .029]$} & {$[-.024, .042]$} \\
$0.0352 * *$ & 0.0213 & 0.0195 \\
{$[.009, .061]$} & {$[-.002, .040]$} & {$[-.012, .048]$} \\
0.0220 & 0.0073 & 0.0058 \\
{$[-.002, .049]$} & {$[-.012, .027]$} & {$[-.024, .036]$} \\
0.0046 & 0.0003 & 0.0000 \\
{$[-.018, .027]$} & {$[-.030, .024]$} & {$[-.039, .032]$} \\
$0.0247 *$ & 0.0120 & 0.0101 \\
{$[.001, .051]$} & {$[-.008, .032]$} & {$[-.016, .036]$} \\
0.0254 & 0.0150 & 0.0141 \\
{$[-.002, .052]$} & {$[-.007, .033]$} & {$[-.009, .033]$} \\
0.0196 & 0.0043 & 0.0036 \\
{$[-.002, .041]$} & {$[-.015, .020]$} & {$[-.016, .021]$} \\
0.0155 & 0.0130 & 0.0144 \\
{$[-.002, .032]$} & {$[-.009, .029]$} & {$[-.009, .031]$} \\
0.0094 & -0.005 & -0.005 \\
{$[-.012, .033]$} & {$[-.023, .009]$} & {$[-.024, .010]$} \\
0.0098 & 0.0056 & 0.0066 \\
{$[-.015, .031]$} & {$[-.018, .024]$} & {$[-.017, .025]$} \\
0.0138 & 0.0048 & 0.0067 \\
{$[-.007, .038]$} & {$[-.012, .022]$} & {$[-.012, .023]$} \\
-0.010 & -0.003 & -0.000 \\
{$[-.027, .010]$} & {$[-.026, .016]$} & {$[-.023, .017]$} \\
-0.001 & 0.0000 & 0.0040 \\
{$[-.023, .024]$} & {$[-.019, .019]$} & {$[-.014, .021]$} \\
-0.010 & -0.014 & -0.005 \\
{$[-.034, .016]$} & {$[-.035, .006]$} & {$[-.033, .018]$} \\
& &
\end{tabular}

Variável dependente: Log(Salário Inicial) Desonerados por CNAE

$\begin{array}{lrr}0.0175 & 0.0076 & 0.0250\end{array}$

$[-.018, .056] \quad[-.033, .037] \quad[-.013, .107]$

0.0477

$0.0299^{*}$

0.0411

$[-.008, .117]$

$-.018, .100] \quad[.000, .046]$

0.0070

$-0.003$

0.0064

$-0.001$

$[-.053, .035]$

$[-.070, .080]$

$[-.027, .022]$

0.0167

$-.076, .032]$

$[-.086, .060]$

0.0045

$[-.059, .041$

$[-.049, .023]$

0.0187

0.0325

0.0139

$[-.014, .038]$

$-0.007$

$\quad-0.010$

$[-.034, .010]$

0.0256

0.0236

$[-.015, .055$

$[-011,045]$

$[-.009, .038]$

0.0200

$[-.010, .036]$

0.0216

$[-.014, .035]$

0.0278

$[-.005, .033]$

$0.0198^{*}$

$0.0380^{*} \quad 0.0242 * *$

$[.013, .056]$

$.005, .044$

0.0051

$-0.003$

0.0093

$[-.034, .051]$

0.0103

$[-.008, .034]$

0.0071

0.0169

0.0151

0.0008

$-.044, .035$

0.0028

$[-.054, .065]$
Desonerados por NCM

\begin{tabular}{ccc}
\hline 0.0290 & 0.0141 & 0.0088 \\
{$[-.006, .066]$} & {$[-.010, .036]$} & {$[-.040, .058]$} \\
0.0280 & 0.0184 & 0.0150
\end{tabular}

$0.0280 \quad 0.0184 \quad\left[\begin{array}{ll}-0.0150 \\ -\end{array}\right.$

$[-.009, .060] \quad[-.008, .043] \quad[-.030, .061]$

$\begin{array}{lll}0.0290 & 0.0168 & 0.0133\end{array}$

$\left[\begin{array}{lll}{[-.002, .061]} & {[-.004, .035]} & {[-.024, .051]}\end{array}\right.$

$\begin{array}{lll}0.0116 & 0.0021 & 0.0000\end{array}$

$\begin{array}{ccc}-.019, .043] & {[-.026, .026]} & {[-.046, .044]}\end{array}$

$[.002,068] \quad[.000,049] \quad[-.016,056]$

$0.0280 \quad[.00, .041-[-.016, .056]$

$\left[\begin{array}{lll}-.012, .063] & {[-.013, .038]} & {[-.023, .043]}\end{array}\right.$

$\begin{array}{lll}0.0265 & 0.0134 & 0.0128\end{array}$

$\begin{array}{ccc}-.003, .057] & {[-.009, .033]} & {[-.014, .038]}\end{array}$

$[-.010,046] \quad[-.019,028] \quad[-.022,032]$

$0.0106 \quad[-019,0.028] \quad[-.022,0032]$

$[-.018, .041] \quad[-.038, .012] \quad[-.043, .014]$

$\begin{array}{lll}0.0067 & -0.003 & -0.001\end{array}$

$\left[\begin{array}{ccc}0.036, .044] & {[-.041, .030]} & {[-.038, .031}\end{array}\right.$

$[-.026,027] \quad[-.037,023] \quad[-.032,022]$

$\begin{array}{lll}-0.007 & -0.009 & -0.005\end{array}$

$[-.032, .017] \quad[-.050, .027] \quad[-.040, .025]$

$\begin{array}{lll}-0.013 & -0.005 & 0.0008\end{array}$

$\begin{array}{lll}-037, .015] & {[-.037, .026]} & {[-.022, .025}\end{array}$

$[-.047, .014] \quad[-.061, .012] \quad[-.050, .023]$

\begin{tabular}{|c|c|c|c|c|c|c|c|c|c|}
\hline Observações & 13032 & 13032 & 13032 & 4968 & 4968 & 4968 & 8136 & 8136 & 8136 \\
\hline$R^{2}$ & .6375 & .7748 & .8040 & .6874 & .8035 & .8240 & .6141 & .7639 & .7974 \\
\hline Setores & 181 & 181 & 181 & 69 & 69 & 69 & 113 & 113 & 113 \\
\hline
\end{tabular}

Nota: Intervalos de Confiança a $10 \%$ de WCBST nos colchetes. ${ }^{* * *} \mathrm{p}<0.01,{ }^{* *} \mathrm{p}<0.05,{ }^{*} \mathrm{p}<0.1$. Coeficientes estimados na regressão de um Event Study do nível salarial em função da desoneração. O período base é sempre o mês imediatamente anterior ao início da vigência do novo regime tributário. A variável "Noventena"refere-se ao período entre a promulgação da lei ou MP da desoneração e sua efetiva vigência. Os bootstraps são realizados com 1000 repetições e pesos Rademacher, como proposto em Cameron, Gelbach e Miller (2008) 
Figura 4 -Event-Studies Trimestrais dos Salários Iniciais - Grande Setor de 2 Dígitos

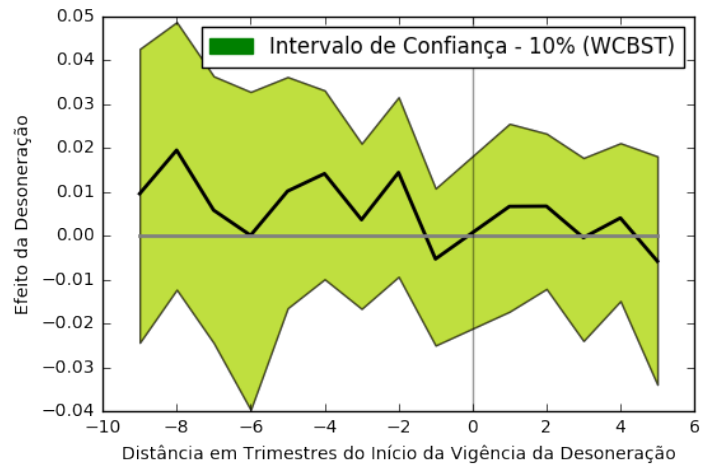

Amostra Completa

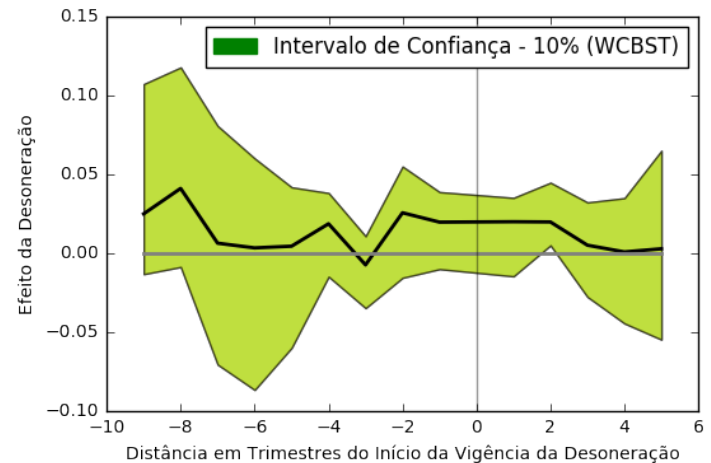

Somente CNAE

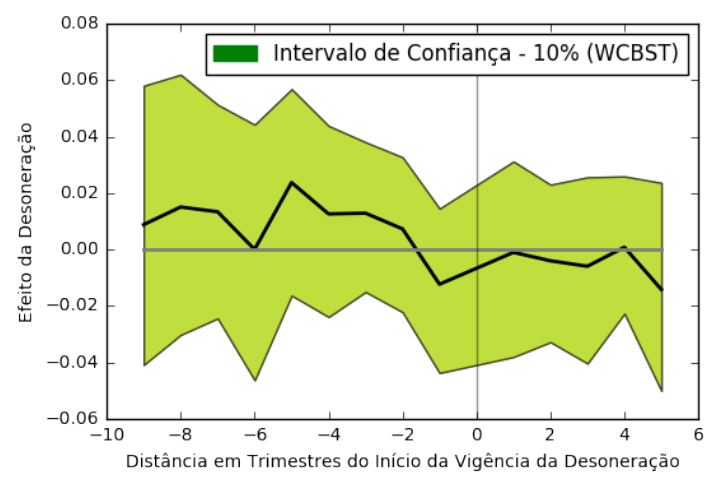

Somente NCM

Nota: Gráficos referentes aos Event Studies das regressões na tabela 14. Apresenta a distribuição dos efeitos estimados da desoneração no decorrer do tempo, assim como seus respectivos intervalos de confiança a $10 \%$

O resultado é dado na tabela 14. Como podemos ver, apenas na especificação do modelo mantendo somente os setores desonerados por CNAE encontramos um efeito significativo, ainda que pequeno, sobre o nível salarial para o segundo trimestre após a desoneração. Ainda assim, os efeitos posteriores são próximos de 0, e mesmo os placebos relacionados aos meses anteriores a este coeficiente atingem um patamar próximo a ele, ainda que não significantes. Sendo assim, não parece haver robustez com relação ao efeito encontrado, e os efeitos de longo prazo são consistentemente próximos de zero.

A segunda especificação, na tabela 15, apresenta resultados para o nível salarial inicial apenas dos trabalhadores sem ensino superior e fora dos cargos de gerência (em função da CBO 2002). Ainda que na primeira especificação tenhamos controlado os resultados por educação e testado a endogeneidade dessa variável, criamos assim uma outra possível variação na robustez da análise aos problemas de possível endogeneidade. Adicionalmente, o grupo de trabalhadores com menor escolaridade e nos cargos iniciais é um filtro ainda mais fino do grupo potencialmente mais afetado. 


\begin{tabular}{|c|c|c|c|c|c|c|c|c|c|}
\hline \multirow[b]{2}{*}{9 ou mais trimestres antes } & \multicolumn{3}{|c|}{ Todos os Setores } & \multicolumn{3}{|c|}{$\begin{array}{c}\text { Variável dependente: } \log \text { (Salário Inicial) } \\
\text { Desonerados por CNAE }\end{array}$} & \multicolumn{3}{|c|}{ Desonerados por NCM } \\
\hline & $\begin{array}{l}0.0195 \\
.011, .046\end{array}$ & $\begin{array}{c}0.0053 \\
-.021, .027]\end{array}$ & & $\begin{array}{c}0.0111 \\
-.041, .035]\end{array}$ & $\begin{array}{l}-0.005 \\
-.054, .020]\end{array}$ & $\begin{array}{c}0.0221 \\
{[-.015, .100]}\end{array}$ & $\begin{array}{l}252 \\
.059]\end{array}$ & $\begin{array}{c}0.0111 \\
{[-.015, .036]}\end{array}$ & $\begin{array}{r}0.0 \\
-.00\end{array}$ \\
\hline trimestres antes & & & & 0.0290 & & & 0.0219 & & \\
\hline & & {$[-.014$} & & $-.013, .054]$ & .022, & {$[-.024$} & 8] & {$[-.019$} & -.0 \\
\hline trimestres antes & 00 & & & 0.0008 & & & & & \\
\hline & & {$[-.0$} & & $020]$ & & & & & \\
\hline 6 trimestres antes & $\begin{array}{l}-0 \\
.03\end{array}$ & -0 & & 11 & -( & $\begin{array}{r}0 \\
-.00\end{array}$ & & & 8 \\
\hline trimestres antes & & & & -0.006 & & & & & \\
\hline 4 trimestr & $\begin{array}{c}0 \\
.06\end{array}$ & {$\left[\begin{array}{r}0 \\
-.0\end{array}\right.$} & $\begin{array}{r}0 . \\
.00\end{array}$ & $\begin{array}{r}0 \\
-.0\end{array}$ & $-(-1$ & 0 & 397 & 0 & 0 \\
\hline 3 trimestres antes & 0.0 & {$\left[\begin{array}{r}-0 \\
-.02\end{array}\right.$} & {$\left[\begin{array}{r}-0 \\
-.01\end{array}\right.$} & 011 & & {$[-0$.} & $944]$ & {$\left[\begin{array}{r}0 . \\
-.02\end{array}\right.$} & {$\left[\begin{array}{r}0 \\
-.01\end{array}\right.$} \\
\hline 2 trimestres antes & {$[-.01$} & {$[-.02$} & {$\left[\begin{array}{rl}0 . \\
-.01\end{array}\right.$} & {$\left[\begin{array}{r}0 \\
-.01\end{array}\right.$} & {$\left[\begin{array}{rl}0 \\
-.0\end{array}\right.$} & {$[-.01$} & {$\left[\begin{array}{r}0 . \\
-.02\end{array}\right.$} & {$[-.02$} & {$\left[\begin{array}{r}0 . \\
-.02\end{array}\right.$} \\
\hline Noventena & $\begin{array}{c}0.0032 \\
{[-.015, .019]}\end{array}$ & {$\left[\begin{array}{r}-0 \\
-.02\end{array}\right.$} & {$[-.02$} & {$\left[\begin{array}{rl}0.0 \\
{[-.01}\end{array}\right.$} & {$[-.04$} & $\begin{aligned} 0 . \\
-.03\end{aligned}$ & $\begin{array}{c}0.0003 \\
{[-.020, .022]}\end{array}$ & $\begin{array}{r}-0.0 \\
{[-.036}\end{array}$ & $\begin{array}{c}-0.009 \\
{[-.035, .010]}\end{array}$ \\
\hline 1 trimestre depois & $\begin{array}{r}0.00 \\
-.018\end{array}$ & $\begin{array}{r}0 . \\
-.02\end{array}$ & $\begin{array}{r}0.0 \\
-.025\end{array}$ & $\begin{array}{r}0.0 \\
-.039\end{array}$ & $\begin{array}{r}-0.6 \\
-.039\end{array}$ & $\begin{array}{r}-0 . \\
-.048\end{array}$ & $\begin{array}{l}6 \\
035] \\
035]\end{array}$ & $\begin{array}{r}0.0 \\
-.03\end{array}$ & $\begin{array}{r}-0 \\
-.03\end{array}$ \\
\hline $2 \operatorname{tr}$ & $\begin{array}{r}0.0 \\
-.002\end{array}$ & $\begin{array}{c}0.0079 \\
{[-.009, .023}\end{array}$ & {$\left[\begin{array}{r}0 . \\
-.01\end{array}\right.$} & $\begin{array}{c}0.0170 \\
{[-.003, .055]}\end{array}$ & $\begin{array}{c}0.0077 \\
{[-.012, .029]}\end{array}$ & $\begin{array}{r}0 . \\
{[-.03}\end{array}$ & $\begin{array}{c}0.0052 \\
{[-.020, .031]}\end{array}$ & $\begin{array}{c}0.0016 \\
{[-.025, .025]}\end{array}$ & $\begin{array}{c}-0.001 \\
{[-.030, .025]}\end{array}$ \\
\hline 3 trimestres depois & $\begin{array}{c}0.0042 \\
{[-.016, .021]}\end{array}$ & $\begin{array}{c}0.0060 \\
{[-.018, .025]}\end{array}$ & $\begin{array}{r}0.0 \\
-.030\end{array}$ & $\begin{array}{c}0.0074 \\
{[-.021, .035]}\end{array}$ & $\begin{array}{c}0.0100 \\
-.020, .040]\end{array}$ & $\begin{array}{r}0.0 \\
-.057\end{array}$ & $\begin{array}{c}0.0031 \\
{[-.018, .027]}\end{array}$ & $\begin{array}{c}0.0016 \\
{[-.034, .028]}\end{array}$ & $\begin{array}{c}-0.003 \\
{[-.040, .026]}\end{array}$ \\
\hline 4 trimestres $\mathrm{d}$ & $\begin{array}{c}0.0077 \\
{[-.012, .027]}\end{array}$ & $\begin{array}{c}0.0084 \\
{[-.009, .024]}\end{array}$ & $\begin{array}{c}0.0042 \\
{[-.022, .025]}\end{array}$ & $\begin{array}{c}0.0006 \\
{[-.035, .030]}\end{array}$ & $\begin{array}{c}-0.002 \\
{[-.044, .016]}\end{array}$ & $\begin{array}{c}-0.009 \\
{[-.092, .020]}\end{array}$ & $\begin{array}{c}0.0058 \\
{[-.018, .034]}\end{array}$ & $\begin{array}{c}0.0080 \\
{[-.016, .030]}\end{array}$ & $\begin{array}{c}0.0017 \\
{[-.024, .024]}\end{array}$ \\
\hline o ou mals trimestres depois & $\begin{array}{c}-0.001 \\
{[-.024, .020]}\end{array}$ & $\begin{array}{c}0.0006 \\
{[-.017, .017]}\end{array}$ & $\begin{array}{c}-0.003 \\
{[-.039, .023]}\end{array}$ & $\begin{array}{c}0.0128 \\
{[-.036, .073]}\end{array}$ & $\begin{array}{c}0.0085 \\
{[-.029, .058]}\end{array}$ & $\begin{array}{c}-0.001 \\
{[-.103, .053]}\end{array}$ & $\begin{array}{c}-0.007 \\
{[-.031, .020]}\end{array}$ & $\begin{array}{c}-0.003 \\
{[-.030, .020]}\end{array}$ & $\begin{array}{c}-0.011 \\
{[-.043, .015]}\end{array}$ \\
\hline
\end{tabular}

Clusters

Efeito Fixo Mensal

Efeito Fixo Setorial

Controles

$\begin{array}{cc}22 & 22 \\ \text { Sim } & \text { Sim } \\ \text { Sim } & \text { Sim } \\ \text { Não } & \text { Sim } \\ \text { Não } & \text { Não }\end{array}$

22
Sim
Sim
Sim
Não

$\begin{array}{cc}22 & 10 \\ \text { Sim } & \text { Sim } \\ \text { Sim } & \text { Sim } \\ \text { Sim } & \text { Não } \\ \text { Sim } & \text { Não }\end{array}$

10
Sim
Sim
Sim
Não

10

51

$\begin{array}{lc}51 & 51 \\ \text { Sim } & \text { Sim } \\ \text { Sim } & \text { Sim } \\ \text { Sim } & \text { Sim } \\ \text { Não } & \text { Sim }\end{array}$

Observações

12312

12312

$\begin{array}{rr}12312 & 4752 \\ 8088 & 7537\end{array}$

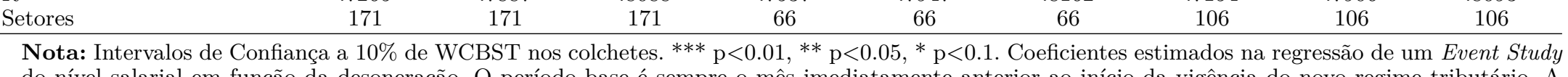

171

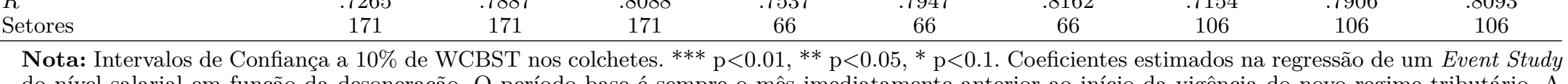

.7947

66

.8162
66

.7154

.7906

7632 do nível salarial em função da desoneração. O período base é sempre o mês imediatamente anterior ao início da vigência do novo regime tributário. A variável "Noventena"refere-se ao período entre a promulgação da lei ou MP da desoneração e sua efetiva vigência. Os bootstraps são realizados com 1000 repetições e pesos Rademacher, como proposto em Cameron, Gelbach e Miller (2008) 
Os resultados também não parecem demonstrar efeito da desoneração sobre o nível salarial. Para as três especificações, os efeitos estimados são todos próximos de zero e não significativos. Para os desonerados por NCM, porém, os placebos parecem demonstrar certa diferença entre os grupos comparados no longo prazo.

Por fim, apresenta-se na tabela 16 a estimação do efeito da desoneração sobre os salários como um todo, mantendo todos os trabalhadores do setor no mês, e não mais só os contratados no período. 
Tabela 16 - Estimação dos Salários no Regime Normal

9 ou mais trimestres antes

8 trimestres antes

7 trimestres antes

6 trimestres antes

5 trimestres antes

4 trimestres antes

3 trimestres ante

2 trimestres antes

Noventena

1 trimestre depois

2 trimestres depois

3 trimestres depois

4 trimestres depois

5 ou mais trimestres depois

Variável dependente: Log(Salário Médio) Desonerados por CNAE

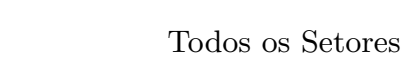

\begin{tabular}{ccc}
\hline $0.0275^{* * *}$ & 0.0144 & 0.0044 \\
{$[.012, .044]$} & {$[-.004, .033]$} & {$[-.012, .021]$} \\
$0.0201 * * *$ & 0.0098 & 0.0012
\end{tabular}

0.0018

0.0018

$-0.005$

$-0.004$

$[-.029, .038]$

$-0.013$

0.0098

$[.008, .032]$

$0.0168^{* *}$

0.0063

$[-.016, .017]$

$[-.021,022]$

$[-.047, .009]$

$-0.006$

$-0.017$

0.0077

$[-.008, .020]$

$-0.002$

$[-.018, .015]$

$-0.008$

$[-.024, .020]$

$-0.007$

$[-.056, .005]$

$-0.024$

$[-.020, .012] \quad[-.026, .007]$

$[-.002, .018$

$-0.000$

$-0.005$

$-.015, .012] \quad[-.020, .008$

$[-.023, .015]$

$\left[\begin{array}{c}-.069, .003] \\ -0.019 *\end{array}\right.$

$-0.005$

$[-.001, .014]$

$0.0084^{*}$

$-0.003$

$-.019, .017]$

$[-.051,-.000]$

$-0.013$

0.0039

$[-.016, .008]$

$[-.017, .018]$

0.0003

$[-.054, .008]$

$-0.005$

$.001, .015$
0.0020

$[-.005, .012$

$[-.009, .011]$

$[-.002, .007]$

0.0024

0.0004

$[-.011, .019]$

$[-.030, .010]$

$-0.000$

$[-.010, .009]$

$[-.001, .005] \quad[-.005, .005]$

$[.000, .003]$

$[-.000, .003]$

0.0005

0.0008

$[-.001, .002]$
-0.002

$[-.003, .002]$

$[-.003, .004]$

$-0.005$

$[-.007, .000] \quad[-.006, .001]$

$\left[\begin{array}{ccc}{[-.010, .002]} & {[-.007, .000} & {[-.006, .001} \\ -0.006 & -0.005 & -0.002\end{array}\right.$

[-.020,.003]

$-0.007$

$-0.003$

$[-.011, .000] \quad[-.008, .003]$

$[-.008, .003]$
-0.005

$[-.014, .000]$

$-0.009 * *$

$[-013, .003]$

$-.024,004$

$[-.022, .010]$

$-0.006$

$[-.025, .012]$

$-0.002$

$-0.010^{* *}$

$-0.004$

$-0.016^{* *}$

$-.018,-.002$

[-.014,.004]

$-0.008$

$[-.027, .007]$

$[-.020, .016]$

$[-.031, .038]$

$-0.010$

$\left[\begin{array}{c}-0.010 \\ -.047, .013 \\ -0.016\end{array}\right.$

$-0.016$

$[-.061, .009]$

$[-.063, .006]$

$-0.025$

$[-.070, .002]$

$[-.050,-.001]$

$-0.013$

$[-.049, .006]$

$-0.005$

$[-.011,007]$

0.0010

$-.005, .005]$
-0.004

$[-.017, .003]$

$-0.002$

$[-.019, .012]$

$-0.004$

$[-.025, .021]$

$-0.000$

$[-.021, .029]$

$[-.024, .060]$
$[-.027, .008]$
Desonerados por NCM

\begin{tabular}{ccc}
\hline $0.0396^{* * *}$ & 0.0233 & $0.0209^{*}$
\end{tabular}

$[.024, .057] \quad[-.001, .049] \quad[.000, .040]$

$[.016, .045] \quad[.004, .040] \quad[-.002, .035]$

$\begin{array}{ccc}0.0279^{* * *} & 0.0202^{* *} & 0.0162\end{array}$

$\left[\begin{array}{lll}0.014, .042] & {[.005, .035]} & {[-.002, .032}\end{array}\right.$

$\begin{array}{lll}0.0179 * * & 0.0139 & 0.0097\end{array}$

$\left[\begin{array}{ccc}0.003, .031] & {[-.000, .028]} & {[-.004, .022} \\ 0.0163 * * & 0.0138 * * & 0.0104\end{array}\right.$

$[.005,026] \quad[.004,024] \quad[-.002,021]$

$\begin{array}{ccc}0.0141^{* * *} & 0.0141^{* *} & 0.0109^{*}\end{array}$

$[.007, .022] \quad[.005 . .023] \quad[.001, .019]$

$0.0146^{* * *} \quad 0.0136^{* * *} \quad 0.0111^{* *}$

$[.007, .022] \quad[.007, .020] \quad[.002, .019]$

$0.0064^{* * *} \quad 0.0070^{* * *} \quad 0.0051$

$[.002, .010] \quad[.004, .009] \quad[-.000, .010]$

$\begin{array}{lll}0.0032^{* * *} & 0.0029^{* *} & 0.0021\end{array}$

$[.002, .004] \quad[.001, .004] \quad[-.000, .004]$

$\begin{array}{lll}-0.001 & -0.001 & -0.001\end{array}$

$\left[\begin{array}{ccc}-.013, .009] & {[-.009, .004]} & {[-.007, .004} \\ -0.005 & -0.005 & -0.004\end{array}\right.$

$[-.020,007] \quad[-.014,002] \quad[-.012,002]$

$\begin{array}{lll}-0.013 & -0.009 & -0.007\end{array}$

$[-.033, .004] \quad[-.020, .001] \quad[-.018, .003]$

$\begin{array}{lll}-0.019 & -0.012^{*} & -0.009\end{array}$

$[-.040, .000] \quad[-.024,-.001] \quad[-.022, .002]$

$[-.059,-.001] \quad[-.045,-.000] \quad[-.034, .005]$

\title{
Clusters
}

Efeito Fixo Mensal

Efeito Fixo Setorial

Controles

88

28

\begin{abstract}
12
\end{abstract}
12

74

.045,-.000

\begin{tabular}{lccccccccc} 
& & & & & & & & \\
Observações & 21240 & 21240 & 21240 & 7488 & 7488 & 14040 & 14040 & 14040 \\
$R^{2}$ & .8352 & .8977 & .9534 & .8713 & .9025 & .9498 & .8188 & .9034 & .9581 \\
Setores & 295 & 295 & 295 & 104 & 104 & 104 & 195 & 195 & 195 \\
\hline
\end{tabular}

Nota: Intervalos de Confiança a $10 \%$ de WCBST nos colchetes. ${ }^{* * *} \mathrm{p}<0.01,{ }^{* *} \mathrm{p}<0.05,{ }^{*} \mathrm{p}<0.1$. Coeficientes estimados na regressão de um Event Study do nível salarial em função da desoneração. O período base é sempre o mês imediatamente anterior ao início da vigência do novo regime tributário. A variável "Noventena"refere-se ao período entre a promulgação da lei ou MP da desoneração e sua efetiva vigência. Os bootstraps são realizados com 1000 repetições

e pesos Rademacher, como proposto em Cameron, Gelbach e Miller (2008) 
Depois de inseridos os controles e as tendências setoriais, nenhum efeito se mantém, para qualquer das especificações. Mais uma vez, os placebos relacionados aos desonerados por NCM mostram certa diferenciação, ainda que em menor grau que a apresentada na variação dos salários iniciais apenas com menor escolaridade.

\subsection{Efeitos sobre o Nível de Emprego}

A análise inicial dos resultados passa pela questão do possível efeito que a desoneração pode ter acarretado às empresas no SIMPLES. Para estas empresas, a desoneração não trouxe mudanças, estando as mesmas, inclusive, já alocadas em um regime de tributação em função da receita bruta (uma exceção é o Anexo IV do SIMPLES, onde a base tributária é diferenciada e, após consulta à Receita Federal, as empresas também foram inseridas na desoneração). Para muitas das empresas que aderem a este regime, a mudança da base tributária pode ser um grande atrativo. Dentro do SIMPLES, porém, o teto do faturamento, que até o fim de 2014 atingia $\mathrm{R} \$ 3.600 .000,00$, representa um impedimento ao crescimento das empresas, que são obrigadas a voltar ao regime tributário normal (Lucro Presumido ou Lucro Real), tendo novamente como base para a contribuição patronal ao INSS a folha salarial. Além disso, a renúncia fiscal em vigor para os setores desonerados apresenta-se como um atrativo ainda mais óbvio para a mudança de regime, com contribuições muito menores do que as vigentes antes do advento do novo regime.

Sendo assim, se a desoneração também causa efeito sobre as empresas dentro do SIMPLES, essa dinâmica tem que ser levada em conta no cálculo do impacto da desoneração. Scherer (2015) usou o SIMPLES como contrafactual em sua análise, dado que não era afetado pelo novo regime. Um fluxo de saída de empresas do SIMPLES, porém, viesaria para baixo o nível de emprego do controle, assim como inflaria artificialmente as contratações do grupo de tratamento. Isso pode explicar o grande impacto estimado pelo autor para a desoneração. Sendo que esse fluxo ocorreria primordialmente entre as empresas de setores desonerados, Dallava (2014) também sofreria desse viés.

Com isso, nossa análise apresenta os resultados para o regime normal (Lucro Presumido ou Lucro Real), para o SIMPLES e para todos os regimes em conjunto. Isso permite analisar se realmente ocorre algum efeito da desoneração sobre o SIMPLES, e é possível interpretar os efeitos para o regime normal e para a análise conjunta como um lower e um upper bound, respectivamente, para o efeito da desoneração.

A tabela 17 mostra os efeitos estimados para o nível de emprego no regime normal. Para os setores desonerados pela CNAE, o efeito positivo sobre o nível de emprego é inequívoco, apresentando coeficientes altos e significantes. Ao controlar por características da força de trabalho e por tendências temporais do setores, o efeito de longo prazo diminui de aproximadamente $11 \%$ para $7,53 \%$, mantendo-se significativo. Para os deso- 
Tabela 17 - Estimação do Nível de Emprego no Regime Normal

\begin{tabular}{|c|c|c|c|c|c|c|}
\hline \multirow{4}{*}{9 ou mais trimestres antes } & \multicolumn{6}{|c|}{ Variável dependente: Log(Trabalhadores) } \\
\hline & \multicolumn{3}{|c|}{ Desonerados por CNAE } & \multicolumn{3}{|c|}{ Desonerados por NCM } \\
\hline & -0.004 & 0.0148 & -0.020 & -0.038 & -0.013 & 0.0316 \\
\hline & {$[-.140, .081]$} & {$[-.140, .108]$} & {$[-.085, .035]$} & {$[-.086, .012]$} & {$[-.052, .027]$} & {$[-.083, .146]$} \\
\hline \multirow{2}{*}{8 trimestres antes } & -0.022 & -0.007 & -0.020 & 0.0065 & 0.0101 & 0.0424 \\
\hline & {$[-.143, .071]$} & {$[-.122, .071]$} & {$[-.094, .057]$} & {$[-.024, .037]$} & {$[-.018, .039]$} & {$[-.054, .137]$} \\
\hline \multirow{2}{*}{7 trimestres antes } & -0.024 & -0.010 & -0.025 & 0.0111 & 0.0121 & 0.0393 \\
\hline & {$[-.133, .067]$} & {$[-.109, .060]$} & {$[-.100, .044]$} & {$[-.020, .043]$} & {$[-.015, .040]$} & {$[-.048, .122]$} \\
\hline \multirow[t]{2}{*}{6 trimestres antes } & -0.013 & -0.001 & -0.019 & 0.0134 & 0.0111 & 0.0339 \\
\hline & {$[-.122, .073]$} & {$[-.094, .054]$} & {$[-.098, .037]$} & {$[-.018, .046]$} & {$[-.019, .041]$} & {$[-.042, .103]$} \\
\hline \multirow[t]{2}{*}{5 trimestres antes } & -0.006 & -0.000 & -0.019 & 0.0183 & 0.0152 & 0.0335 \\
\hline & {$[-.103, .081]$} & {$[-.081, .064]$} & {$[-.092$,} & {$[-.009, .047]$} & {$[-.019, .049]$} & {$[-.039, .100]$} \\
\hline \multirow[t]{2}{*}{4 trimestres antes } & -0.022 & -0.016 & -0.028 & 0.0126 & 0.0053 & 0.0232 \\
\hline & {$[-.097, .040]$} & {$[-.079, .024]$} & {$[-.087$} & {$[-.010, .038]$} & {$[-.011, .024]$} & {$[-.01$} \\
\hline \multirow[t]{2}{*}{3 trimestres antes } & -0.017 & -0.012 & -0.017 & 0.0141 & 0.0082 & 0.0205 \\
\hline & {$[-.058, .030]$} & {$[-.046, .016]$} & {$[-.053$} & {$[-.003, .033]$} & {$[-.007, .025]$} & {$[-.009, .049]$} \\
\hline \multirow[t]{2}{*}{2 trimestres antes } & 0.0015 & 0.0034 & 0.0087 & 0.0060 & 0.0070 & 0.0136 \\
\hline & {$[-.023, .023]$} & {$[-.022, .022]$} & {$[-.019, .025]$} & {$[-.008, .021]$} & {$[-.009, .023]$} & {$[-.006, .033]$} \\
\hline \multirow[t]{2}{*}{ Noventena } & 0.0054 & 0.0055 & 0.0053 & 0.0036 & 0.0031 & 0.0061 \\
\hline & {$[-.009, .016]$} & {$[-.005, .014]$} & {$[-.007, .014]$} & {$[-.001, .008]$} & {$[-.004, .009]$} & {$[-.001, .013]$} \\
\hline \multirow[t]{2}{*}{1 trimestre depois } & 0.0061 & 0.0071 & 0.0138 & -0.004 & 0.0052 & 0.0017 \\
\hline & {$[-.004, .030]$} & {$[-.009, .038]$} & {$[-.002, .043]$} & {$[-.029, .021]$} & {$[-.017, .028]$} & {$[-.014, .019]$} \\
\hline \multirow[t]{2}{*}{2 trimestres depois } & 0.0074 & 0.0077 & 0.0171 & -0.012 & -0.003 & -0.010 \\
\hline & {$[-.011, .046]$} & {$[-.013, .046]$} & {$[-.007, .049]$} & {$[-.046, .022]$} & {$[-.031, .025]$} & {$[-.031, .012]$} \\
\hline \multirow{2}{*}{3 trimestres depois } & $0.0331 * * *$ & 0.0285 & $0.0367 * *$ & -0.009 & 0.0007 & -0.011 \\
\hline & {$[.017, .063]$} & {$[-.004, .060]$} & {$[.014, .050]$} & {$[-.050, .031]$} & {$[-.037, .037]$} & {$[-.040, .018]$} \\
\hline \multirow[t]{2}{*}{4 trimestres depois } & $0.0484^{* * *}$ & $0.0392 * *$ & $0.0405^{*}$ & -0.011 & -0.000 & -0.016 \\
\hline & {$[.026, .085]$} & {$[.014, .071]$} & {$[.008, .061]$} & {$[-.050, .027]$} & {$[-.037, .034]$} & {$[-.046, .013]$} \\
\hline \multirow[t]{2}{*}{5 ou mais trimestres depois } & $0.1160 * *$ & $0.1011^{*}$ & $0.0753 * *$ & -0.013 & 0.0018 & -0.021 \\
\hline & {$[.022, .282]$} & {$[.007, .256]$} & {$[.022, .144]$} & {$[-.068, .038]$} & {$[-.052, .052]$} & {$[-.071, .028]$} \\
\hline
\end{tabular}

\begin{tabular}{|c|c|c|c|c|c|c|}
\hline Clusters & 12 & 12 & 12 & 19 & 19 & 19 \\
\hline Efeito Fixo Mensal & Sim & Sim & Sim & Sim & Sim & Sim \\
\hline Efeito Fixo Setorial & Sim & Sim & Sim & Sim & Sim & Sim \\
\hline Controles & Não & Sim & Sim & Não & Sim & Sim \\
\hline Tendência Linear Setorial & Não & Não & Sim & Não & Não & Sim \\
\hline Observações & 7488 & 7488 & 7488 & 4968 & 4968 & 4968 \\
\hline$R^{2}$ & .2093 & .2435 & .8203 & .1784 & .3454 & .6847 \\
\hline Setores & 104 & 104 & 104 & 69 & 69 & 69 \\
\hline
\end{tabular}

Figura 5 - Event-Studies Trimestrais do Emprego no Regime Normal

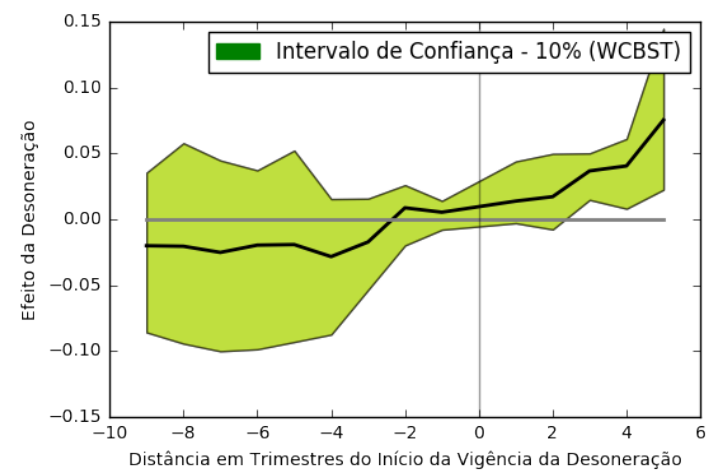

Somente CNAE

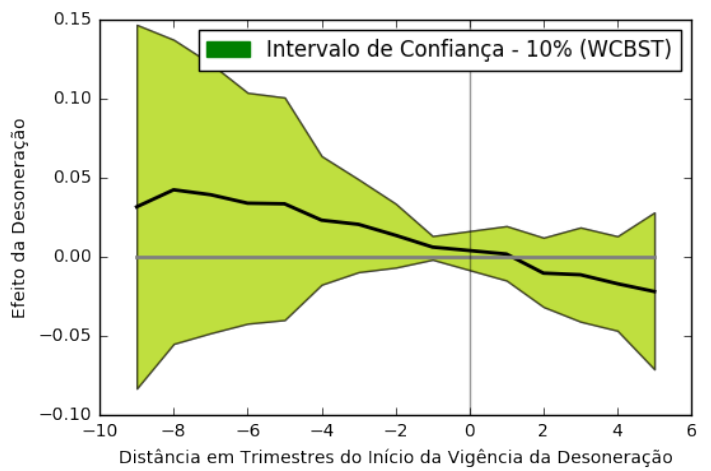

Somente NCM

Nota: Gráficos referentes aos Event Studies das regressões na tabela 17. Apresenta a distribuição dos efeitos estimados da desoneração no decorrer do tempo, assim como seus respectivos intervalos de confiança a 10\% 
nerados por NCM, porém, não parece haver melhora no nível de emprego proveniente da desoneração. Como apontado anteriormente, porém, o incremento encontrado para a CNAE pode estar sendo contaminado pela entrada de empresas do SIMPLES no regime normal de tributação.

Tabela 18 - Estimação do Nível de Emprego no SIMPLES

\begin{tabular}{|c|c|c|c|c|c|c|}
\hline \multirow{4}{*}{9 ou mais trimestres antes } & \multicolumn{6}{|c|}{ Variável dependente: Log(Trabalhadores) } \\
\hline & \multicolumn{3}{|c|}{ Desonerados por CNAE } & \multicolumn{3}{|c|}{ Desonerados por NCM } \\
\hline & 0.0418 & 0.0346 & -0.003 & -0.056 & -0.020 & -0.004 \\
\hline & {$[-.082, .121]$} & {$[-.089, .145]$} & {$[-.089, .120]$} & {$[-.193, .092]$} & {$[-.139, .103]$} & {$[-.214, .172]$} \\
\hline \multirow[t]{2}{*}{8 trimestres antes } & -0.026 & -0.005 & -0.039 & -0.042 & -0.056 & -0.048 \\
\hline & {$[-.140, .046]$} & {$[-.095, .079]$} & {$[-.126, .059]$} & {$[-.111, .028]$} & {$[-.130, .015]$} & {$[-.215, .101]$} \\
\hline \multirow[t]{2}{*}{7 trimestres antes } & -0.033 & -0.014 & -0.044 & -0.040 & -0.052 & -0.047 \\
\hline & {$[-.136, .032]$} & {$[-.096, .067]$} & {$[-.132, .055]$} & {$[-.112, .030]$} & {$[-.123, .016]$} & {$[-.204, .093]$} \\
\hline \multirow[t]{2}{*}{6 trimestres antes } & -0.027 & -0.016 & -0.039 & -0.017 & -0.034 & -0.032 \\
\hline & {$[-.136, .048]$} & {$[-.087, .065]$} & {$[-.132, .061]$} & {$[-.078, .044]$} & {$[-.099, .026]$} & {$[-.165, .089]$} \\
\hline \multirow[t]{2}{*}{5 trimestres antes } & -0.045 & -0.019 & -0.043 & -0.005 & -0.022 & -0.022 \\
\hline & {$[-.143, .015]$} & {$[-.088, .020]$} & {$[-.128, .025]$} & {$[-.059, .048]$} & {$[-.084, .038]$} & {$[-.138, .083]$} \\
\hline \multirow[t]{2}{*}{4 trimestres antes } & -0.047 & -0.035 & -0.050 & -0.001 & -0.007 & -0.001 \\
\hline & {$[-.136, .005]$} & {$[-.097, .003]$} & {$[-.128, .015]$} & {$[-.036, .035]$} & {$[-.039, .024]$} & {$[-.068, .058]$} \\
\hline \multirow[t]{2}{*}{3 trimestres antes } & -0.030 & -0.026 & -0.036 & -0.009 & -0.007 & -0.002 \\
\hline & {$[-.094, .006]$} & {$[-.069, .008]$} & {$[-.094, .014]$} & {$[-.036, .017]$} & {$[-.026, .012]$} & {$[-.046, .040]$} \\
\hline \multirow[t]{2}{*}{2 trimestres antes } & 0.0194 & -0.010 & -0.008 & -0.012 & -0.006 & -0.001 \\
\hline & {$[-.003, .043]$} & {$[-.032, .019]$} & {$[-.030, .022]$} & {$[-.032, .005]$} & {$[-.015, .004]$} & {$[-.030, .026]$} \\
\hline \multirow[t]{2}{*}{ Noventena } & 0.0109 & 0.0059 & 0.0056 & -0.001 & $0.0038^{*}$ & 0.0045 \\
\hline & {$[-.009, .029]$} & {$[-.006, .017]$} & {$[-.011, .023]$} & {$[-.006, .004]$} & {$[.000, .007]$} & {$[-.006, .015]$} \\
\hline \multirow{2}{*}{1 trimestre depois } & $-0.034^{* *}$ & $-0.039 * * *$ & $-0.032 * * *$ & -0.006 & -0.018 & -0.018 \\
\hline & {$[-.078,-.008]$} & {$[-.072,-.014]$} & {$[-.063,-.010]$} & {$[-.051, .037]$} & {$[-.057, .013]$} & {$[-.053, .012]$} \\
\hline \multirow[t]{2}{*}{2 trimestres depois } & -0.036 & $-0.044^{* * *}$ & $-0.032^{* *}$ & 0.0090 & 0.0002 & 0.0001 \\
\hline & {$[-.084, .002]$} & {$[-.074,-.020]$} & {$[-.069,-.011]$} & {$[-.049, .071]$} & {$[-.047, .044]$} & {$[-.047, .048]$} \\
\hline \multirow[t]{2}{*}{3 trimestres depois } & -0.020 & $-0.040^{* *}$ & -0.021 & 0.0144 & 0.0038 & 0.0029 \\
\hline & {$[-.072, .015]$} & {$[-.061,-.015]$} & {$[-.075, .012]$} & {$[-.053, .089]$} & {$[-.053, .058]$} & {$[-.057, .064]$} \\
\hline \multirow[t]{2}{*}{4 trimestres depois } & -0.033 & $-0.040^{* * *}$ & -0.020 & 0.0180 & 0.0155 & 0.0127 \\
\hline & {$[-.088, .013]$} & {$[-.061,-.022]$} & {$[-.070, .006]$} & {$[-.054, .090]$} & {$[-.046, .071]$} & {$[-.073, .096]$} \\
\hline \multirow[t]{2}{*}{5 ou mais trimestres depois } & -0.049 & $-0.084^{* * *}$ & $-0.035^{*}$ & 0.0098 & 0.0010 & 0.0091 \\
\hline & {$[-.128, .036]$} & {$[-.148,-.040]$} & {$[-.096,-.003]$} & {$[-.088, .118]$} & {$[-.084, .090]$} & {$[-.117, .145]$} \\
\hline Clusters & 12 & 12 & 12 & 18 & 18 & 18 \\
\hline Efeito Fixo Mensal & Sim & Sim & Sim & Sim & Sim & Sim \\
\hline Efeito Fixo Setorial & Sim & Sim & Sim & Sim & Sim & Sim \\
\hline Controles & Não & Sim & Sim & Não & Sim & Sim \\
\hline Tendência Linear Setorial & Não & Não & Sim & Não & Não & Sim \\
\hline Observações & 7056 & 7056 & 7056 & 4320 & 4320 & 4320 \\
\hline$R^{2}$ & .3551 & .4885 & .8653 & .1046 & .2443 & .6251 \\
\hline Setores & 98 & 98 & 98 & 60 & 60 & 60 \\
\hline
\end{tabular}

A tabela 18 mostra os resultados para uma regressão do nível de emprego apenas com trabalhadores de empresas do SIMPLES. Para alguns dos setores analisados, o nível de emprego neste regime tributário é extremamente baixo. Sendo assim, mantemos o limite mínimo de 100 trabalhadores por setor, retirando alguns dos ramos analisados no regime normal. Enquanto, mais uma vez, a desoneração por NCM não parece apresentar efeito, o nível de emprego apresenta queda entre os setores desonerados pela CNAE. Esse resultado reforça a ideia de que nossos resultados anteriores podem estar sendo inflados pela realocação de empresas em busca dos benefícios concedidos pela desoneração, e que já teriam realizado essa contratação de qualquer maneira.

Ainda assim, é importante notar que o regime do SIMPLES tem um número de trabalhadores bastante inferior ao encontrado no regime normal. O número total de trabalhadores nos setores desonerados pela CNAE, em agosto de 2011 (mês da promulgação 
Figura 6 - Event-Studies Trimestrais do Emprego no SIMPLES

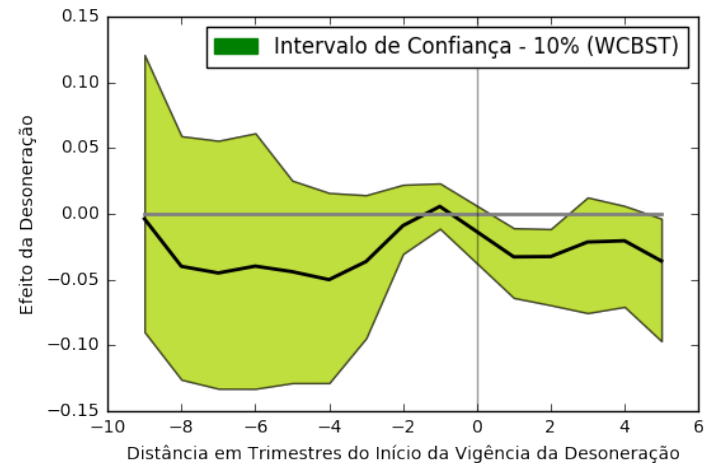

Somente CNAE

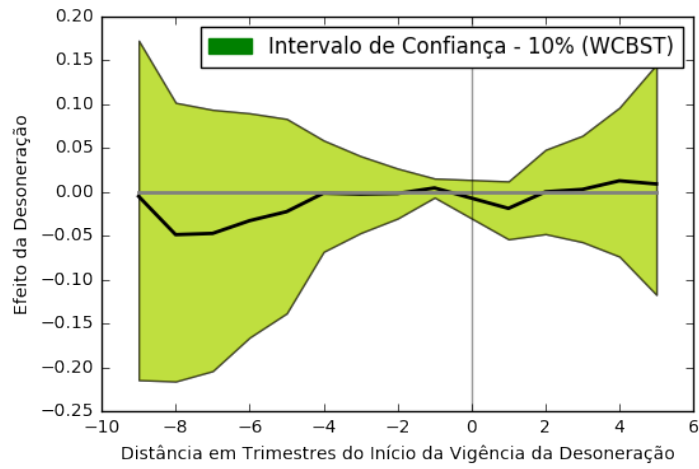

Somente NCM

Nota: Gráficos referentes aos Event Studies das regressões na tabela 18. Apresenta a distribuição dos efeitos estimados da desoneração no decorrer do tempo, assim como seus respectivos intervalos de confiança a $10 \%$

da primeira MP relacionada ao novo regime), era de aproximadamente 9,2 milhões de trabalhadores, estando 6,2 milhões dos mesmos empregados em empresas fora do SIMPLES. Sendo assim, a maior representatividade deste regime, aliada a um efeito estimado da desoneração mais alto do que o encontrado (em números absolutos) no SIMPLES, indica que o impacto líquido da desoneração sobre o emprego ainda é positivo.

Para embasar a interpretação do efeito negativo da desoneração sobre o emprego no regime do SIMPLES, analisamos a entrada e a saída deste regime. Dada a opção anual pelo mesmo, as regressões também são realizadas nesse nível de observação. As regressões são apresentadas no apêndice, e reúnem apenas as empresas de setores comparáveis em 3 dígitos da CNAE.

A tabela 22 mostra o impacto da desoneração na proporção de empresas no SIMPLES. A análise parece demonstrar que não houve um impacto observável nessa variável. Ainda assim, o SIMPLES é caracterizado por ser um regime formado por empresas de menor porte, com uma minoria de empresas apresentando grande quantidade de empregados. Por outro lado, é justamente essa minoria que se atrairia pela mudança da base tributária, e que estaria restrita pelos limites de faturamento impostos pelo SIMPLES. Em função disso, a proporção também é analisada apenas para empresas com mais de 10 e com mais de 100 funcionários. Ainda assim, nenhum efeito da desoneração sobre a proporção de firmas é encontrado.

A regressão apresentada na tabela 23 se utiliza dessa mesma interpretação para identificar a saída das empresas. Se as firmas com maior número de funcionários são justamente aquelas que saem do SIMPLES em busca da desoneração da folha, isso tenderia a diminuir o número médio de funcionários entre as empresas do regime. Os coeficientes das regressões para o SIMPLES vão de acordo com essa interpretação, mas não são sig- 
nificativos. Ainda que tenhamos observado um efeito negativo da desoneração no nível de emprego do SIMPLES, o fluxo de saída em função do novo regime não parece ser substancial.

Tabela 19 - Estimação do Nível de Emprego no Total

\begin{tabular}{|c|c|c|c|c|c|c|}
\hline \multirow{3}{*}{9 ou mais trimestres antes } & \multicolumn{6}{|c|}{ Variável dependente: Log(Trabalhadores) } \\
\hline & \multicolumn{3}{|c|}{ Desonerados por CNAE } & \multicolumn{3}{|c|}{ Desonerados por NCM } \\
\hline & $\begin{array}{c}0.0261 \\
{[-.089, .096]}\end{array}$ & $\begin{array}{c}0.0419 \\
{[-.094, .131]}\end{array}$ & $\begin{array}{c}-0.014 \\
{[-.077, .037]}\end{array}$ & $\begin{array}{c}-0.051^{*} \\
{[-.097,-.003]}\end{array}$ & $\begin{array}{c}-0.021 \\
{[-.058, .017]}\end{array}$ & $\begin{array}{c}0.0236 \\
{[-.079, .128]}\end{array}$ \\
\hline \multirow[t]{2}{*}{8 trimestres antes } & -0.001 & 0.0058 & -0.018 & -0.008 & 0.0026 & 0.0337 \\
\hline & {$[-.100, .066]$} & {$[-.094, .071]$} & {$[-.077, .035]$} & {$[-.035, .017]$} & {$[-.022, .027]$} & {$[-.049, .117]$} \\
\hline \multirow[t]{2}{*}{7 trimestres antes } & -0.000 & 0.0036 & -0.017 & -0.003 & 0.0033 & 0.0281 \\
\hline & {$[-.086, .059]$} & {$[-.079, .060]$} & {$[-.072, .031]$} & {$[-.032, .024]$} & {$[-.021, .027]$} & {$[-.047, .103]$} \\
\hline \multirow[t]{2}{*}{6 trimestres antes } & 0.0114 & 0.0096 & -0.006 & 0.0015 & 0.0043 & 0.0244 \\
\hline & {$[-.069, .066]$} & {$[-.064, .056]$} & {$[-.069, .034]$} & {$[-.022, .027]$} & {$[-.021, .030]$} & {$[-.041, .090]$} \\
\hline \multirow{2}{*}{5 trimestres antes } & 0.0069 & 0.0094 & -0.008 & 0.0080 & 0.0084 & 0.0231 \\
\hline & {$[-.062, .063]$} & {$[-.058, .058]$} & {$[-.066, .040]$} & {$[-.012, .029]$} & {$[-.020, .036]$} & {$[-.037, .083]$} \\
\hline \multirow[t]{2}{*}{4 trimestres antes } & -0.000 & -0.003 & -0.012 & 0.0082 & 0.0059 & 0.0221 \\
\hline & {$[-.051, .044]$} & {$[-.047, .028]$} & {$[-.056, .021]$} & {$[-.012, .030]$} & {$[-.010, .023]$} & {$[-.014, .058]$} \\
\hline \multirow[t]{2}{*}{3 trimestres antes } & -0.000 & -0.003 & -0.007 & 0.0107 & 0.0085 & 0.0196 \\
\hline & {$[-.030, .030]$} & {$[-.026, .018]$} & {$[-.035, .019]$} & {$[-.004, .027]$} & {$[-.005, .023]$} & {$[-.008, .047]$} \\
\hline \multirow[t]{2}{*}{2 trimestres antes } & 0.0086 & 0.0023 & 0.0067 & 0.0051 & 0.0064 & 0.0129 \\
\hline & {$[-.011, .023]$} & {$[-.016, .020]$} & {$[-.013, .021]$} & {$[-.008, .018]$} & {$[-.009, .022]$} & {$[-.008, .033]$} \\
\hline \multirow[t]{2}{*}{ Noventena } & 0.0053 & 0.0043 & 0.0041 & 0.0034 & 0.0025 & 0.0054 \\
\hline & {$[-.005, .013]$} & {$[-.003, .010]$} & {$[-.006, .011]$} & {$[-.001, .008]$} & {$[-.004, .008]$} & {$[-.002, .012]$} \\
\hline \multirow{2}{*}{1 trimestre depois } & 0.0030 & -0.000 & 0.0058 & -0.007 & 0.0020 & 0.0000 \\
\hline & {$[-.007, .024]$} & {$[-.017, .024]$} & {$[-.005, .028]$} & {$[-.031, .015]$} & {$[-.020, .025]$} & {$[-.015, .015]$} \\
\hline \multirow[t]{2}{*}{2 trimestres depois } & 0.0032 & -0.000 & 0.0081 & -0.013 & -0.007 & -0.012 \\
\hline & {$[-.013, .036]$} & {$[-.020, .031]$} & {$[-.008, .032]$} & {$[-.043, .015]$} & {$[-.033, .019]$} & {$[-.033, .007]$} \\
\hline \multirow[t]{2}{*}{3 trimestres depois } & $0.0210^{* *}$ & 0.0109 & $0.0236^{* *}$ & -0.012 & -0.006 & -0.017 \\
\hline & {$[.003, .052]$} & {$[-.016, .047]$} & {$[.007, .038]$} & {$[-.047, .022]$} & {$[-.036, .024]$} & {$[-.046, .010]$} \\
\hline \multirow[t]{2}{*}{4 trimestres depois } & $0.0243 *$ & 0.0188 & 0.0258 & -0.014 & -0.007 & -0.023 \\
\hline & {$[.001, .066]$} & {$[-.001, .050]$} & {$[-.001, .054]$} & {$[-.048, .019]$} & {$[-.035, .021]$} & {$[-.052, .006]$} \\
\hline \multirow{2}{*}{5 ou mais trimestres depois } & 0.0673 & 0.0577 & 0.0419 & -0.016 & -0.004 & -0.027 \\
\hline & {$[-.011, .202]$} & {$[-.023, .192]$} & {$[-.009, .111]$} & {$[-.062, .026]$} & {$[-.043, .034]$} & {$[-.071, .017]$} \\
\hline Cluste & 12 & 12 & & 19 & 19 & 19 \\
\hline Efeito Fixo Mensal & Sim & Sim & Sim & $\operatorname{Sim}$ & Sim & Sim \\
\hline Efeito Fixo Setorial & Sim & Sim & Sim & Sim & Sim & Sim \\
\hline Controles & Não & Sim & Sim & Não & Sim & Sim \\
\hline Tendência Linear Setorial & Não & Não & Sim & Não & Não & Sim \\
\hline Observações & 7488 & 7488 & 7488 & 4968 & 4968 & 4968 \\
\hline$R^{2}$ & .3467 & .3735 & .9001 & .2319 & .4075 & .7613 \\
\hline Setores & 104 & 104 & 104 & 69 & 69 & 69 \\
\hline
\end{tabular}

Os resultados para o nível de emprego nos regimes tributários em conjunto, reunindo todo o mercado de trabalho (entre os setores "analisáveis") são apresentados na tabela 19. Os efeitos para CNAE sofrem uma diminuição, como esperado. Adicionalmente, enquanto a significância estatística mantém-se para alguns dos coeficientes dos trimestres posteriores, os efeitos de longo prazo não são mais significativos, ainda que positivos.

Para os desonerados por NCM, mais uma vez não observa-se efeito sobre o nível de emprego. Reunindo os efeitos considerados nos dois regimes tributários separadamente e em seu conjunto, a desoneração por NCM não parece ter trazido um aumento no número de contratações em seus setores, sendo o impacto negativo de curto prazo sobre os empregados no SIMPLES a única dinâmica observada na análise. Os desonerados por CNAE, por outro lado, apresentam um crescimento no nível de emprego e uma possível realocação de regimes tributários em função da CPRB. Consequentemente, prosseguimos com nossa 
Figura 7 - Event-Studies Trimestrais do Emprego no Total

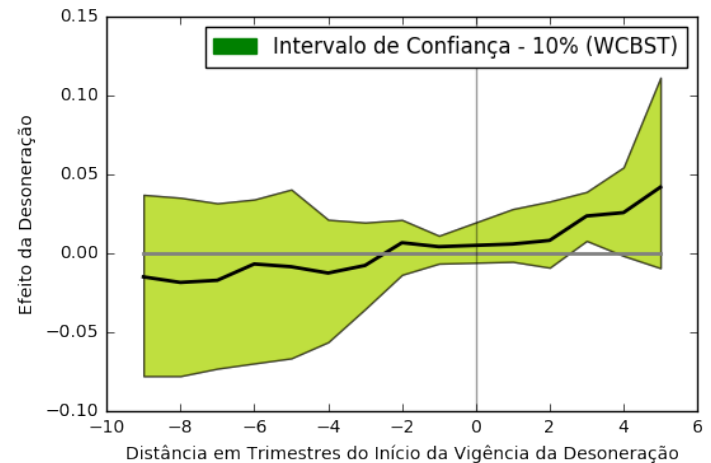

Somente CNAE

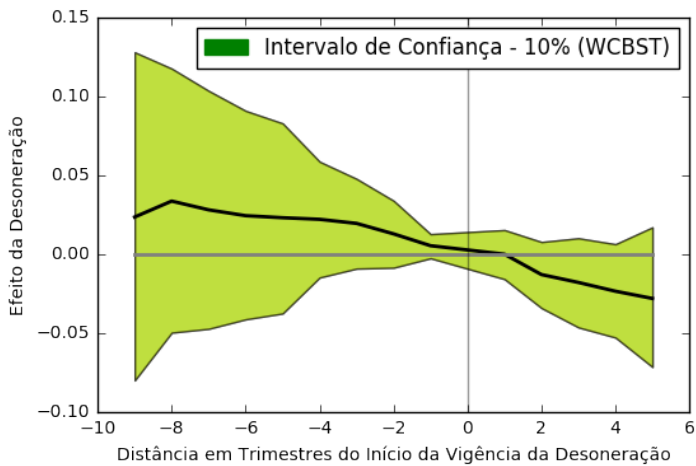

Somente NCM

Nota: Gráficos referentes aos Event Studies das regressões na tabela 19. Apresenta a distribuição dos efeitos estimados da desoneração no decorrer do tempo, assim como seus respectivos intervalos de confiança a $10 \%$

análise focando apenas no nível de emprego das desonerações realizadas em função da CNAE.

\subsection{Efeitos Diferenciados sobre o Emprego}

A tabela apresentada no anexo 2, calculada pela ANFIP, mostra a relação entre a contribuição patronal efetivamente paga pelos setores desonerados (na CPRB) e aquela que pagariam se estivessem no regime antigo (CPP). Dada a heterogeneidade dos setores econômicos, o impacto da desoneração pode ter sido bastante diferente entre os mesmos. O grau de intensividade de mão de obra certamente influi no ganho trazido pelo novo regime, assim como a taxa de lucro do setor. Uma margem de lucro muito baixa pode, inclusive, vir a ser suprimida pelo incremento dos custos tributários vinculados à receita.

A tabela 20 mostra os resultados de uma regressão dividindo os efeitos entre os setores com uma desoneração mais e menos intensa. A divisão dos setores é realizada em função da mediana da proporção entre a contribuição patronal efetiva e a que seria realizada no antigo regime $\left(\frac{C P R B}{C P P}\right)$, que é usada com uma proxy para a intensidade da desoneração. Dada a provável reestruturação das empresas em função da nova tributação, é possível que haja ruído nesta medida. Se a mudança contribui para o aumento das contratações (como parece ser o caso), por exemplo, isso acaba por aumentar a estimativa do que seria pago no regime antigo, que tem a folha salarial como base de cálculo.

Como esperado, o efeito é positivo para ambas as especificações, e maior para os setores de desoneração mais intensa. O efeito de longo prazo para os setores com maior desoneração é significativo quando inserimos apenas controles, mas perde significância ao inserirmos as tendências temporais setoriais. 
Tabela 20 - Separação do Efeito pela Intensidade da Desoneração

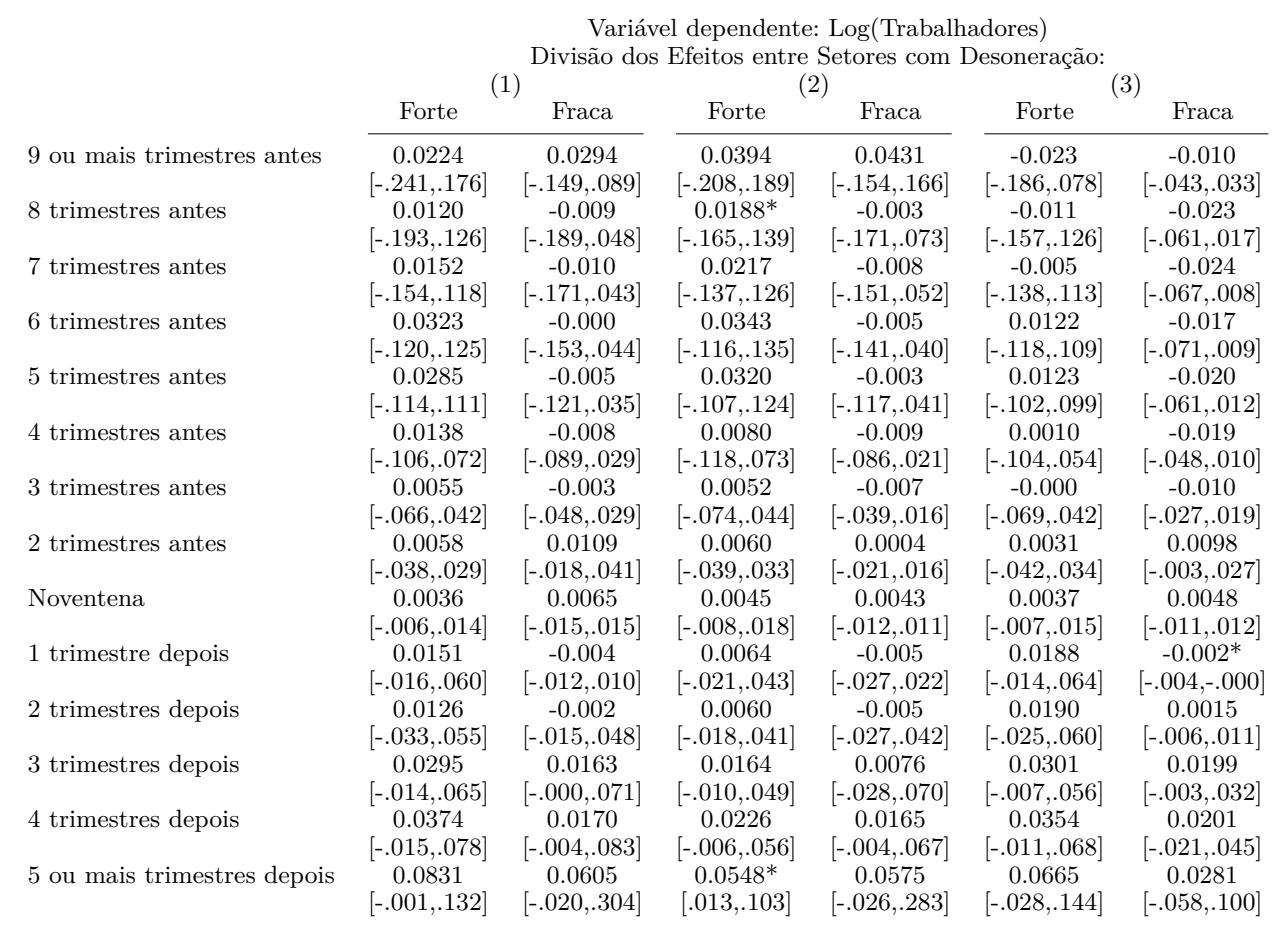

$\begin{array}{lccc}\text { Clusters } & 12 & 12 & 12 \\ \text { Efeito Fixo Mensal } & \text { Sim } & \text { Sim } & \text { Sim } \\ \text { Efeito Fixo Setorial } & \text { Sim } & \text { Sim } & \text { Sim } \\ \text { Controles } & \text { Não } & \text { Sim } & \text { Sim } \\ \text { Tendência Linear Setorial } & \text { Não } & \text { Não } & \text { Sim } \\ & & & 7488 \\ \text { Observações } & 7488 & 7488 & .9005 \\ R^{2} & .3473 & .3470 & 104 \\ \text { Setores } & 104 & 104 & \end{array}$

Nota: Intervalos de Confiança a $10 \%$ de WCBST nos colchetes. ${ }^{* * *} \mathrm{p}<0.01,{ }^{*} \mathrm{p}<0.05,{ }^{*} \mathrm{p}<0.1$. Coeficientes estimados na regressão de um Event Study do nível de emprego em função da desoneração. O período base é sempre o mês imediatamente anterior ao início da vigência do novo regime tributário. A variável "Noventena"refere-se ao período entre a promulgação da lei ou MP da desoneração e sua efetiva vigência. Os bootstraps são realizados com 1000 repetições e pesos Rademacher, como proposto em Cameron, Gelbach e Miller (2008)

Figura 8 - Event-Studies Trimestrais do Emprego no Total por Intensidade

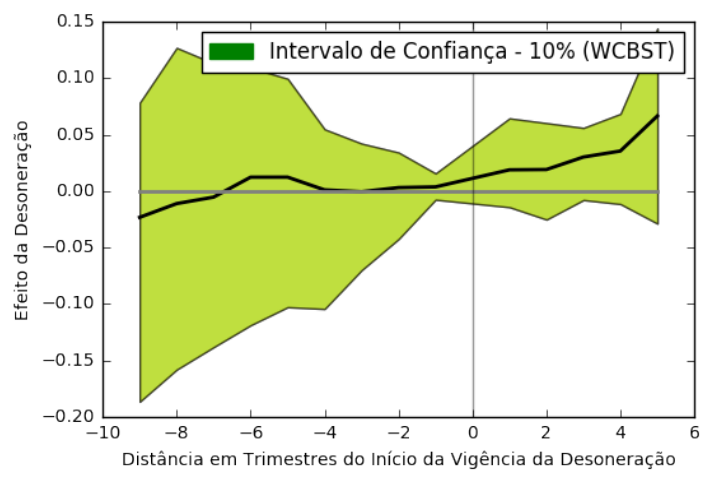

Setores com desoneração mais intensa

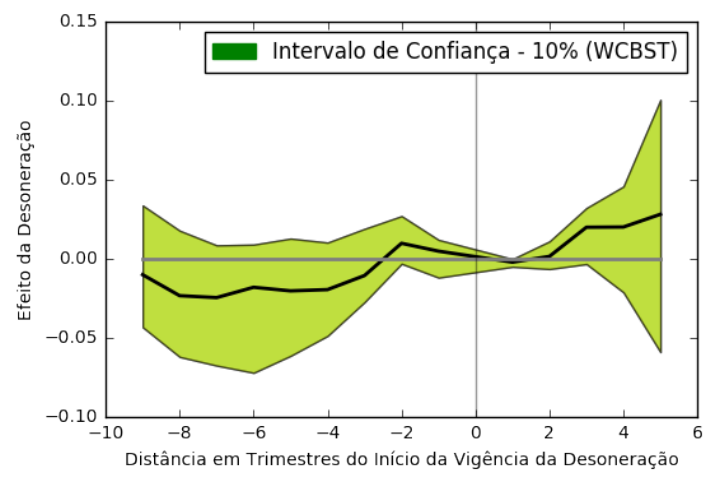

Setores com desonerção menos intensa

Nota: Gráficos referentes aos Event Studies das regressões na tabela 20. Apresenta a distribuição dos efeitos estimados da desoneração no decorrer do tempo, assim como seus respectivos intervalos de confiança a $10 \%$ 
Outra diferenciação interessante é trazida pela revogação da desoneração salarial. A medida provisória 774, de março de 2017, extinguiu a desoneração para a grande maioria dos setores contemplados. Um pequeno grupo de atividades, porém, abrangendo transporte, comunicação e construção civil, manteve-se no regime. Uma lista dos setores mantidos pela MP e que é análisável de acordo com a estratégia de identificação adotata é apresentada no anexo, na tabela 28. A justificativa do governo foi a de que os demais setores não responderam aos incentivos. Mais uma vez, porém, não houve apresentação de qualquer tipo de análise que embasasse a decisão tomada. A tabela 21 mostra os resultados da divisão do impacto entre os setores mantidos e os retirados da CPRB.

Tabela 21 - Separação do Efeito entre Setores Mantidos e Retirados pela MP №774

\begin{tabular}{|c|c|c|c|c|c|c|}
\hline \multirow[b]{3}{*}{9 ou mais trimestres antes } & \multicolumn{6}{|c|}{$\begin{array}{l}\text { Variável dependente: Log(Trabalhadores) } \\
\text { Divisão dos Efeitos entre Setores: }\end{array}$} \\
\hline & Mantidos & Retirados & Mantidos & Retirados & Mantidos & Retirados \\
\hline & $\begin{array}{c}0.0909 \\
{[-.118, .179]}\end{array}$ & $\begin{array}{l}-0.005 \\
{[-.217, .080]}\end{array}$ & $\begin{array}{c}0.1136 \\
{[-.098, .249]}\end{array}$ & $\begin{array}{c}0.0082 \\
{[-.206, .103]}\end{array}$ & $\begin{array}{c}-0.003 \\
{[-.091, .056]}\end{array}$ & $\begin{array}{c}-0.024 \\
{[-.124, .054]}\end{array}$ \\
\hline 8 trimestres antes & $\begin{array}{c}0.0101 \\
{[-.191, .094]}\end{array}$ & {$\left[\begin{array}{l}-0.005 \\
{[-.172, .071]}\end{array}\right.$} & $\begin{array}{c}0.0233 \\
{[-.175, .142]}\end{array}$ & $\begin{array}{c}-0.001 \\
{[-.139, .066]}\end{array}$ & $\begin{array}{c}-0.018 \\
{[-.078, .036]}\end{array}$ & $\begin{array}{c}-0.022 \\
{[-.129, .081]}\end{array}$ \\
\hline 7 trimestres antes & $\begin{array}{c}0.0073 \\
{[-.161, .084]}\end{array}$ & {$\left[\begin{array}{c}-0.003 \\
-.143, .069]\end{array}\right.$} & {$\left[\begin{array}{c}0.0207 \\
{[-.143, .129]}\end{array}\right.$} & $\begin{array}{c}-0.003 \\
{[-.121, .056]}\end{array}$ & {$\left[\begin{array}{c}-0.016 \\
{[-.071, .038]}\end{array}\right.$} & {$\left[\begin{array}{c}-0.020 \\
{[-.121, .064]}\end{array}\right.$} \\
\hline 6 trimestres antes & $\begin{array}{c}0.0124 \\
{[-.154, .094]}\end{array}$ & $\begin{array}{c}0.0096 \\
{[-.117, .072]}\end{array}$ & $\begin{array}{c}0.0197 \\
{[-.127, .115]}\end{array}$ & $\begin{array}{c}0.0024 \\
{[-.101, .047]}\end{array}$ & $\begin{array}{c}-0.008 \\
{[-.058, .045]}\end{array}$ & $\begin{array}{c}-0.010 \\
{[-.115, .053]}\end{array}$ \\
\hline 5 trimestres antes & $\begin{array}{c}0.0102 \\
{[-.139, .076]}\end{array}$ & {$\left[\begin{array}{c}0.0033 \\
-.113, .078]\end{array}\right.$} & $\begin{array}{c}0.0168 \\
{[-.111, .094]}\end{array}$ & $\begin{array}{c}0.0042 \\
{[-.095, .069]}\end{array}$ & {$\left[\begin{array}{c}-0.006 \\
-.045, .030]\end{array}\right.$} & $\begin{array}{c}-0.013 \\
{[-.110, .063]}\end{array}$ \\
\hline 4 trimestres antes & $\begin{array}{c}0.0269 \\
{[-.080, .080]}\end{array}$ & $\begin{array}{c}-0.014 \\
{[-.104, .034]}\end{array}$ & $\begin{array}{c}0.0297 \\
{[-.048, .088]}\end{array}$ & {$\left[\begin{array}{c}-0.020 \\
{[-.091, .010]}\end{array}\right.$} & $\begin{array}{c}0.0151 \\
-.023, .045]\end{array}$ & $\begin{array}{c}-0.027 \\
{[-.100, .017]}\end{array}$ \\
\hline 3 trimestres antes & $\begin{array}{c}0.0181 \\
{[-.015, .058]}\end{array}$ & $\begin{array}{c}-0.010 \\
{[-.066, .027]}\end{array}$ & $\begin{array}{c}0.0245^{*} \\
{[-.011, .070]}\end{array}$ & $\begin{array}{c}-0.017 \\
{[-.059, .004]}\end{array}$ & $\begin{array}{c}0.0124 \\
{[-.010, .057]}\end{array}$ & $\begin{array}{c}-0.018 \\
{[-.067, .016]}\end{array}$ \\
\hline 2 trimestres antes & $\begin{array}{c}0.0157^{*} \\
{[.001, .031]}\end{array}$ & $\begin{array}{c}0.0056 \\
{[-.031, .025]}\end{array}$ & $\begin{array}{c}0.0174 * \\
.000, .036]\end{array}$ & $\begin{array}{c}-0.005 \\
{[-.041, .023]}\end{array}$ & $\begin{array}{c}0.0103 \\
{[-.007, .044]}\end{array}$ & $\begin{array}{c}0.0047 \\
{[-.029, .026]}\end{array}$ \\
\hline Noventena & $\begin{array}{c}0.0054 \\
{[-.006, .012]}\end{array}$ & $\begin{array}{c}0.0054 \\
{[-.012, .015]}\end{array}$ & $\begin{array}{c}0.0053 \\
{[-.004, .013]}\end{array}$ & $\begin{array}{c}0.0041 \\
{[-.010, .012]}\end{array}$ & $\begin{array}{c}0.0038 \\
{[-.006, .014]}\end{array}$ & $\begin{array}{c}0.0046 \\
{[-.009, .012]}\end{array}$ \\
\hline 1 trimestre depois & $\begin{array}{c}-0.006 \\
{[-.017, .015]}\end{array}$ & $\begin{array}{c}0.0064 \\
{[-.007, .041]}\end{array}$ & $\begin{array}{c}-0.005 \\
{[-.015, .016]}\end{array}$ & $\begin{array}{c}-0.000 \\
{[-.021, .039]}\end{array}$ & $\begin{array}{c}-0.001 \\
{[-.008, .007]}\end{array}$ & $\begin{array}{c}0.0092 \\
{[-.010, .043]}\end{array}$ \\
\hline 2 trimestres depois & $\begin{array}{c}-0.008 \\
{[-.035, .050]}\end{array}$ & $\begin{array}{c}0.0067 \\
{[-.016, .043]}\end{array}$ & $\begin{array}{c}-0.004 \\
{[-.022, .043]}\end{array}$ & $\begin{array}{c}-0.002 \\
{[-.023, .046]}\end{array}$ & $\begin{array}{c}0.0001 \\
{[-.017, .017]}\end{array}$ & $\begin{array}{c}0.0117 \\
{[-.011, .047]}\end{array}$ \\
\hline 3 trimestres depois & $\begin{array}{c}0.0051 \\
{[-.025, .066]}\end{array}$ & $\begin{array}{c}0.0252^{*} \\
{[.002, .057]}\end{array}$ & $\begin{array}{c}0.0047 \\
{[-.016, .052]}\end{array}$ & $\begin{array}{c}0.0092 \\
{[-.022, .056]}\end{array}$ & $\begin{array}{c}0.0141 \\
{[-.011, .037]}\end{array}$ & $\begin{array}{c}0.0282^{*} \\
{[.003, .048]}\end{array}$ \\
\hline 4 trimestres depois & $\begin{array}{c}0.0013 \\
{[-.033, .072]}\end{array}$ & $\begin{array}{c}0.0297^{*} \\
{[.001, .075]}\end{array}$ & $\begin{array}{c}0.0025 \\
{[-.024, .054]}\end{array}$ & $\begin{array}{c}0.0215 \\
{[-.009, .067]}\end{array}$ & $\begin{array}{c}0.0140 \\
{[-.037, .049]}\end{array}$ & $\begin{array}{c}0.0322 \\
{[-.012, .066]}\end{array}$ \\
\hline 5 ou mais trimestres depois & $\begin{array}{c}0.1271 \\
{[-.080, .571]}\end{array}$ & $\begin{array}{c}0.0403 \\
{[-.012, .119]}\end{array}$ & $\begin{array}{c}0.1286 \\
{[-.067, .548]}\end{array}$ & $\begin{array}{c}0.0259 \\
{[-.019, .097]}\end{array}$ & $\begin{array}{c}0.0106 \\
{[-.086, .085]}\end{array}$ & $\begin{array}{c}0.0546 \\
{[-.023, .145]}\end{array}$ \\
\hline $\begin{array}{l}\text { Clusters } \\
\text { Efeito Fixo Mensal } \\
\text { Efeito Fixo Setorial } \\
\text { Controles } \\
\text { Tendência Linear Setorial }\end{array}$ & $\begin{array}{l}\mathrm{S} \\
\mathrm{S} \\
\mathrm{N} \\
\mathrm{N}\end{array}$ & & $\begin{array}{l}\mathbf{S} \\
\mathbf{S} \\
\mathbf{S} \\
\mathrm{N}\end{array}$ & & $\begin{array}{l}\mathrm{Si} \\
\mathrm{Si} \\
\mathrm{Si} \\
\mathrm{Si}\end{array}$ & \\
\hline $\begin{array}{l}\text { Observações } \\
R^{2} \\
\text { Setores }\end{array}$ & $\begin{array}{r}7 \\
.3 \\
1 \\
\end{array}$ & & $\begin{array}{r}7 \\
.3 \\
1\end{array}$ & & $\begin{array}{r}74 \\
.90 \\
1 \\
\end{array}$ & \\
\hline
\end{tabular}

Ainda que não significativo, o efeito de longo prazo estimado para os setores mantidos na desoneração nas regressões sem tendências temporais é bastante alto, superando $12 \%$. A adição da tendência temporal, porém, absorve este efeito, o que pode indicar que essa diferença seria explicada por uma tendência já presente de crescimento daqueles setores. Os setores retirados, por outro lado, apresentam efeito significativo de aumento do emprego, e mesmo o impacto de longo prazo da desoneração, apesar de não ser signi- 
ficativo, é superior ao dos setores mantidos.

Figura 9 - Event-Studies Trimestrais do Emprego no Total em função da MP 774

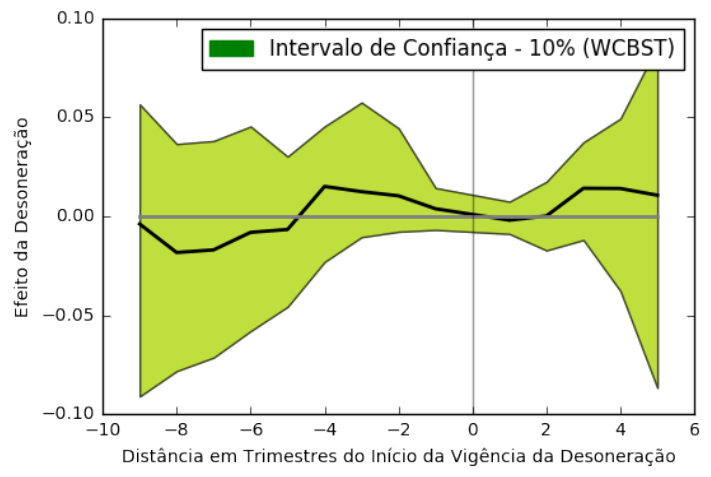

Mantidos pela MP 774

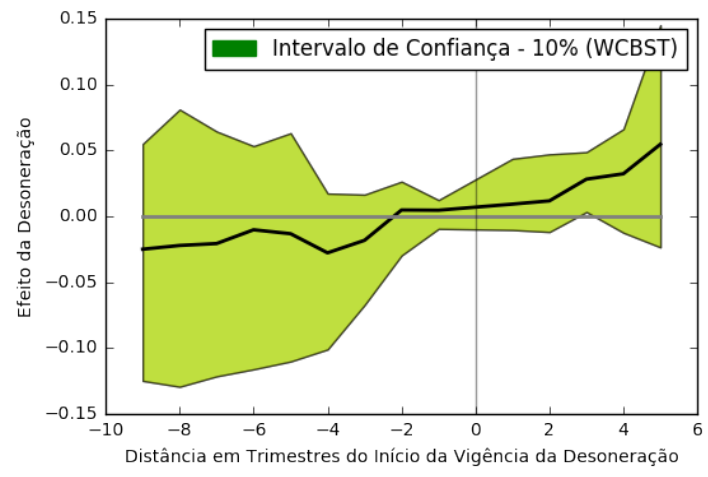

Retirados pela MP 774

Nota: Gráficos referentes aos Event Studies das regressões na tabela 21. Apresenta a distribuição dos efeitos estimados da desoneração no decorrer do tempo, assim como seus respectivos intervalos de confiança a $10 \%$

Os resultados apresentados apontam para um efeito claro da desoneração da folha salarial sobre o nível de emprego dos setores alocados através da CNAE no regime tributário comum. A possível realocação tributária das empresas encontrada, porém, nos leva a analisar o efeito do novo regime no mercado de trabalho como um todo, reunindo os regimes tributários. Neste sentido, ainda que tenhamos encontrado efeitos significativos e que os coeficientes estimados tenham sido consistentemente positivos, os efeitos de longo prazo estimados não são significativos na regressão com controles e tendências temporais em nenhuma das especificações realizadas.

Como discutido em Esarey e Menger (2015), porém, ainda que o WCBST corrija o problema de subestimação dos erros em face a um número reduzido de clusters, o poder do teste de hipótese proporcionado pelo método ainda é baixo quando o número de clusters é muito pequeno (como é o caso ao realizarmos a regressão apenas com os desonerados pela CNAE, clusterizando em 12 divisões desta cassificação). Como uma forma de analisar essa questão, calculamos o intervalo de confiança das estimações do nível de emprego da CNAE assumindo correlação apenas entre os erros dos setores dentro de um mesmo grupo (referente aos 3 primeiros dígitos da classificação). As regressões são apresentadas no apêndice, na tabela 24. Nessa especificação, o número de clusters sobe para 41, o que possibilitaria a clusterização dos erros como correção do viés. Os gráficos abaixo apresentam tanto o intervalo de confiança calculado através do WCBST quanto o intervalo dos erros clusterizados. Como se pode ver, os efeitos de longo prazo passam a ser estatisticamente significativos a $10 \%$ para a estimação conjunta, para a desoneração mais intensa e para os setores retirados da CPRB pela MP 774.

No mesmo sentido, as análises específicas para as empresas dentro e fora do SIMPLES encontraram efeitos significantes sobre o nível emprego, e como ressaltado ante- 
riormente, a maior intensidade do efeito positivo para as empresas do regime normal, aliada ao maior número de trabalhadores neste regime, também aponta para um efeito significativo da desoneração sobre o nível de emprego.

Figura 10 - Event-Studies Trimestrais do Emprego no Total - Comparação dos Erros

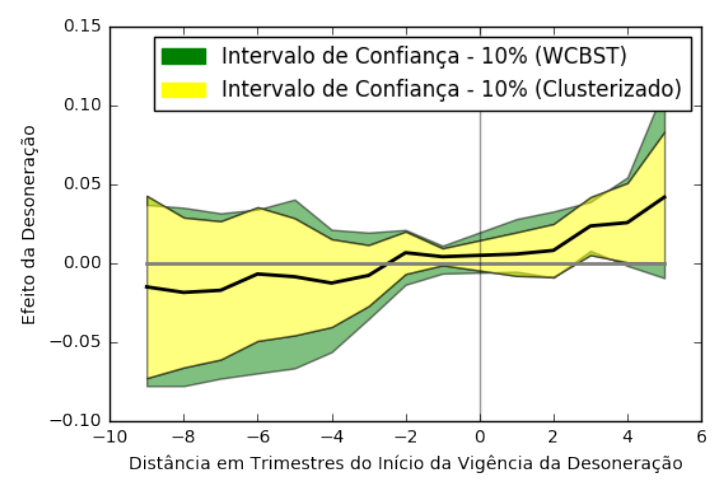

Desonerados por CNAE

Figura 11 - Event-Studies Trimestrais do Emprego no Total em função da MP 774 Comparação dos Erros

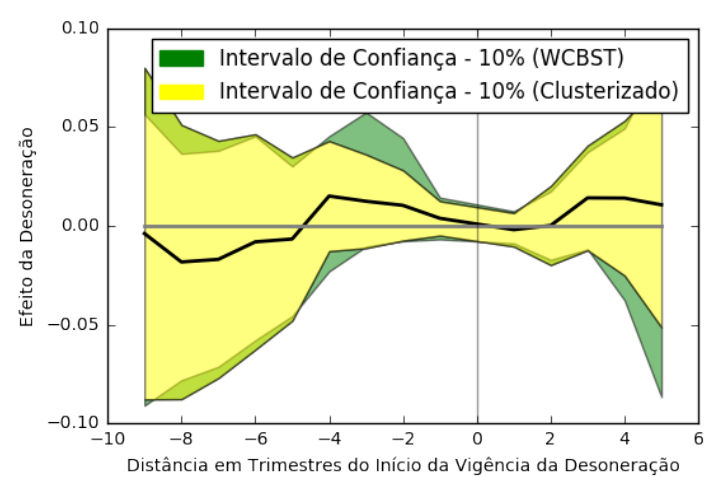

Mantidos pela MP 774

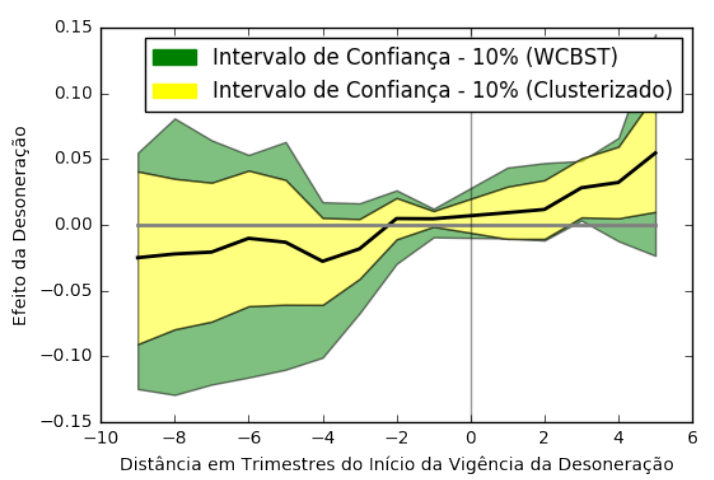

Retirados pela MP 774 
Figura 12 - Event-Studies Trimestrais do Emprego no Total por Intensidade - Comparação dos Erros

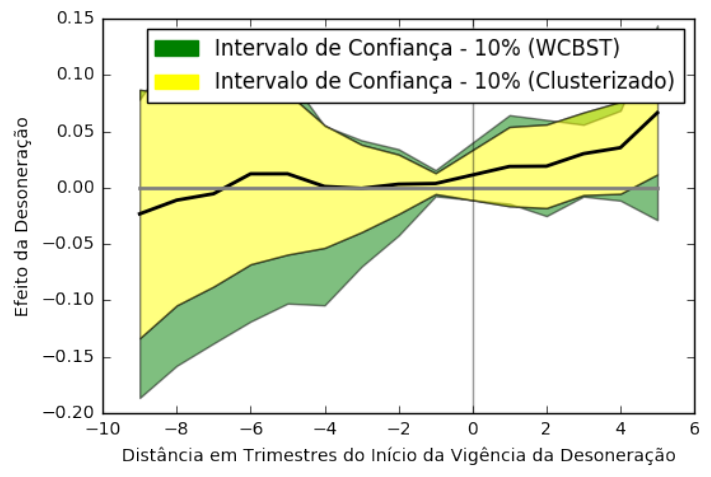

Setores com desoneração mais intensa

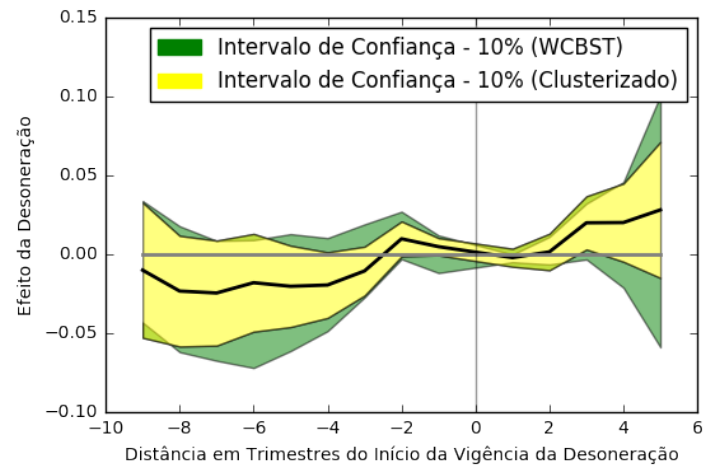

Setores com desoneração menos intensa 



\section{Considerações Finais}

Este trabalho analisou os efeitos da desoneração da folha salarial no mercado de trabalho brasileiro. Realizada como uma política de incentivos fiscais em larga escala, a desoneração não teve critérios claros de alocação de setores, criando a possibilidade de comparação entre setores similares. Utilizando dados da Relação Anual de Informações Sociais entre 2009 e 2014, foi possível observar a evolução dos salários e do nível de emprego destes setores, estimando o efeito da desoneração sobre estas variáveis através de um Event Study.

Os resultados não encontram efeito sobre o nível salarial dos setores desonerados, assim como para o nível de emprego das empresas desoneradas em função do NCM de seus produtos. Para os desonerados por sua classificação na CNAE, porém, há um efeito claro da desoneração sobre as empresas no regime normal de tributação (fora do SIMPLES), indo de acordo com o apresentado em estudos anteriores sobre o tema. Uma análise das empresas do SIMPLES, porém, aponta para uma queda (ainda que em menor magnitude) do nível de emprego, o que indica que a utilização das empresas do SIMPLES como contrafactuais, como realizado em Scherer (2015), pode acarretar em problemas de endogeneidade.

Dos aproximadamente 9,2 milhões de trabalhadores empregados nos setores desonerados pela CNAE em agosto de 2011 (quando da promulgação da MP 540, iniciando a desoneração), 6,2 milhões trabalhavam em empresas fora do SIMPLES. O efeito de longo prazo da desoneração para este grupo é de 7,5\%, o que, comparado ao efeito negativo de $3,5 \%$ para as empresas do SIMPLES, ainda indica um efeito líquido positivo da medida sobre o emprego.

Ao realizar a análise para o nível de emprego como um todo, porém, reunindo os diferentes regimes tributários, os efeitos de longo prazo encontrados sobre o nível de emprego não são significativos na análise utilizando WCBST, ainda que os resultados ainda se apresentem consistentemente positivos. Se assumirmos uma correlação um pouco menos geral dos erros, porém, clusterizando os mesmos entre setores na mesma divisão (3 primeiros dígitos da CNAE), encontramos efeito para o emprego em geral e para a desoneração ocorrida de maneira mais intensiva, assim como para os setores retirados do regime pela MP 774 .

Uma das possíveis contribuições da análise se relaciona à discussão sobre as vantagens de uma eventual mudança da base tributária de encargos sociais, como a contribuição previdenciária. Como discutido, o debate do combate à informalidade do mercado de trabalho brasileiro traz essa como uma de suas propostas. O fato da desoneração realizar essa 
mudança em conjunto com uma considerável renúncia fiscal, porém, dificulta a avaliação do real impacto da mudança tributária isoladamente.

Em um dos exercícios realizados, dividimos os efeitos entre os setores com desoneração mais e menos intensa. Ainda que a medida tenha sido realizada posteriormente, o que pode causar ruído, os efeitos são menores e não significantes para os desonerados em menor grau. Estes resultados podem indicar que os efeitos sobre o nível de emprego encontrados sofreram maior influência em função dos benefícios fiscais do que da mudança da base tributária. O fato do SIMPLES já oferecer a possibilidade de mudança de base tributária para a contribuição previdenciária, porém, pode já ter incentivado as empresas que valorizavam essa mudança anteriormente, o que também vai de acordo com a interpretação de que seriam essas as firmas que voltariam para o regime normal quando encontram incentivos similares no mesmo.

Outra questão não identificada em nossa análise é a possível realocação entre setores. O aumento observado no nível de emprego não é necessariamente proveniente de trabalhadores desempregados ou informais, e pode ter sido acarretado pela realocação setorial dos mesmos. Se há, de fato, um crescimento dos desonerados em detrimento dos demais setores, este efeito deletério não está sendo observado nas estimações.

Ainda assim, mesmo assumindo o efeito estimado de $4,2 \%$ da desoneração da folha salarial sobre o nível de emprego, o resultado da política de desonerações do governo Dilma ainda não parece ser positivo. Tomando como base os 9,2 milhões de trabalhadores nos setores desonerados pela CNAE em agosto, a desoneração seria responsável pela criação de 386.400 empregos nos mesmos, 37,7\% de todas as vagas criadas entre o início do novo regime e dezembro de 2014. Segundo o cálculo de ANFIP (2015), somente no ano de 2014 deixaram de ser arrecadados 31,5 bilhões de reais pela Previdência. Neste montante já está incluída a CPRB paga no novo regime. Mesmo diminuindo a renúncia em função da contribuição de $11 \%$ dos salários paga pelos empregos gerados, o custo por emprego gerado ainda é de cerca de $\mathrm{R} \$ 79.000,00$ por ano. Como comparação, o custo estimado por emprego criado da renúncia fiscal no SIMPLES Nacional é de $\mathrm{R} \$ 2.800,00$ reais ao ano, enquanto na Zona Franca de Manaus, outro exemplo de uma renúncia criticada de tributação, esse número chega a $\mathrm{R} \$ 191.000,00$ (Folha de S. Paulo (2013)). 


\section{Referências}

ANFIP. Nota Técnica sobre a Desoneração da Folha de Pagamentos. [S.l.], 2015. Citado 4 vezes nas páginas 19, 23, 24 e 62.

ANGRIST, J. D.; PISCHKE, J.-S. Mostly harmless econometrics: An empiricist's companion. [S.l.]: Princeton university press, 2008. Citado na página 34.

ANSILIERO, G. et al. A desoneração da folha de pagamentos e sua relação com a formalidade no mercado de trabalho. [S.l.], 2008. Citado na página 18.

ASHENFELTER, O. Estimating the effect of training programs on earnings. The Review of Economics and Statistics, JSTOR, p. 47-57, 1978. Citado na página 34.

AUTOR, D. H. Outsourcing at will: The contribution of unjust dismissal doctrine to the growth of employment outsourcing. Journal of Labor Economics, January, 2003. Citado na página 33.

BERTRAND, M.; DUFLO, E.; MULLAINATHAN, S. How much should we trust differences-in-differences estimates? [S.1.], 2002. Citado 2 vezes nas páginas 34 e 41.

BESLEY, T.; BURGESS, R. Can labor regulation hinder economic performance? evidence from india. The Quarterly Journal of Economics, Oxford University Press, v. 119, n. 1, p. 91-134, 2004. Citado na página 34.

BOSCH, M.; GOÑI-PACCHIONI, E.; MALONEY, W. Trade liberalization, labor reforms and formal-informal employment dynamics. Labour Economics, Elsevier, v. 19, n. 5, p. 653-667, 2012. Citado na página 18.

CAMERON, A. C.; GELBACH, J. B.; MILLER, D. L. Bootstrap-based improvements for inference with clustered errors. The Review of Economics and Statistics, MIT Press, v. 90, n. 3, p. 414-427, 2008. Citado 13 vezes nas páginas 36, 38, 40, 41, 42, 44, 46, 48, $50,51,53,55$ e 56 .

CAMERON, A. C.; MILLER, D. L. A practitioner's guide to cluster-robust inference. Journal of Human Resources, University of Wisconsin Press, v. 50, n. 2, p. 317-372, 2015. Citado 2 vezes nas páginas 34 e 41.

DALLAVA, C. C. Impactos da desoneração da folha de pagamantos sobre o nível de emprego no mercado de trabalho brasileiro: um estudo a partir dos dados da rais. 2014. Citado 2 vezes nas páginas 26 e 49.

ESAREY, J.; MENGER, A. Practical and effective approaches to dealing with clustered data. Department of Political Science, Rice University, Unpublished Manuscript, 2015. Citado 2 vezes nas páginas 41 e 57.

FERNANDES, R.; GREMAUD, A. P.; NARITA, R. d. T. Estrutura tributária e formalização da economia: simulando diferentes alternativas para o brasil. Anais do XXIX Encontro da Sociedade Brasileira de Econometria, 2004. Citado 2 vezes nas páginas 25 e 26. 
FERNANDES, R.; MENEZES-FILHO, N. A. Impactos dos encargos trabalhistas sobre o setor formal da economia. O Mercado de Trabalho no Brasil: Políticas, Resultados e Desafios. $1^{a}$ ed. São Paulo, v. 1, p. 149-175, 2002. Citado na página 25.

Folha de S. Paulo. Emprego gerado na zona franca de Manaus significa $R \$ 191$ mil em renúncia. 2013. [Online; Visualizado em 31/05/2017]. Disponível em: <http://www1.folha.uol.com.br/mercado/2013/12/1381563-emprego-gerado-nazona-franca-de-manaus-significa-r-191-mil-em-renuncia.shtml>. Citado na página 62 .

GRUBER, J. The incidence of payroll taxation: evidence from Chile. [S.1.], 1995. Citado na página 25 .

GRUBER, J.; KRUEGER, A. B. The incidence of mandated employer-provided insurance: Lessons from workers' compensation insurance. In: Tax Policy and the Economy, Volume 5. [S.1.]: The MIT Press, 1991. p. 111-144. Citado na página 25.

HECKMAN, J. J. et al. Introduction to"law and employment: Lessons from latin american and the caribbean". In: Law and Employment: Lessons from Latin America and the caribbean. [S.1.]: University of Chicago Press, 2004. p. 1-108. Citado na página 25.

KUGLER, A. D.; KUGLER, M. The labour market effects of payroll taxes in a middle-income country: evidence from colombia. CEPR discussion paper, 2003. Citado na página 25 .

MACKINNON, J. G.; WEBB, M. D. Wild bootstrap inference for wildly different cluster sizes. Journal of Applied Econometrics, Wiley Online Library, 2016. Citado na página 41.

O Estado de S. Paulo. Eu errei ao promover uma grande desoneração. 2017. [Online; Visualizado em 31/05/2017]. Disponível em: <http://economia.estadao.com.br/noticias/geral,dilma-eu-errei-ao-promover-uma-grande-desoneracao,70001696541>. Citado na página 17.

O Globo. Governo suspende desoneração da folha. 2017. [Online; Visualizado em 31/05/2017]. Disponível em: <https://oglobo.globo.com/economia/governo-suspendedesoneracao-da-folha-anuncia-corte-de-421-bi-21133408>. Citado na página 17.

OCDE. The OECD Jobs Report. [S.l.], 1994. Citado na página 18.

PAIVA, L. H.; ANSILIERO, G. A desoneração da contribuição patronal sobre a folha de pagamentos-uma solução à procura de problemas. Planejamento e Políticas Públicas, v. 1, n. 32, 2009. Citado na página 18.

SCHERER, C. Payroll tax reduction in brazil: Effects on employment and wages. ISS

Working Paper Series/General Series, ISS Working Papers-General Series, v. 602, n. 602, p. 1-64, 2015. Citado 3 vezes nas páginas 26, 49 e 61.

ULYSSEA, G. Informalidade no mercado de trabalho brasileiro. Texto para Discussão, IPEA, p. 12, 2005. Citado na página 17.

ULYSSEA, G.; REIS, M. C. Imposto sobre trabalho e seu impacto nos setores formal e informal. Instituto de Pesquisa Econômica Aplicada (Ipea), 2006. Citado 2 vezes nas páginas 25 e 26. 
Apêndices 



\section{APÊNDICE A - Regressões de Saída do SIM- PLES}

Tabela 22 - Estimação da Proporção de Firmas no SIMPLES

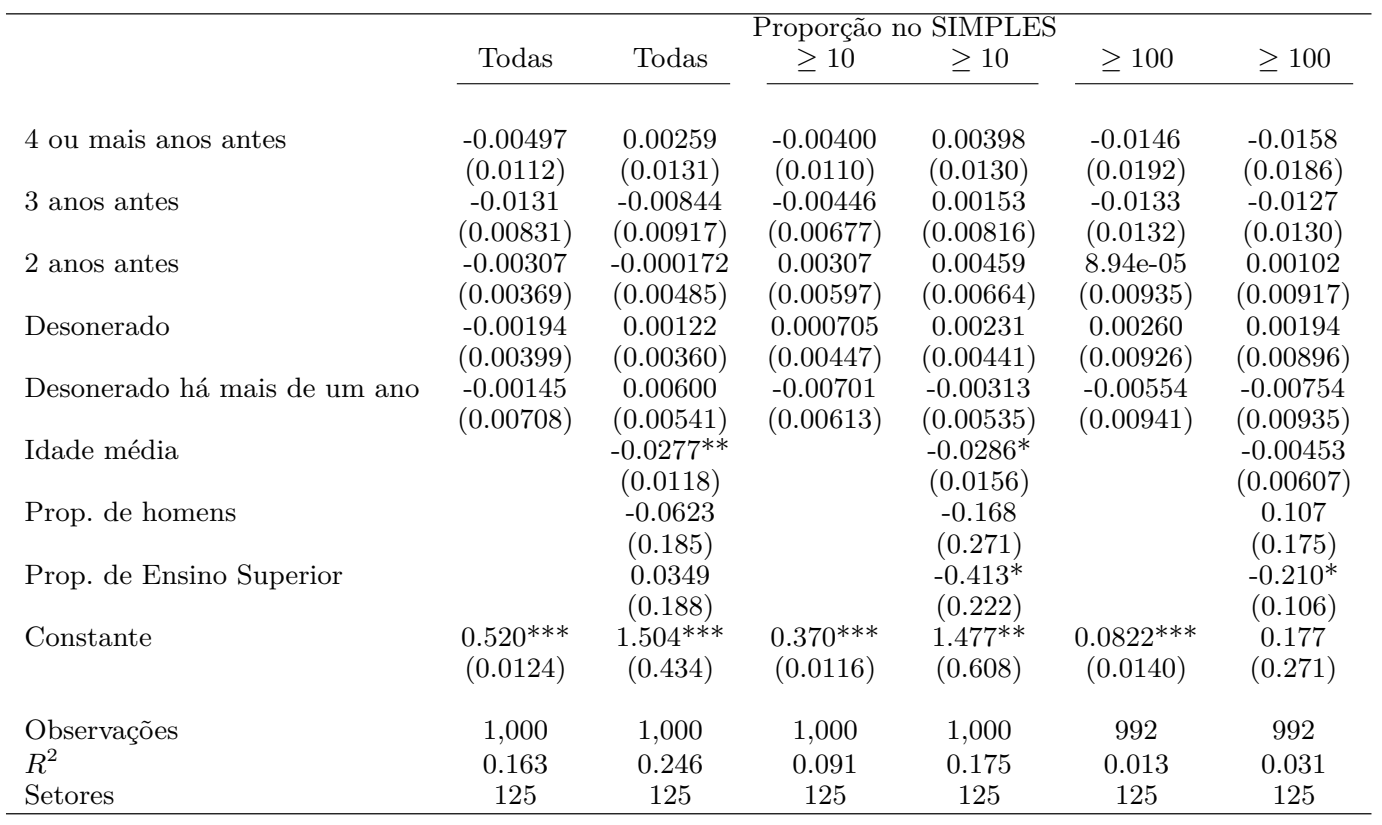

Nota: Erros Padrão Clusterizados nos Parênteses. *** $\mathrm{p}<0.01,{ }^{*} \mathrm{p}<0.05,{ }^{*} \mathrm{p}<0.1$. Coeficientes estimados na regressão de um Event Study do tamanho das firmas em função da desoneração. O período base é sempre o ano imediatamente anterior ao início da vigência do novo regime tributário. 
Tabela 23 - Estimação do Tamanho das Firmas

\begin{tabular}{|c|c|c|c|c|}
\hline \multirow{4}{*}{4 ou mais anos antes } & \multicolumn{2}{|c|}{ SIMPLES } & \multicolumn{2}{|c|}{ Fora do SIMPLES } \\
\hline & $\underline{\log \text { (Trabalhadores) }}$ & Log(Trabalhadores) & Log(Trabalhadores) & Log(Trabalhadores) \\
\hline & -0.0108 & -0.00463 & -0.0285 & -0.0282 \\
\hline & $(0.0347)$ & $(0.0355)$ & $(0.0337)$ & $(0.0323)$ \\
\hline \multirow[t]{2}{*}{3 anos antes } & 0.0133 & 0.0175 & -0.0261 & -0.0245 \\
\hline & $(0.0334)$ & $(0.0322)$ & $(0.0238)$ & $(0.0233)$ \\
\hline \multirow{2}{*}{2 anos antes } & 0.0108 & 0.0128 & -0.00335 & -0.00323 \\
\hline & $(0.0287)$ & $(0.0289)$ & $(0.0177)$ & $(0.0177)$ \\
\hline \multirow[t]{2}{*}{ Desonerado } & -0.0157 & -0.00452 & -0.00821 & -0.00942 \\
\hline & $(0.0262)$ & $(0.0245)$ & $(0.0173)$ & $(0.0172)$ \\
\hline \multirow[t]{2}{*}{ Desonerado há mais de um ano } & -0.0422 & -0.0373 & 0.00408 & 0.00418 \\
\hline & $(0.0390)$ & $(0.0367)$ & $(0.0303)$ & $(0.0294)$ \\
\hline \multirow{2}{*}{ Constante } & $1.894^{* * *}$ & $0.993^{*}$ & $3.250^{* * *}$ & $3.299^{* * *}$ \\
\hline & $(0.0251)$ & $(0.500)$ & $(0.0171)$ & $(0.420)$ \\
\hline Controles & Não & Sim & Não & Sim \\
\hline Efeito-fixo de ano & Sim & Sim & Sim & Sim \\
\hline Observações & 999 & 999 & 1,000 & 1,000 \\
\hline$R^{2}$ & 0.016 & 0.050 & 0.096 & 0.098 \\
\hline Setores & 125 & 125 & 125 & 125 \\
\hline
\end{tabular}




\section{APÊNDICE B - Regressões com Erros Clus- terizados}

Tabela 24 - Estimação do Nível de Emprego Total dos Desonerados pela CNAE

\begin{tabular}{|c|c|c|c|c|c|}
\hline \multirow{3}{*}{9 ou mais trimestres antes } & \multicolumn{5}{|c|}{$\begin{array}{l}\text { Variável Dependente: Log(Trabalhadores) } \\
\quad(2)\end{array}$} \\
\hline & Total & Mantidos - MP774 & Retirados - MP774 & Des. mais intensa & Des. menos intensa \\
\hline & $\begin{array}{l}-0.0149 \\
(0.0344)\end{array}$ & $\begin{array}{c}-0.00389 \\
(0.0500)\end{array}$ & $\begin{array}{l}-0.0250 \\
(0.0391)\end{array}$ & $\begin{array}{c}-0.0233 \\
(0.0656)\end{array}$ & $\begin{array}{l}-0.0100 \\
(0.0255)\end{array}$ \\
\hline 8 trimestres antes & -0.0184 & -0.0183 & -0.0221 & -0.0111 & -0.0233 \\
\hline 7 trimestres antes & $\begin{array}{l}-0.0171 \\
(0.0261)\end{array}$ & $\begin{array}{c}-0.0170 \\
(0.0358)\end{array}$ & $\begin{array}{l}-0.0207 \\
(0.0314)\end{array}$ & $\begin{array}{r}-0.00536 \\
(0.0489)\end{array}$ & $\begin{array}{c}-0.0245 \\
(0.0198)\end{array}$ \\
\hline 6 trimestres antes & $\begin{array}{r}-0.00675 \\
(0.0252)\end{array}$ & $\begin{array}{c}-0.00811 \\
(0.0325)\end{array}$ & $\begin{array}{c}-0.0102 \\
(0.0307)\end{array}$ & $\begin{array}{c}0.0123 \\
(0.0477)\end{array}$ & $\begin{array}{l}-0.0180 \\
(0.0184)\end{array}$ \\
\hline 5 trimestres antes & $\begin{array}{c}-0.00849 \\
(0.0221)\end{array}$ & $\begin{array}{c}-0.00666 \\
(0.0246)\end{array}$ & $\begin{array}{c}-0.0132 \\
(0.0282)\end{array}$ & $\begin{array}{c}0.0123 \\
(0.0426)\end{array}$ & $\begin{array}{c}-0.0203 \\
(0.0153)\end{array}$ \\
\hline 4 trimestres antes & $\begin{array}{l}-0.0125 \\
(0.0166)\end{array}$ & $\begin{array}{c}0.0151 \\
(0.0166)\end{array}$ & $\begin{array}{l}-0.0277 \\
(0.0196)\end{array}$ & $\begin{array}{l}0.00106 \\
(0.0324)\end{array}$ & $\begin{array}{l}-0.0195 \\
(0.0124)\end{array}$ \\
\hline 3 trimestres antes & $\begin{array}{c}-0.00768 \\
(0.0115)\end{array}$ & $\begin{array}{c}0.0125 \\
(0.0141)\end{array}$ & $\begin{array}{c}-0.0182 \\
(0.0135)\end{array}$ & $\begin{array}{c}-0.000577 \\
(0.0231)\end{array}$ & $\begin{array}{c}-0.0106 \\
(0.00919)\end{array}$ \\
\hline 2 trimestres antes & $\begin{array}{c}0.00673 \\
(0.00800)\end{array}$ & $\begin{array}{c}0.0104 \\
(0.0106)\end{array}$ & $\begin{array}{c}0.00480 \\
(0.00933)\end{array}$ & $\begin{array}{l}0.00312 \\
(0.0157)\end{array}$ & $\begin{array}{c}0.00984 \\
(0.00656)\end{array}$ \\
\hline Noventena & $\begin{array}{c}0.00420 \\
(0.00319)\end{array}$ & $\begin{array}{c}0.00384 \\
(0.00518)\end{array}$ & $\begin{array}{c}0.00463 \\
(0.00352)\end{array}$ & $\begin{array}{c}0.00371 \\
(0.00551)\end{array}$ & $\begin{array}{c}0.00486 \\
(0.00323)\end{array}$ \\
\hline 1 trimestre depois & $\begin{array}{c}0.00589 \\
(0.00819)\end{array}$ & $\begin{array}{l}-0.00195 \\
(0.00504)\end{array}$ & $\begin{array}{c}0.00927 \\
(0.0118)\end{array}$ & $\begin{array}{c}0.0188 \\
(0.0209)\end{array}$ & $\begin{array}{l}-0.00210 \\
(0.00336)\end{array}$ \\
\hline 2 trimestres depois & $\begin{array}{c}0.00818 \\
(0.00999)\end{array}$ & $\begin{array}{c}0.000187 \\
(0.0119)\end{array}$ & $\begin{array}{c}0.0117 \\
(0.0133)\end{array}$ & $\begin{array}{c}0.0191 \\
(0.0220)\end{array}$ & $\begin{array}{c}0.00155 \\
(0.00687)\end{array}$ \\
\hline 3 trimestres depois & $\begin{array}{c}0.0237^{* *} \\
(0.0109)\end{array}$ & $\begin{array}{c}0.0142 \\
(0.0158)\end{array}$ & $\begin{array}{c}0.0282^{* *} \\
(0.0133)\end{array}$ & $\begin{array}{c}0.0302 \\
(0.0218)\end{array}$ & $\begin{array}{l}0.0200^{*} \\
(0.0100)\end{array}$ \\
\hline 4 trimestres depois & $\begin{array}{c}0.0258^{*} \\
(0.0150)\end{array}$ & $\begin{array}{c}0.0141 \\
(0.0233)\end{array}$ & $\begin{array}{l}0.0323^{*} \\
(0.0162)\end{array}$ & $\begin{array}{c}0.0355 \\
(0.0243)\end{array}$ & $\begin{array}{c}0.0201 \\
(0.0147)\end{array}$ \\
\hline 5 trimestres depois & $\begin{array}{c}0.0420^{*} \\
(0.0246)\end{array}$ & $\begin{array}{c}0.0107 \\
(0.0370)\end{array}$ & $\begin{array}{c}0.0547^{* *} \\
(0.0266)\end{array}$ & $\begin{array}{c}0.0665^{* *} \\
(0.0325)\end{array}$ & $\begin{array}{c}0.0282 \\
(0.0256)\end{array}$ \\
\hline Clusters & 41 & & & & 11 \\
\hline Efeito Fixo Mensal & Sim & & & & $\mathrm{im}$ \\
\hline Efeito Fixo Setorial & Sim & & & & $\mathrm{im}$ \\
\hline Controles & Sim & & & & $\mathrm{im}$ \\
\hline Tendência Linear Setorial & Sim & & & & $\mathrm{im}$ \\
\hline Observações & 7488 & & 88 & & 188 \\
\hline$R^{2}$ & 0.900 & & 01 & & 901 \\
\hline Setores & 104 & & & & 04 \\
\hline
\end{tabular}

Nota: Erros Padrão Clusterizados nos Parênteses. ${ }^{* * *} \mathrm{p}<0.01,{ }^{* *} \mathrm{p}<0.05,{ }^{*} \mathrm{p}<0.1$ Coeficientes estimados na regressão de um Event Study do nível de emprego em função da desoneração. O período base é sempre o mês imediatamente anterior ao início da vigência do novo regime tributário. A variável "Noventena"refere-se ao período entre a promulgação da lei ou MP da desoneração e sua efetiva vigência. Os erros são clusterizados entre os setores dentro de um mesmo grupo (3 primeiros dígitos da CNAE), totalizando 41 grupos. 

Anexos 



\section{ANEXO A - Setores Comparáveis}

\section{A.1 Lista de Setores Comparáveis - 2 Dígitos da CNAE}

\begin{tabular}{|c|c|c|c|c|c|}
\hline \multirow{2}{*}{ Grupo } & \multirow{2}{*}{ CNAE } & \multicolumn{3}{|c|}{ Desoneração } & \multirow{2}{*}{ Descrição } \\
\hline & & Desonerado & CNAE & $\mathrm{NCM}$ & \\
\hline 1 & 1113 & 0 & 0 & 0 & Cultivo de cereais \\
\hline 1 & 1121 & 0 & 0 & 0 & $\begin{array}{l}\text { Cultivo de algodão herbáceo e de outras fibras de } \\
\text { lavoura temporária }\end{array}$ \\
\hline 1 & 1130 & 0 & 0 & 0 & Cultivo de canadeacucar \\
\hline 1 & 1148 & 0 & 0 & 0 & Cultivo de fumo \\
\hline 1 & 1156 & 0 & 0 & 0 & Cultivo de soja \\
\hline 1 & 1164 & 0 & 0 & 0 & $\begin{array}{l}\text { Cultivo de oleaginosas de lavoura temporaria, exceto } \\
\text { soja }\end{array}$ \\
\hline 1 & 1229 & 0 & 0 & 0 & Floricultura \\
\hline 1 & 1318 & 0 & 0 & 0 & Cultivo de laranja \\
\hline 1 & 1326 & 0 & 0 & 0 & Cultivo de uva \\
\hline 1 & 1334 & 0 & 0 & 0 & $\begin{array}{l}\text { Cultivo de frutas de lavoura permanente, exceto la- } \\
\text { ranja e uva }\end{array}$ \\
\hline 1 & 1342 & 0 & 0 & 0 & Cultivo de cafe \\
\hline 1 & 1351 & 0 & 0 & 0 & Cultivo de cacau \\
\hline 1 & 1393 & 0 & 0 & 0 & $\begin{array}{l}\text { Cultivo de plantas de lavoura permanente nao espe- } \\
\text { cificadas anteriormente }\end{array}$ \\
\hline 1 & 1415 & 0 & 0 & 0 & Producao de sementes certificadas \\
\hline 1 & 1423 & 0 & 0 & 0 & $\begin{array}{l}\text { Producao de mudas e outras formas de propagacao } \\
\text { vegetal, certificadas }\end{array}$ \\
\hline 1 & 1610 & 0 & 0 & 0 & Atividades de apoio a agricultura \\
\hline 1 & 1628 & 0 & 0 & 0 & Atividades de apoio a pecuaria \\
\hline 1 & 1636 & 0 & 0 & 0 & Atividades de poscolheita \\
\hline 1 & 1199 & 1 & 0 & 1 & $\begin{array}{l}\text { Cultivo de plantas de lavoura temporaria nao espe- } \\
\text { cificadas anteriormente }\end{array}$ \\
\hline 1 & 1211 & 1 & 0 & 1 & Horticultura \\
\hline 1 & 1512 & 1 & 0 & 1 & Criacao de bovinos \\
\hline 1 & 1521 & 1 & 0 & 1 & Criacao de outros animais de grande porte \\
\hline 1 & 1539 & 1 & 0 & 1 & Criacao de caprinos e ovinos \\
\hline 1 & 1547 & 1 & 0 & 1 & Criacao de suinos \\
\hline 1 & 1555 & 1 & 0 & 1 & Criacao de aves \\
\hline
\end{tabular}

Nota: Tabela de classes da CNAE onde existem tanto tratados quanto controles dentro de um mesmo grupo (2 dígitos). Para a desoneração, "NCM" e "CNAE" indicam o modo pelo qual o setor foi desonerado (pelo NCM de seus produtos ou por sua área de atividade), enquanto "Desonerado" indica desoneração, independente do modo. "1" indica que houve desoneração pelo critério definido, enquanto "0" indica que não houve tratamento 


\begin{tabular}{|c|c|c|c|c|c|}
\hline \multirow[t]{2}{*}{ Grupo } & \multirow[t]{2}{*}{ CNAE } & \multicolumn{3}{|c|}{ Desoneração } & \multirow[t]{2}{*}{ Descrição } \\
\hline & & Desonerado & CNAE & $\mathrm{NCM}$ & \\
\hline 1 & 1598 & 1 & 0 & 1 & Criacao de animais nao especificados anteriormente \\
\hline 2 & 2306 & 0 & 0 & 0 & Atividades de apoio a producao florestal \\
\hline 2 & 2101 & 1 & 0 & 1 & Producao florestal florestas plantadas \\
\hline 2 & 2209 & 1 & 0 & 1 & Producao florestal florestas nativas \\
\hline 8 & 8916 & 0 & 0 & 0 & $\begin{array}{l}\text { Extracao de minerais para fabricacao de adubos, fer- } \\
\text { tilizantes e outros produtos quimicos }\end{array}$ \\
\hline 8 & 8932 & 0 & 0 & 0 & $\begin{array}{l}\text { Extracao de gemas (pedras preciosas e semiprecio- } \\
\text { sas) }\end{array}$ \\
\hline 8 & 8991 & 0 & 0 & 0 & $\begin{array}{l}\text { Extracao de minerais naometalicos nao especificados } \\
\text { anteriormente }\end{array}$ \\
\hline 8 & 8100 & 1 & 0 & 1 & Extracao de pedra, areia e argila \\
\hline 8 & 8924 & 1 & 0 & 1 & Extracao e refino de sal marinho e salgema \\
\hline 10 & 10317 & 0 & 0 & 0 & Fabricacao de conservas de frutas \\
\hline 10 & 10325 & 0 & 0 & 0 & Fabricacao de conservas de legumes e outros vegetais \\
\hline 10 & 10414 & 0 & 0 & 0 & $\begin{array}{l}\text { Fabricacao de oleos vegetais em bruto, exceto oleo de } \\
\text { milho }\end{array}$ \\
\hline 10 & 10422 & 0 & 0 & 0 & $\begin{array}{l}\text { Fabricacao de oleos vegetais refinados, exceto oleo de } \\
\text { milho }\end{array}$ \\
\hline 10 & 10431 & 0 & 0 & 0 & $\begin{array}{l}\text { Fabricacao de margarina e outras gorduras vegetais } \\
\text { e de oleos nao comestiveis de animais }\end{array}$ \\
\hline 10 & 10511 & 0 & 0 & 0 & Preparacao do leite \\
\hline 10 & 10538 & 0 & 0 & 0 & Fabricacao de sorvetes e outros gelados comestiveis \\
\hline 10 & 10635 & 0 & 0 & 0 & Fabricacao de farinha de mandioca e derivados \\
\hline 10 & 10660 & 0 & 0 & 0 & Fabricacao de alimentos para animais \\
\hline 10 & 10716 & 0 & 0 & 0 & Fabricacao de acucar em bruto \\
\hline 10 & 10724 & 0 & 0 & 0 & Fabricacao de acucar refinado \\
\hline 10 & 10813 & 0 & 0 & 0 & Torrefacao e moagem de cafe \\
\hline 10 & 10821 & 0 & 0 & 0 & Fabricacao de produtos a base de cafe \\
\hline 10 & 10937 & 0 & 0 & 0 & $\begin{array}{l}\text { Fabricacao de produtos derivados do cacau, de cho- } \\
\text { colates e confeitos }\end{array}$ \\
\hline 10 & 10953 & 0 & 0 & 0 & $\begin{array}{l}\text { Fabricacao de especiarias, molhos, temperos e condi- } \\
\text { mentos }\end{array}$ \\
\hline 10 & 10112 & 1 & 0 & 1 & Abate de reses, exceto suinos \\
\hline 10 & 10121 & 1 & 0 & 1 & Abate de suinos, aves e outros pequenos animais \\
\hline 10 & 10139 & 1 & 0 & 1 & Fabricacao de produtos de carne \\
\hline 10 & 10201 & 1 & 0 & 1 & $\begin{array}{l}\text { Preservacao do pescado e fabricacao de produtos do } \\
\text { pescado }\end{array}$ \\
\hline 10 & 10333 & 1 & 0 & 1 & Fabricacao de sucos de frutas, hortalicas e legumes \\
\hline 10 & 10520 & 1 & 0 & 1 & Fabricacao de laticinios \\
\hline 10 & 10619 & 1 & 0 & 1 & $\begin{array}{l}\text { Beneficiamento de arroz e fabricacao de produtos do } \\
\text { arroz }\end{array}$ \\
\hline
\end{tabular}

Nota: Tabela de classes da CNAE onde existem tanto tratados quanto controles dentro de um mesmo grupo (2 dígitos). Para a desoneração, "NCM" e "CNAE" indicam o modo pelo qual o setor foi desonerado (pelo NCM de seus produtos ou por sua área de atividade), enquanto "Desonerado" indica desoneração, independente do modo. "1" indica que houve desoneração pelo critério definido, enquanto "0" indica que não houve tratamento 


\begin{tabular}{|c|c|c|c|c|c|}
\hline \multirow[t]{2}{*}{ Grupo } & \multirow[t]{2}{*}{ CNAE } & \multicolumn{3}{|c|}{ Desoneração } & \multirow[t]{2}{*}{ Descrição } \\
\hline & & Desonerado & CNAE & NCM & \\
\hline 10 & 10627 & 1 & 0 & 1 & Moagem de trigo e fabricacao de derivados \\
\hline 10 & 10643 & 1 & 0 & 1 & $\begin{array}{l}\text { Fabricacao de farinha de milho e derivados, exceto } \\
\text { oleos de milho }\end{array}$ \\
\hline 10 & 10651 & 1 & 0 & 1 & $\begin{array}{l}\text { Fabricacao de amidos e feculas de vegetais e de oleos } \\
\text { de milho }\end{array}$ \\
\hline 10 & 10694 & 1 & 0 & 1 & $\begin{array}{l}\text { Moagem e fabricacao de produtos de origem vegetal } \\
\text { nao especificados anteriormente }\end{array}$ \\
\hline 10 & 10911 & 1 & 0 & 1 & Fabricacao de produtos de panificacao \\
\hline 10 & 10929 & 1 & 0 & 1 & Fabricacao de biscoitos e bolachas \\
\hline 10 & 10945 & 1 & 0 & 1 & Fabricacao de massas alimenticias \\
\hline 10 & 10961 & 1 & 0 & 1 & Fabricacao de alimentos e pratos prontos \\
\hline 10 & 10996 & 1 & 0 & 1 & $\begin{array}{l}\text { Fabricacao de produtos alimenticios nao especifica- } \\
\text { dos anteriormente }\end{array}$ \\
\hline 11 & 11119 & 0 & 0 & 0 & $\begin{array}{l}\text { Fabricacao de aguardentes e outras bebidas destila- } \\
\text { das }\end{array}$ \\
\hline 11 & 11127 & 0 & 0 & 0 & Fabricacao de vinho \\
\hline 11 & 11135 & 0 & 0 & 0 & Fabricacao de malte, cervejas e chopes \\
\hline 11 & 11216 & 0 & 0 & 0 & Fabricacao de aguas envasadas \\
\hline 11 & 11224 & 1 & 0 & 1 & $\begin{array}{l}\text { Fabricacao de refrigerantes e de outras bebidas nao- } \\
\text { alcoolicas }\end{array}$ \\
\hline 12 & 12107 & 0 & 0 & 0 & Processamento industrial do fumo \\
\hline 12 & 12204 & 1 & 0 & 1 & Fabricacao de produtos do fumo \\
\hline 13 & 13405 & 0 & 0 & 0 & Acabamentos em fios, tecidos e artefatos texteis \\
\hline 13 & 13111 & 1 & 0 & 1 & Preparacao e fiacao de fibras de algodao \\
\hline 13 & 13120 & 1 & 0 & 1 & $\begin{array}{l}\text { Preparacao e fiacao de fibras texteis naturais, exceto } \\
\text { algodao }\end{array}$ \\
\hline 13 & 13138 & 1 & 0 & 1 & Fiacao de fibras artificiais e sinteticas \\
\hline 13 & 13146 & 1 & 0 & 1 & Fabricacao de linhas para costurar e bordar \\
\hline 13 & 13219 & 1 & 0 & 1 & Tecelagem de fios de algodao \\
\hline 13 & 13227 & 1 & 0 & 1 & $\begin{array}{l}\text { Tecelagem de fios de fibras texteis naturais, exceto } \\
\text { algodao }\end{array}$ \\
\hline 13 & 13235 & 1 & 0 & 1 & Tecelagem de fios de fibras artificiais e sinteticas \\
\hline 13 & 13308 & 1 & 0 & 1 & Fabricacao de tecidos de malha \\
\hline 13 & 13511 & 1 & 0 & 1 & Fabricacao de artefatos texteis para uso domestico \\
\hline 13 & 13529 & 1 & 0 & 1 & Fabricacao de artefatos de tapecaria \\
\hline 13 & 13537 & 1 & 0 & 1 & Fabricacao de artefatos de cordoaria \\
\hline 13 & 13545 & 1 & 0 & 1 & Fabricacao de tecidos especiais, inclusive artefatos \\
\hline 13 & 13596 & 1 & 0 & 1 & $\begin{array}{l}\text { Fabricacao de outros produtos texteis nao especifica- } \\
\text { dos anteriormente }\end{array}$ \\
\hline 16 & 16102 & 0 & 0 & 0 & Desdobramento de madeira \\
\hline
\end{tabular}

Nota: Tabela de classes da CNAE onde existem tanto tratados quanto controles dentro de um mesmo grupo (2 dígitos). Para a desoneração, "NCM" e "CNAE" indicam o modo pelo qual o setor foi desonerado (pelo NCM de seus produtos ou por sua área de atividade), enquanto "Desonerado" indica desoneração, independente do modo. "1" indica que houve desoneração pelo critério definido, enquanto "0" indica que não houve tratamento 


\begin{tabular}{|c|c|c|c|c|c|}
\hline \multirow[t]{2}{*}{ Grupo } & \multirow[t]{2}{*}{ CNAE } & \multicolumn{3}{|c|}{ Desoneração } & \multirow[t]{2}{*}{ Descrição } \\
\hline & & Desonerado & CNAE & $\mathrm{NCM}$ & \\
\hline 16 & 16218 & 0 & 0 & 0 & $\begin{array}{l}\text { Fabricacao de madeira laminada e de chapas de ma- } \\
\text { deira compensada, prensada e aglomerada }\end{array}$ \\
\hline 16 & 16226 & 1 & 0 & 1 & $\begin{array}{l}\text { Fabricacao de estruturas de madeira e de artigos de } \\
\text { carpintaria para construcao }\end{array}$ \\
\hline 16 & 16234 & 1 & 0 & 1 & $\begin{array}{l}\text { Fabricacao de artefatos de tanoaria e de embalagens } \\
\text { de madeira }\end{array}$ \\
\hline 16 & 16293 & 1 & 0 & 1 & $\begin{array}{l}\text { Fabricacao de artefatos de madeira, palha, cortica, } \\
\text { vime e material trancado nao especificados anterior- } \\
\text { mente, exceto moveis }\end{array}$ \\
\hline 18 & 18121 & 0 & 0 & 0 & Impressao de material de seguranca \\
\hline 18 & 18130 & 0 & 0 & 0 & Impressao de materiais para outros usos \\
\hline 18 & 18229 & 0 & 0 & 0 & Servicos de acabamentos graficos \\
\hline 18 & 18300 & 0 & 0 & 0 & $\begin{array}{l}\text { Reproducao de materiais gravados em qualquer su- } \\
\text { porte }\end{array}$ \\
\hline 18 & 18211 & 1 & 0 & 1 & Servicos de preimpressao \\
\hline 18 & 18113 & 1 & 1 & 0 & $\begin{array}{l}\text { Impressao de jornais, livros, revistas e outras publi- } \\
\text { cacoes periodicas }\end{array}$ \\
\hline 20 & 20118 & 0 & 0 & 0 & Fabricacao de cloro e alcalis \\
\hline 20 & 20126 & 0 & 0 & 0 & Fabricacao de intermediarios para fertilizantes \\
\hline 20 & 20134 & 0 & 0 & 0 & Fabricacao de adubos e fertilizantes \\
\hline 20 & 20142 & 0 & 0 & 0 & Fabricacao de gases industriais \\
\hline 20 & 20193 & 0 & 0 & 0 & $\begin{array}{l}\text { Fabricacao de produtos quimicos inorganicos nao es- } \\
\text { pecificados anteriormente }\end{array}$ \\
\hline 20 & 20215 & 0 & 0 & 0 & Fabricacao de produtos petroquimicos basicos \\
\hline 20 & 20223 & 0 & 0 & 0 & $\begin{array}{l}\text { Fabricacao de intermediarios para plastificantes, re- } \\
\text { sinas e fibras }\end{array}$ \\
\hline 20 & 20312 & 0 & 0 & 0 & Fabricacao de resinas termoplasticas \\
\hline 20 & 20321 & 0 & 0 & 0 & Fabricacao de resinas termofixas \\
\hline 20 & 20339 & 0 & 0 & 0 & Fabricacao de elastomeros \\
\hline 20 & 20720 & 0 & 0 & 0 & Fabricacao de tintas de impressao \\
\hline 20 & 20916 & 0 & 0 & 0 & Fabricacao de adesivos e selantes \\
\hline 20 & 20924 & 0 & 0 & 0 & Fabricacao de explosivos \\
\hline 20 & 20932 & 0 & 0 & 0 & Fabricacao de aditivos de uso industrial \\
\hline 20 & 20291 & 1 & 0 & 1 & $\begin{array}{l}\text { Fabricacao de produtos quimicos organicos nao es- } \\
\text { pecificados anteriormente }\end{array}$ \\
\hline 20 & 20401 & 1 & 0 & 1 & Fabricacao de fibras artificiais e sinteticas \\
\hline 20 & 20517 & 1 & 0 & 1 & Fabricacao de defensivos agricolas \\
\hline 20 & 20525 & 1 & 0 & 1 & Fabricacao de desinfestantes domissanitarios \\
\hline 20 & 20614 & 1 & 0 & 1 & Fabricacao de saboes e detergentes sinteticos \\
\hline 20 & 20622 & 1 & 0 & 1 & Fabricacao de produtos de limpeza e polimento \\
\hline
\end{tabular}

Nota: Tabela de classes da CNAE onde existem tanto tratados quanto controles dentro de um mesmo grupo (2 dígitos). Para a desoneração, "NCM" e "CNAE" indicam o modo pelo qual o setor foi desonerado (pelo NCM de seus produtos ou por sua área de atividade), enquanto "Desonerado" indica desoneração, independente do modo. "1" indica que houve desoneração pelo critério definido, enquanto "0" indica que não houve tratamento 


\begin{tabular}{|c|c|c|c|c|c|}
\hline \multirow[t]{2}{*}{ Grupo } & \multirow[t]{2}{*}{ CNAE } & \multicolumn{3}{|c|}{ Desoneração } & \multirow[t]{2}{*}{ Descrição } \\
\hline & & Desonerado & CNAE & $\mathrm{NCM}$ & \\
\hline 20 & 20631 & 1 & 0 & 1 & $\begin{array}{l}\text { Fabricacao de cosmeticos, produtos de perfumaria e } \\
\text { de higiene pessoal }\end{array}$ \\
\hline 20 & 20711 & 1 & 0 & 1 & Fabricacao de tintas, vernizes, esmaltes e lacas \\
\hline 20 & 20738 & 1 & 0 & 1 & $\begin{array}{l}\text { Fabricacao de impermeabilizantes, solventes e pro- } \\
\text { dutos afins }\end{array}$ \\
\hline 20 & 20941 & 1 & 0 & 1 & Fabricacao de catalisadores \\
\hline 20 & 20991 & 1 & 0 & 1 & $\begin{array}{l}\text { Fabricacao de produtos quimicos nao especificados } \\
\text { anteriormente }\end{array}$ \\
\hline 22 & 22129 & 0 & 0 & 0 & Reforma de pneumaticos usados \\
\hline 22 & 22111 & 1 & 0 & 1 & Fabricacao de pneumaticos e de camarasdear \\
\hline 22 & 22196 & 1 & 0 & 1 & $\begin{array}{l}\text { Fabricacao de artefatos de borracha nao especifica- } \\
\text { dos anteriormente }\end{array}$ \\
\hline 22 & 22218 & 1 & 0 & 1 & $\begin{array}{l}\text { Fabricacao de laminados planos e tubulares de ma- } \\
\text { terial plastico }\end{array}$ \\
\hline 22 & 22226 & 1 & 0 & 1 & Fabricacao de embalagens de material plastico \\
\hline 22 & 22234 & 1 & 0 & 1 & $\begin{array}{l}\text { Fabricacao de tubos e acessorios de material plastico } \\
\text { para uso na construcao }\end{array}$ \\
\hline 22 & 22293 & 1 & 0 & 1 & $\begin{array}{l}\text { Fabricacao de artefatos de material plastico nao es- } \\
\text { pecificados anteriormente }\end{array}$ \\
\hline 23 & 23206 & 0 & 0 & 0 & Fabricacao de cimento \\
\hline 23 & 23117 & 1 & 0 & 1 & Fabricacao de vidro plano e de seguranca \\
\hline 23 & 23125 & 1 & 0 & 1 & Fabricacao de embalagens de vidro \\
\hline 23 & 23192 & 1 & 0 & 1 & Fabricacao de artigos de vidro \\
\hline 23 & 23303 & 1 & 0 & 1 & $\begin{array}{l}\text { Fabricacao de artefatos de concreto, cimento, fibro- } \\
\text { cimento, gesso e materiais semelhantes }\end{array}$ \\
\hline 23 & 23419 & 1 & 0 & 1 & Fabricacao de produtos ceramicos refratarios \\
\hline 23 & 23427 & 1 & 0 & 1 & $\begin{array}{l}\text { Fabricacao de produtos ceramicos naorefratarios } \\
\text { para uso estrutural na construcao }\end{array}$ \\
\hline 23 & 23494 & 1 & 0 & 1 & $\begin{array}{l}\text { Fabricacao de produtos ceramicos naorefratarios nao } \\
\text { especificados anteriormente }\end{array}$ \\
\hline 23 & 23915 & 1 & 0 & 1 & Aparelhamento e outros trabalhos em pedras \\
\hline 23 & 23923 & 1 & 0 & 1 & Fabricacao de cal e gesso \\
\hline 23 & 23991 & 1 & 0 & 1 & $\begin{array}{l}\text { Fabricacao de produtos de minerais naometalicos nao } \\
\text { especificados anteriormente }\end{array}$ \\
\hline 24 & 24121 & 0 & 0 & 0 & Producao de ferroligas \\
\hline 24 & 24415 & 0 & 0 & 0 & Metalurgia do aluminio e suas ligas \\
\hline 24 & 24423 & 0 & 0 & 0 & Metalurgia dos metais preciosos \\
\hline 24 & 24521 & 0 & 0 & 0 & Fundicao de metais naoferrosos e suas ligas \\
\hline 24 & 24113 & 1 & 0 & 1 & Producao de ferrogusa \\
\hline 24 & 24211 & 1 & 0 & 1 & Producao de semiacabados de aco \\
\hline 24 & 24229 & 1 & 0 & 1 & Producao de laminados planos de aco \\
\hline
\end{tabular}

Nota: Tabela de classes da CNAE onde existem tanto tratados quanto controles dentro de um mesmo grupo (2 dígitos). Para a desoneração, "NCM" e "CNAE" indicam o modo pelo qual o setor foi desonerado (pelo NCM de seus produtos ou por sua área de atividade), enquanto "Desonerado" indica desoneração, independente do modo. "1" indica que houve desoneração pelo critério definido, enquanto "0" indica que não houve tratamento 


\begin{tabular}{|c|c|c|c|c|c|}
\hline \multirow[t]{2}{*}{ Grupo } & \multirow[t]{2}{*}{ CNAE } & \multicolumn{3}{|c|}{ Desoneração } & \multirow[t]{2}{*}{ Descrição } \\
\hline & & Desonerado & CNAE & $\mathrm{NCM}$ & \\
\hline 24 & 24237 & 1 & 0 & 1 & Producao de laminados longos de aco \\
\hline 24 & 24245 & 1 & 0 & 1 & $\begin{array}{l}\text { Producao de relaminados, trefilados e perfilados de } \\
\text { aco }\end{array}$ \\
\hline 24 & 24318 & 1 & 0 & 1 & Producao de tubos de aco com costura \\
\hline 24 & 24393 & 1 & 0 & 1 & Producao de outros tubos de ferro e aco \\
\hline 24 & 24431 & 1 & 0 & 1 & Metalurgia do cobre \\
\hline 24 & 24491 & 1 & 0 & 1 & $\begin{array}{l}\text { Metalurgia dos metais naoferrosos e suas ligas nao } \\
\text { especificados anteriormente }\end{array}$ \\
\hline 24 & 24512 & 1 & 0 & 1 & Fundicao de ferro e aco \\
\hline 25 & 25390 & 0 & 0 & 0 & $\begin{array}{l}\text { Servicos de usinagem, solda, tratamento e revesti- } \\
\text { mento em metais }\end{array}$ \\
\hline 25 & 25110 & 1 & 0 & 1 & Fabricacao de estruturas metalicas \\
\hline 25 & 25128 & 1 & 0 & 1 & Fabricacao de esquadrias de metal \\
\hline 25 & 25136 & 1 & 0 & 1 & Fabricacao de obras de caldeiraria pesada \\
\hline 25 & 25217 & 1 & 0 & 1 & $\begin{array}{l}\text { Fabricacao de tanques, reservatorios metalicos e cal- } \\
\text { deiras para aquecimento central }\end{array}$ \\
\hline 25 & 25225 & 1 & 0 & 1 & $\begin{array}{l}\text { Fabricacao de caldeiras geradoras de vapor, exceto } \\
\text { para aquecimento central e para veiculos }\end{array}$ \\
\hline 25 & 25314 & 1 & 0 & 1 & $\begin{array}{l}\text { Producao de forjados de aco e de metais naoferrosos } \\
\text { e suas ligas }\end{array}$ \\
\hline 25 & 25322 & 1 & 0 & 1 & $\begin{array}{l}\text { Producao de artefatos estampados de metal e meta- } \\
\text { lurgia do po }\end{array}$ \\
\hline 25 & 25411 & 1 & 0 & 1 & Fabricacao de artigos de cutelaria \\
\hline 25 & 25420 & 1 & 0 & 1 & $\begin{array}{l}\text { Fabricacao de artigos de serralheria, exceto esqua- } \\
\text { drias }\end{array}$ \\
\hline 25 & 25438 & 1 & 0 & 1 & Fabricacao de ferramentas \\
\hline 25 & 25501 & 1 & 0 & 1 & $\begin{array}{l}\text { Fabricacao de equipamento belico pesado, armas de } \\
\text { fogo e municoes }\end{array}$ \\
\hline 25 & 25918 & 1 & 0 & 1 & Fabricacao de embalagens metalicas \\
\hline 25 & 25926 & 1 & 0 & 1 & Fabricacao de produtos de trefilados de metal \\
\hline 25 & 25934 & 1 & 0 & 1 & $\begin{array}{l}\text { Fabricacao de artigos de metal para uso domestico e } \\
\text { pessoal }\end{array}$ \\
\hline 25 & 25993 & 1 & 0 & 1 & $\begin{array}{l}\text { Fabricacao de produtos de metal nao especificados } \\
\text { anteriormente }\end{array}$ \\
\hline 29 & 29506 & 0 & 0 & 0 & $\begin{array}{l}\text { Recondicionamento e recuperacao de motores para } \\
\text { veiculos automotores }\end{array}$ \\
\hline 29 & 29107 & 1 & 0 & 1 & Fabricacao de automoveis, camionetas e utilitarios \\
\hline 29 & 29204 & 1 & 0 & 1 & Fabricacao de caminhoes e onibus \\
\hline 29 & 29301 & 1 & 0 & 1 & $\begin{array}{l}\text { Fabricacao de cabines, carrocerias e reboques para } \\
\text { veiculos automotores }\end{array}$ \\
\hline
\end{tabular}

Nota: Tabela de classes da CNAE onde existem tanto tratados quanto controles dentro de um mesmo grupo (2 dígitos). Para a desoneração, "NCM" e "CNAE" indicam o modo pelo qual o setor foi desonerado (pelo NCM de seus produtos ou por sua área de atividade), enquanto "Desonerado" indica desoneração, independente do modo. "1" indica que houve desoneração pelo critério definido, enquanto "0" indica que não houve tratamento 


\begin{tabular}{|c|c|c|c|c|c|}
\hline \multirow[t]{2}{*}{ Grupo } & \multirow[t]{2}{*}{ CNAE } & \multicolumn{3}{|c|}{ Desoneração } & \multirow[t]{2}{*}{ Descrição } \\
\hline & & Desonerado & CNAE & $\mathrm{NCM}$ & \\
\hline 29 & 29417 & 1 & 0 & 1 & $\begin{array}{l}\text { Fabricacao de pecas e acessorios para o sistema mo- } \\
\text { tor de veiculos automotores }\end{array}$ \\
\hline 29 & 29425 & 1 & 0 & 1 & $\begin{array}{l}\text { Fabricacao de pecas e acessorios para os sistemas de } \\
\text { marcha e transmissao de veiculos automotores }\end{array}$ \\
\hline 29 & 29433 & 1 & 0 & 1 & $\begin{array}{l}\text { Fabricacao de pecas e acessorios para o sistema de } \\
\text { freios de veiculos automotores }\end{array}$ \\
\hline 29 & 29441 & 1 & 0 & 1 & $\begin{array}{l}\text { Fabricacao de pecas e acessorios para o sistema de } \\
\text { direcao e suspensao de veiculos automotores }\end{array}$ \\
\hline 29 & 29450 & 1 & 0 & 1 & $\begin{array}{l}\text { Fabricacao de material eletrico e eletronico para vei- } \\
\text { culos automotores, exceto baterias }\end{array}$ \\
\hline 29 & 29492 & 1 & 0 & 1 & $\begin{array}{l}\text { Fabricacao de pecas e acessorios para veiculos auto- } \\
\text { motores nao especificados anteriormente }\end{array}$ \\
\hline 32 & 32116 & 0 & 0 & 0 & $\begin{array}{l}\text { Lapidacao de gemas e fabricacao de artefatos de ou- } \\
\text { rivesaria e joalheria }\end{array}$ \\
\hline 32 & 32124 & 0 & 0 & 0 & Fabricacao de bijuterias e artefatos semelhantes \\
\hline 32 & 32205 & 0 & 0 & 0 & Fabricacao de instrumentos musicais \\
\hline 32 & 32302 & 1 & 0 & 1 & Fabricacao de artefatos para pesca e esporte \\
\hline 32 & 32400 & 1 & 0 & 1 & Fabricacao de brinquedos e jogos recreativos \\
\hline 32 & 32507 & 1 & 0 & 1 & $\begin{array}{l}\text { Fabricacao de instrumentos e materiais para uso me- } \\
\text { dico e odontologico e de artigos opticos }\end{array}$ \\
\hline 32 & 32914 & 1 & 0 & 1 & Fabricacao de escovas, pinceis e vassouras \\
\hline 32 & 32922 & 1 & 0 & 1 & $\begin{array}{l}\text { Fabricacao de equipamentos e acessorios para segu- } \\
\text { ranca e protecao pessoal e profissional }\end{array}$ \\
\hline 32 & 32990 & 1 & 0 & 1 & $\begin{array}{l}\text { Fabricacao de produtos diversos nao especificados } \\
\text { anteriormente }\end{array}$ \\
\hline 33 & 33112 & 0 & 0 & 0 & $\begin{array}{l}\text { Manutencao e reparacao de tanques, reservatorios } \\
\text { metalicos e caldeiras, exceto para veiculos }\end{array}$ \\
\hline 33 & 33139 & 0 & 0 & 0 & $\begin{array}{l}\text { Manutencao e reparacao de maquinas e equipamen- } \\
\text { tos eletricos }\end{array}$ \\
\hline 33 & 33147 & 0 & 0 & 0 & $\begin{array}{l}\text { Manutencao e reparacao de maquinas e equipamen- } \\
\text { tos da industria mecanica }\end{array}$ \\
\hline 33 & 33155 & 0 & 0 & 0 & Manutencao e reparacao de veiculos ferroviarios \\
\hline 33 & 33198 & 0 & 0 & 0 & $\begin{array}{l}\text { Manutencao e reparacao de equipamentos e produtos } \\
\text { nao especificados anteriormente }\end{array}$ \\
\hline 33 & 33210 & 0 & 0 & 0 & Instalacao de maquinas e equipamentos industriais \\
\hline 33 & 33295 & 0 & 0 & 0 & $\begin{array}{l}\text { Instalacao de equipamentos nao especificados anteri- } \\
\text { ormente }\end{array}$ \\
\hline 33 & 33121 & 1 & 1 & 0 & $\begin{array}{l}\text { Manutencao e reparacao de equipamentos eletronicos } \\
\text { e opticos }\end{array}$ \\
\hline 33 & 33163 & 1 & 1 & 0 & Manutencao e reparacao de aeronaves \\
\hline 33 & 33171 & 1 & 1 & 0 & Manutencao e Reparacao de Embarcacoes \\
\hline
\end{tabular}

Nota: Tabela de classes da CNAE onde existem tanto tratados quanto controles dentro de um mesmo grupo (2 dígitos). Para a desoneração, "NCM" e "CNAE" indicam o modo pelo qual o setor foi desonerado (pelo NCM de seus produtos ou por sua área de atividade), enquanto "Desonerado" indica desoneração, independente do modo. "1" indica que houve desoneração pelo critério definido, enquanto "0" indica que não houve tratamento 


\begin{tabular}{|c|c|c|c|c|c|}
\hline \multirow[t]{2}{*}{ Grupo } & \multirow[t]{2}{*}{ CNAE } & \multicolumn{3}{|c|}{ Desoneração } & \multirow[t]{2}{*}{ Descrição } \\
\hline & & Desonerado & CNAE & $\mathrm{NCM}$ & \\
\hline 38 & 38114 & 0 & 0 & 0 & Coleta de residuos naoperigosos \\
\hline 38 & 38122 & 0 & 0 & 0 & Coleta de residuos perigosos \\
\hline 38 & 38211 & 0 & 0 & 0 & Tratamento e disposicao de residuos naoperigosos \\
\hline 38 & 38220 & 0 & 0 & 0 & Tratamento e disposicao de residuos perigosos \\
\hline 38 & 38327 & 0 & 0 & 0 & Recuperacao de materiais plasticos \\
\hline 38 & 38394 & 0 & 0 & 0 & $\begin{array}{l}\text { Recuperacao de materiais nao especificados anterior- } \\
\text { mente }\end{array}$ \\
\hline 38 & 38319 & 1 & 0 & 1 & Recuperacao de materiais metalicos \\
\hline 41 & 41107 & 0 & 0 & 0 & Incorporacao de empreendimentos imobiliarios \\
\hline 41 & 41204 & 1 & 1 & 0 & Construcao de edificios \\
\hline 47 & 47113 & 0 & 0 & 0 & $\begin{array}{l}\text { Comercio varejista de mercadorias em geral, com pre- } \\
\text { dominancia de produtos alimenticios hipermercados } \\
\text { e supermercados }\end{array}$ \\
\hline 47 & 47121 & 0 & 0 & 0 & $\begin{array}{l}\text { Comercio varejista de mercadorias em geral, com pre- } \\
\text { dominancia de produtos alimenticios minimercados, } \\
\text { mercearias e armazens }\end{array}$ \\
\hline 47 & 47211 & 0 & 0 & 0 & $\begin{array}{l}\text { Comercio varejista de produtos de padaria, laticinio, } \\
\text { doces, balas e semelhantes }\end{array}$ \\
\hline 47 & 47229 & 0 & 0 & 0 & $\begin{array}{l}\text { Comercio varejista de carnes e pescados acougues e } \\
\text { peixarias }\end{array}$ \\
\hline 47 & 47237 & 0 & 0 & 0 & Comercio varejista de bebidas \\
\hline 47 & 47245 & 0 & 0 & 0 & Comercio varejista de hortifrutigranjeiros \\
\hline 47 & 47296 & 0 & 0 & 0 & $\begin{array}{l}\text { Comercio varejista de produtos alimenticios em geral } \\
\text { ou especializado em produtos alimenticios nao espe- } \\
\text { cificados anteriormente e produtos do fumo }\end{array}$ \\
\hline 47 & 47318 & 0 & 0 & 0 & $\begin{array}{l}\text { Comercio varejista de combustiveis para veiculos au- } \\
\text { tomotores }\end{array}$ \\
\hline 47 & 47326 & 0 & 0 & 0 & Comercio varejista de lubrificantes \\
\hline 47 & 47415 & 0 & 0 & 0 & Comercio varejista de tintas e materiais para pintura \\
\hline 47 & 47423 & 0 & 0 & 0 & Comercio varejista de material eletrico \\
\hline 47 & 47431 & 0 & 0 & 0 & Comercio varejista de vidros \\
\hline 47 & 47563 & 0 & 0 & 0 & $\begin{array}{l}\text { Comercio varejista especializado de instrumentos } \\
\text { musicais e acessorios }\end{array}$ \\
\hline 47 & 47571 & 0 & 0 & 0 & $\begin{array}{l}\text { Comercio varejista especializado de pecas e acesso- } \\
\text { rios para aparelhos eletroeletronicos para uso domes- } \\
\text { tico, exceto informatica e comunicacao }\end{array}$ \\
\hline 47 & 47717 & 0 & 0 & 0 & $\begin{array}{l}\text { Comercio varejista de produtos farmaceuticos para } \\
\text { uso humano e veterinario }\end{array}$ \\
\hline 47 & 47733 & 0 & 0 & 0 & Comercio varejista de artigos medicos e ortopedicos \\
\hline 47 & 47741 & 0 & 0 & 0 & Comercio varejista de artigos de optica \\
\hline 47 & 47831 & 0 & 0 & 0 & Comercio varejista de joias e relogios \\
\hline
\end{tabular}

Nota: Tabela de classes da CNAE onde existem tanto tratados quanto controles dentro de um mesmo grupo (2 dígitos). Para a desoneração, "NCM" e "CNAE" indicam o modo pelo qual o setor foi desonerado (pelo NCM de seus produtos ou por sua área de atividade), enquanto "Desonerado" indica desoneração, independente do modo. "1" indica que houve desoneração pelo critério definido, enquanto "0" indica que não houve tratamento 


\begin{tabular}{|c|c|c|c|c|c|}
\hline \multirow[t]{2}{*}{ Grupo } & \multirow[t]{2}{*}{ CNAE } & \multicolumn{3}{|c|}{ Desoneração } & \multirow[t]{2}{*}{ Descrição } \\
\hline & & Desonerado & CNAE & $\mathrm{NCM}$ & \\
\hline 47 & 47849 & 0 & 0 & 0 & $\begin{array}{l}\text { Comercio varejista de gas liqüefeito de petroleo } \\
\text { (GLP) }\end{array}$ \\
\hline 47 & 47857 & 0 & 0 & 0 & Comercio varejista de artigos usados \\
\hline 47 & 47130 & 1 & 1 & 0 & $\begin{array}{l}\text { Comercio varejista de mercadorias em geral, sem pre- } \\
\text { dominancia de produtos alimenticios }\end{array}$ \\
\hline 47 & 47440 & 1 & 1 & 0 & $\begin{array}{l}\text { Comercio varejista de ferragens, madeira e materiais } \\
\text { de construcao }\end{array}$ \\
\hline 47 & 47512 & 1 & 1 & 0 & $\begin{array}{l}\text { Comercio varejista especializado de equipamentos e } \\
\text { suprimentos de informatica }\end{array}$ \\
\hline 47 & 47521 & 1 & 1 & 0 & $\begin{array}{l}\text { Comercio varejista especializado de equipamentos de } \\
\text { telefonia e comunicacao }\end{array}$ \\
\hline 47 & 47539 & 1 & 1 & 0 & $\begin{array}{l}\text { Comercio varejista especializado de eletrodomesticos } \\
\text { e equipamentos de audio e video }\end{array}$ \\
\hline 47 & 47547 & 1 & 1 & 0 & $\begin{array}{l}\text { Comercio varejista especializado de moveis, colchoa- } \\
\text { ria e artigos de iluminacao }\end{array}$ \\
\hline 47 & 47555 & 1 & 1 & 0 & $\begin{array}{l}\text { Comercio varejista especializado de tecidos e artigos } \\
\text { de cama, mesa e banho }\end{array}$ \\
\hline 47 & 47598 & 1 & 1 & 0 & $\begin{array}{l}\text { Comercio varejista de artigos de uso domestico nao } \\
\text { especificados anteriormente }\end{array}$ \\
\hline 47 & 47610 & 1 & 1 & 0 & $\begin{array}{l}\text { Comercio varejista de livros, jornais, revistas e pape- } \\
\text { laria }\end{array}$ \\
\hline 47 & 47628 & 1 & 1 & 0 & Comercio varejista de discos, CDs, DVDs e fitas \\
\hline 47 & 47636 & 1 & 1 & 0 & Comercio varejista de artigos recreativos e esportivos \\
\hline 47 & 47725 & 1 & 1 & 0 & $\begin{array}{l}\text { Comercio varejista de cosmeticos, produtos de per- } \\
\text { fumaria e de higiene pessoal }\end{array}$ \\
\hline 47 & 47814 & 1 & 1 & 0 & $\begin{array}{l}\text { Comercio varejista de artigos do vestuario e acesso- } \\
\text { rios }\end{array}$ \\
\hline 47 & 47822 & 1 & 1 & 0 & Comercio varejista de calcados e artigos de viagem \\
\hline 47 & 47890 & 1 & 1 & 0 & $\begin{array}{l}\text { Comercio varejista de outros produtos novos nao es- } \\
\text { pecificados anteriormente }\end{array}$ \\
\hline 49 & 49230 & 0 & 0 & 0 & Transporte rodoviario de taxi \\
\hline 49 & 49248 & 0 & 0 & 0 & Transporte escolar \\
\hline 49 & 49299 & 0 & 0 & 0 & $\begin{array}{l}\text { Transporte rodoviario coletivo de passageiros, sob re- } \\
\text { gime de fretamento, e outros transportes rodoviarios } \\
\text { nao especificados anteriormente }\end{array}$ \\
\hline 49 & 49400 & 0 & 0 & 0 & Transporte dutoviario \\
\hline 49 & 49507 & 0 & 0 & 0 & Trens turisticos, telefericos e similares \\
\hline 49 & 49116 & 1 & 1 & 0 & Transporte ferroviario de carga \\
\hline 49 & 49124 & 1 & 1 & 0 & Transporte metroferroviario de passageiros \\
\hline 49 & 49213 & 1 & 1 & 0 & $\begin{array}{l}\text { Transporte rodoviario coletivo de passageiros, com } \\
\text { itinerario fixo, municipal e em regiao metropolitana }\end{array}$ \\
\hline
\end{tabular}

Nota: Tabela de classes da CNAE onde existem tanto tratados quanto controles dentro de um mesmo grupo (2 dígitos). Para a desoneração, "NCM" e "CNAE" indicam o modo pelo qual o setor foi desonerado (pelo NCM de seus produtos ou por sua área de atividade), enquanto "Desonerado" indica desoneração, independente do modo. "1" indica que houve desoneração pelo critério definido, enquanto "0" indica que não houve tratamento 


\begin{tabular}{|c|c|c|c|c|c|}
\hline \multirow[t]{2}{*}{ Grupo } & \multirow[t]{2}{*}{ CNAE } & \multicolumn{3}{|c|}{ Desoneração } & \multirow[t]{2}{*}{ Descrição } \\
\hline & & Desonerado & CNAE & $\mathrm{NCM}$ & \\
\hline 49 & 49221 & 1 & 1 & 0 & $\begin{array}{l}\text { Transporte rodoviario coletivo de passageiros, com } \\
\text { itinerario fixo, intermunicipal, interestadual e inter- } \\
\text { nacional }\end{array}$ \\
\hline 49 & 49302 & 1 & 1 & 0 & Transporte rodoviario de carga \\
\hline 50 & 50912 & 0 & 0 & 0 & Transporte por navegacao de travessia \\
\hline 50 & 50998 & 0 & 0 & 0 & $\begin{array}{l}\text { Transportes aquaviarios nao especificados anterior- } \\
\text { mente }\end{array}$ \\
\hline 50 & 50114 & 1 & 1 & 0 & Transporte maritimo de cabotagem \\
\hline 50 & 50122 & 1 & 1 & 0 & Transporte maritimo de longo curso \\
\hline 50 & 50211 & 1 & 1 & 0 & Transporte por navegacao interior de carga \\
\hline 50 & 50220 & 1 & 1 & 0 & $\begin{array}{l}\text { Transporte por navegacao interior de passageiros em } \\
\text { linhas regulares }\end{array}$ \\
\hline 50 & 50301 & 1 & 1 & 0 & Navegacao de apoio \\
\hline 52 & 52117 & 0 & 0 & 0 & Armazenamento \\
\hline 52 & 52214 & 0 & 0 & 0 & $\begin{array}{l}\text { Concessionarias de rodovias, pontes, tuneis e servicos } \\
\text { relacionados }\end{array}$ \\
\hline 52 & 52222 & 0 & 0 & 0 & Terminais rodoviarios e ferroviarios \\
\hline 52 & 52231 & 0 & 0 & 0 & Estacionamento de veiculos \\
\hline 52 & 52290 & 0 & 0 & 0 & $\begin{array}{l}\text { Atividades auxiliares dos transportes terrestres nao } \\
\text { especificadas anteriormente }\end{array}$ \\
\hline 52 & 52320 & 0 & 0 & 0 & Atividades de agenciamento maritimo \\
\hline 52 & 52397 & 0 & 0 & 0 & $\begin{array}{l}\text { Atividades auxiliares dos transportes aquaviarios } \\
\text { nao especificadas anteriormente }\end{array}$ \\
\hline 52 & 52401 & 0 & 0 & 0 & Atividades auxiliares dos transportes aereos \\
\hline 52 & 52508 & 0 & 0 & 0 & $\begin{array}{l}\text { Atividades relacionadas a organizacao do transporte } \\
\text { de carga }\end{array}$ \\
\hline 52 & 52125 & 1 & 1 & 0 & Carga e descarga \\
\hline 52 & 52311 & 1 & 1 & 0 & Gestao de portos e terminais \\
\hline 55 & 55906 & 0 & 0 & 0 & $\begin{array}{l}\text { Outros tipos de alojamento nao especificados anteri- } \\
\text { ormente }\end{array}$ \\
\hline 55 & 55108 & 1 & 1 & 0 & Hoteis e similares \\
\hline 58 & 58191 & 0 & 0 & 0 & $\begin{array}{l}\text { Edicao de cadastros, listas e de outros produtos gra- } \\
\text { ficos }\end{array}$ \\
\hline 58 & 58212 & 0 & 0 & 0 & Edicao integrada a impressao de livros \\
\hline 58 & 58298 & 0 & 0 & 0 & $\begin{array}{l}\text { Edicao integrada a impressao de cadastros, listas e } \\
\text { de outros produtos graficos }\end{array}$ \\
\hline 58 & 58115 & 1 & 1 & 0 & Edicao de livros \\
\hline 58 & 58123 & 1 & 1 & 0 & Edicao de jornais \\
\hline 58 & 58131 & 1 & 1 & 0 & Edicao de revistas \\
\hline 58 & 58221 & 1 & 1 & 0 & Edicao integrada a impressao de jornais \\
\hline 58 & 58239 & 1 & 1 & 0 & Edicao integrada a impressao de revistas \\
\hline
\end{tabular}

Nota: Tabela de classes da CNAE onde existem tanto tratados quanto controles dentro de um mesmo grupo (2 dígitos). Para a desoneração, "NCM" e "CNAE" indicam o modo pelo qual o setor foi desonerado (pelo NCM de seus produtos ou por sua área de atividade), enquanto "Desonerado" indica desoneração, independente do modo. "1" indica que houve desoneração pelo critério definido, enquanto "0" indica que não houve tratamento 


\begin{tabular}{|c|c|c|c|c|c|}
\hline \multirow[t]{2}{*}{ Grupo } & \multirow[t]{2}{*}{ CNAE } & \multicolumn{3}{|c|}{ Desoneração } & \multirow[t]{2}{*}{ Descrição } \\
\hline & & Desonerado & CNAE & $\mathrm{NCM}$ & \\
\hline 60 & 60225 & 0 & 0 & 0 & $\begin{array}{l}\text { Programadoras e atividades relacionadas a televisao } \\
\text { por assinatura }\end{array}$ \\
\hline 60 & 60101 & 1 & 1 & 0 & Atividades de radio \\
\hline 60 & 60217 & 1 & 1 & 0 & Atividades de televisao aberta \\
\hline 63 & 63917 & 0 & 0 & 0 & Agencias de noticias \\
\hline 63 & 63992 & 0 & 0 & 0 & $\begin{array}{l}\text { Outras atividades de prestacao de servicos de infor- } \\
\text { macao nao especificadas anteriormente }\end{array}$ \\
\hline 63 & 63119 & 1 & 1 & 0 & $\begin{array}{l}\text { Tratamento de dados, provedores de servicos de apli- } \\
\text { cacao e servicos de hospedagem na internet }\end{array}$ \\
\hline 63 & 63194 & 1 & 1 & 0 & $\begin{array}{l}\text { Portais, provedores de conteudo e outros servicos de } \\
\text { informacao na internet }\end{array}$ \\
\hline 82 & 82113 & 0 & 0 & 0 & $\begin{array}{l}\text { Servicos combinados de escritorio e apoio adminis- } \\
\text { trativo }\end{array}$ \\
\hline 82 & 82199 & 0 & 0 & 0 & $\begin{array}{l}\text { Fotocopias, preparacao de documentos e outros ser- } \\
\text { vicos especializados de apoio administrativo }\end{array}$ \\
\hline 82 & 82300 & 0 & 0 & 0 & $\begin{array}{l}\text { Atividades de organizacao de eventos, exceto cultu- } \\
\text { rais e esportivos }\end{array}$ \\
\hline 82 & 82911 & 0 & 0 & 0 & Atividades de cobrancas e informacoes cadastrais \\
\hline 82 & 82920 & 0 & 0 & 0 & Envasamento e empacotamento sob contrato \\
\hline 82 & 82997 & 0 & 0 & 0 & $\begin{array}{l}\text { Atividades de servicos prestados principalmente as } \\
\text { empresas nao especificadas anteriormente }\end{array}$ \\
\hline 82 & 82202 & 1 & 1 & 0 & Atividades de teleatendimento \\
\hline
\end{tabular}

Nota: Tabela de classes da CNAE onde existem tanto tratados quanto controles dentro de um mesmo grupo (2 dígitos). Para a desoneração, "NCM" e "CNAE" indicam o modo pelo qual o setor foi desonerado (pelo NCM de seus produtos ou por sua área de atividade), enquanto "Desonerado" indica desoneração, independente do modo. "1" indica que houve desoneração pelo critério definido, enquanto "0" indica que não houve tratamento 


\section{A.2 Lista de Setores Comparáveis - 3 Dígitos da CNAE}

\begin{tabular}{|c|c|c|c|c|c|}
\hline \multirow{2}{*}{ Grupo } & \multirow{2}{*}{ CNAE } & \multicolumn{3}{|c|}{ Desoneração } & \multirow{2}{*}{ Descrição } \\
\hline & & Desonerado & CNAE & $\mathrm{NCM}$ & \\
\hline 011 & 1113 & 0 & 0 & 0 & Cultivo de cereais \\
\hline 011 & 1121 & 0 & 0 & 0 & $\begin{array}{l}\text { Cultivo de algodao herbaceo e de outras fibras de } \\
\text { lavoura temporaria }\end{array}$ \\
\hline 011 & 1130 & 0 & 0 & 0 & Cultivo de canadeacucar \\
\hline 011 & 1148 & 0 & 0 & 0 & Cultivo de fumo \\
\hline 011 & 1156 & 0 & 0 & 0 & Cultivo de soja \\
\hline 011 & 1164 & 0 & 0 & 0 & $\begin{array}{l}\text { Cultivo de oleaginosas de lavoura temporaria, exceto } \\
\text { soja }\end{array}$ \\
\hline 011 & 1199 & 1 & 0 & 1 & $\begin{array}{l}\text { Cultivo de plantas de lavoura temporaria nao espe- } \\
\text { cificadas anteriormente }\end{array}$ \\
\hline 012 & 1229 & 0 & 0 & 0 & Floricultura \\
\hline 012 & 1211 & 1 & 0 & 1 & Horticultura \\
\hline 089 & 8916 & 0 & 0 & 0 & $\begin{array}{l}\text { Extracao de minerais para fabricacao de adubos, fer- } \\
\text { tilizantes e outros produtos quimicos }\end{array}$ \\
\hline 089 & 8932 & 0 & 0 & 0 & $\begin{array}{l}\text { Extracao de gemas (pedras preciosas e semiprecio- } \\
\text { sas) }\end{array}$ \\
\hline 089 & 8991 & 0 & 0 & 0 & $\begin{array}{l}\text { Extracao de minerais nao metalicos nao especificados } \\
\text { anteriormente }\end{array}$ \\
\hline 089 & 8924 & 1 & 0 & 1 & Extracao e refino de sal marinho e salgema \\
\hline 103 & 10317 & 0 & 0 & 0 & Fabricacao de conservas de frutas \\
\hline 103 & 10325 & 0 & 0 & 0 & Fabricacao de conservas de legumes e outros vegetais \\
\hline 103 & 10333 & 1 & 0 & 1 & Fabricacao de sucos de frutas, hortalicas e legumes \\
\hline 105 & 10511 & 0 & 0 & 0 & Preparacao do leite \\
\hline 105 & 10538 & 0 & 0 & 0 & Fabricacao de sorvetes e outros gelados comestiveis \\
\hline 105 & 10520 & 1 & 0 & 1 & Fabricacao de laticinios \\
\hline 106 & 10635 & 0 & 0 & 0 & Fabricacao de farinha de mandioca e derivados \\
\hline 106 & 10660 & 0 & 0 & 0 & Fabricacao de alimentos para animais \\
\hline 106 & 10619 & 1 & 0 & 1 & $\begin{array}{l}\text { Beneficiamento de arroz e fabricacao de produtos do } \\
\text { arroz }\end{array}$ \\
\hline 106 & 10627 & 1 & 0 & 1 & Moagem de trigo e fabricacao de derivados \\
\hline 106 & 10643 & 1 & 0 & 1 & $\begin{array}{l}\text { Fabricacao de farinha de milho e derivados, exceto } \\
\text { oleos de milho }\end{array}$ \\
\hline 106 & 10651 & 1 & 0 & 1 & $\begin{array}{l}\text { Fabricacao de amidos e feculas de vegetais e de oleos } \\
\text { de milho }\end{array}$ \\
\hline 106 & 10694 & 1 & 0 & 1 & $\begin{array}{l}\text { Moagem e fabricacao de produtos de origem vegetal } \\
\text { nao especificados anteriormente }\end{array}$ \\
\hline 109 & 10937 & 0 & 0 & 0 & $\begin{array}{l}\text { Fabricacao de produtos derivados do cacau, de cho- } \\
\text { colates e confeitos }\end{array}$ \\
\hline
\end{tabular}

Nota: Tabela de classes da CNAE onde existem tanto tratados quanto controles dentro de um mesmo grupo (3 dígitos). Para a desoneração, "NCM" e "CNAE" indicam o modo pelo qual o setor foi desonerado (pelo NCM de seus produtos ou por sua área de atividade), enquanto "Desonerado" indica desoneração, independente do modo. "1" indica que houve desoneração pelo critério definido, enquanto "0" indica que não houve tratamento 


\begin{tabular}{|c|c|c|c|c|c|}
\hline \multirow[t]{2}{*}{ Grupo } & \multirow[t]{2}{*}{ CNAE } & \multicolumn{3}{|c|}{ Desoneração } & \multirow[t]{2}{*}{ Descrição } \\
\hline & & Desonerado & CNAE & $\mathrm{NCM}$ & \\
\hline 109 & 10953 & 0 & 0 & 0 & $\begin{array}{l}\text { Fabricacao de especiarias, molhos, temperos e condi- } \\
\text { mentos }\end{array}$ \\
\hline 109 & 10911 & 1 & 0 & 1 & Fabricacao de produtos de panificacao \\
\hline 109 & 10929 & 1 & 0 & 1 & Fabricacao de biscoitos e bolachas \\
\hline 109 & 10945 & 1 & 0 & 1 & Fabricacao de massas alimenticias \\
\hline 109 & 10961 & 1 & 0 & 1 & Fabricacao de alimentos e pratos prontos \\
\hline 109 & 10996 & 1 & 0 & 1 & $\begin{array}{l}\text { Fabricacao de produtos alimenticios nao especifica- } \\
\text { dos anteriormente }\end{array}$ \\
\hline 112 & 11216 & 0 & 0 & 0 & Fabricacao de aguas envasadas \\
\hline 112 & 11224 & 1 & 0 & 1 & $\begin{array}{l}\text { Fabricacao de refrigerantes e de outras bebidas nao- } \\
\text { alcoolicas }\end{array}$ \\
\hline 162 & 16218 & 0 & 0 & 0 & $\begin{array}{l}\text { Fabricacao de madeira laminada e de chapas de ma- } \\
\text { deira compensada, prensada e aglomerada }\end{array}$ \\
\hline 162 & 16226 & 1 & 0 & 1 & $\begin{array}{l}\text { Fabricacao de estruturas de madeira e de artigos de } \\
\text { carpintaria para construcao }\end{array}$ \\
\hline 162 & 16234 & 1 & 0 & 1 & $\begin{array}{l}\text { Fabricacao de artefatos de tanoaria e de embalagens } \\
\text { de madeira }\end{array}$ \\
\hline 162 & 16293 & 1 & 0 & 1 & $\begin{array}{l}\text { Fabricacao de artefatos de madeira, palha, cortica, } \\
\text { vime e material trancado nao especificados anterior- } \\
\text { mente, exceto moveis }\end{array}$ \\
\hline 181 & 18121 & 0 & 0 & 0 & Impressao de material de seguranca \\
\hline 181 & 18130 & 0 & 0 & 0 & Impressao de materiais para outros usos \\
\hline 181 & 18113 & 1 & 1 & 0 & $\begin{array}{l}\text { Impressao de jornais, livros, revistas e outras publi- } \\
\text { cacoes periodicas }\end{array}$ \\
\hline 182 & 18229 & 0 & 0 & 0 & Servicos de acabamentos graficos \\
\hline 182 & 18211 & 1 & 0 & 1 & Servicos de preimpressao \\
\hline 202 & 20215 & 0 & 0 & 0 & Fabricacao de produtos petroquimicos basicos \\
\hline 202 & 20223 & 0 & 0 & 0 & $\begin{array}{l}\text { Fabricacao de intermediarios para plastificantes, re- } \\
\text { sinas e fibras }\end{array}$ \\
\hline 202 & 20291 & 1 & 0 & 1 & $\begin{array}{l}\text { Fabricacao de produtos quimicos organicos nao es- } \\
\text { pecificados anteriormente }\end{array}$ \\
\hline 207 & 20720 & 0 & 0 & 0 & Fabricacao de tintas de impressao \\
\hline 207 & 20711 & 1 & 0 & 1 & Fabricacao de tintas, vernizes, esmaltes e lacas \\
\hline 207 & 20738 & 1 & 0 & 1 & $\begin{array}{l}\text { Fabricacao de impermeabilizantes, solventes e pro- } \\
\text { dutos afins }\end{array}$ \\
\hline 209 & 20916 & 0 & 0 & 0 & Fabricacao de adesivos e selantes \\
\hline 209 & 20924 & 0 & 0 & 0 & Fabricacao de explosivos \\
\hline 209 & 20932 & 0 & 0 & 0 & Fabricacao de aditivos de uso industrial \\
\hline 209 & 20941 & 1 & 0 & 1 & Fabricacao de catalisadores \\
\hline 209 & 20991 & 1 & 0 & 1 & $\begin{array}{l}\text { Fabricacao de produtos quimicos nao especificados } \\
\text { anteriormente }\end{array}$ \\
\hline
\end{tabular}

Nota: Tabela de classes da CNAE onde existem tanto tratados quanto controles dentro de um mesmo grupo (3 dígitos). Para a desoneração, "NCM" e "CNAE" indicam o modo pelo qual o setor foi desonerado (pelo NCM de seus produtos ou por sua área de atividade), enquanto "Desonerado" indica desoneração, independente do modo. "1" indica que houve desoneração pelo critério definido, enquanto "0" indica que não houve tratamento 


\begin{tabular}{|c|c|c|c|c|c|}
\hline \multirow[t]{2}{*}{ Grupo } & \multirow[t]{2}{*}{ CNAE } & \multicolumn{3}{|c|}{ Desoneração } & \multirow[t]{2}{*}{ Descrição } \\
\hline & & Desonerado & CNAE & $\mathrm{NCM}$ & \\
\hline 221 & 22129 & 0 & 0 & 0 & Reforma de pneumaticos usados \\
\hline 221 & 22111 & 1 & 0 & 1 & Fabricacao de pneumaticos e de camarasdear \\
\hline 221 & 22196 & 1 & 0 & 1 & $\begin{array}{l}\text { Fabricacao de artefatos de borracha nao especifica- } \\
\text { dos anteriormente }\end{array}$ \\
\hline 241 & 24121 & 0 & 0 & 0 & Producao de ferroligas \\
\hline 241 & 24113 & 1 & 0 & 1 & Producao de ferrogusa \\
\hline 244 & 24415 & 0 & 0 & 0 & Metalurgia do aluminio e suas ligas \\
\hline 244 & 24423 & 0 & 0 & 0 & Metalurgia dos metais preciosos \\
\hline 244 & 24431 & 1 & 0 & 1 & Metalurgia do cobre \\
\hline 244 & 24491 & 1 & 0 & 1 & $\begin{array}{l}\text { Metalurgia dos metais naoferrosos e suas ligas nao } \\
\text { especificados anteriormente }\end{array}$ \\
\hline 245 & 24521 & 0 & 0 & 0 & Fundicao de metais naoferrosos e suas ligas \\
\hline 245 & 24512 & 1 & 0 & 1 & Fundicao de ferro e aco \\
\hline 253 & 25390 & 0 & 0 & 0 & $\begin{array}{l}\text { Servicos de usinagem, solda, tratamento e revesti- } \\
\text { mento em metais }\end{array}$ \\
\hline 253 & 25314 & 1 & 0 & 1 & $\begin{array}{l}\text { Producao de forjados de aco e de metais naoferrosos } \\
\text { e suas ligas }\end{array}$ \\
\hline 253 & 25322 & 1 & 0 & 1 & $\begin{array}{l}\text { Producao de artefatos estampados de metal e meta- } \\
\text { lurgia do po }\end{array}$ \\
\hline 331 & 33112 & 0 & 0 & 0 & $\begin{array}{l}\text { Manutencao e reparacao de tanques, reservatorios } \\
\text { metalicos e caldeiras, exceto para veiculos }\end{array}$ \\
\hline 331 & 33139 & 0 & 0 & 0 & $\begin{array}{l}\text { Manutencao e reparacao de maquinas e equipamen- } \\
\text { tos eletricos }\end{array}$ \\
\hline 331 & 33147 & 0 & 0 & 0 & $\begin{array}{l}\text { Manutencao e reparacao de maquinas e equipamen- } \\
\text { tos da industria mecanica }\end{array}$ \\
\hline 331 & 33155 & 0 & 0 & 0 & Manutencao e reparacao de veiculos ferroviarios \\
\hline 331 & 33198 & 0 & 0 & 0 & $\begin{array}{l}\text { Manutencao e reparacao de equipamentos e produtos } \\
\text { nao especificados anteriormente }\end{array}$ \\
\hline 331 & 33121 & 1 & 1 & 0 & $\begin{array}{l}\text { Manutencao e reparacao de equipamentos eletronicos } \\
\text { e opticos }\end{array}$ \\
\hline 331 & 33163 & 1 & 1 & 0 & Manutencao e reparacao de aeronaves \\
\hline 331 & 33171 & 1 & 1 & 0 & Manutencao e Reparacao de Embarcacoes \\
\hline 383 & 38327 & 0 & 0 & 0 & Recuperacao de materiais plasticos \\
\hline 383 & 38394 & 0 & 0 & 0 & $\begin{array}{l}\text { Recuperacao de materiais nao especificados anterior- } \\
\text { mente }\end{array}$ \\
\hline 383 & 38319 & 1 & 0 & 1 & Recuperacao de materiais metalicos \\
\hline 471 & 47113 & 0 & 0 & 0 & $\begin{array}{l}\text { Comercio varejista de mercadorias em geral, com pre- } \\
\text { dominancia de produtos alimenticios hipermercados } \\
\text { e supermercados }\end{array}$ \\
\hline
\end{tabular}

Nota: Tabela de classes da CNAE onde existem tanto tratados quanto controles dentro de um mesmo grupo (3 dígitos). Para a desoneração, "NCM" e "CNAE" indicam o modo pelo qual o setor foi desonerado (pelo NCM de seus produtos ou por sua área de atividade), enquanto "Desonerado" indica desoneração, independente do modo. "1" indica que houve desoneração pelo critério definido, enquanto "0" indica que não houve tratamento 


\begin{tabular}{|c|c|c|c|c|c|}
\hline \multirow[t]{2}{*}{ Grupo } & \multirow[t]{2}{*}{ CNAE } & \multicolumn{3}{|c|}{ Desoneração } & \multirow[t]{2}{*}{ Descrição } \\
\hline & & Desonerado & CNAE & $\mathrm{NCM}$ & \\
\hline 471 & 47121 & 0 & 0 & 0 & $\begin{array}{l}\text { Comercio varejista de mercadorias em geral, com pre- } \\
\text { dominancia de produtos alimenticios minimercados, } \\
\text { mercearias e armazens }\end{array}$ \\
\hline 471 & 47130 & 1 & 1 & 0 & $\begin{array}{l}\text { Comercio varejista de mercadorias em geral, sem pre- } \\
\text { dominancia de produtos alimenticios }\end{array}$ \\
\hline 474 & 47415 & 0 & 0 & 0 & Comercio varejista de tintas e materiais para pintura \\
\hline 474 & 47423 & 0 & 0 & 0 & Comercio varejista de material eletrico \\
\hline 474 & 47431 & 0 & 0 & 0 & Comercio varejista de vidros \\
\hline 474 & 47440 & 1 & 1 & 0 & $\begin{array}{l}\text { Comercio varejista de ferragens, madeira e materiais } \\
\text { de construcao }\end{array}$ \\
\hline 475 & 47563 & 0 & 0 & 0 & $\begin{array}{l}\text { Comercio varejista especializado de instrumentos } \\
\text { musicais e acessorios }\end{array}$ \\
\hline 475 & 47571 & 0 & 0 & 0 & $\begin{array}{l}\text { Comercio varejista especializado de pecas e acesso- } \\
\text { rios para aparelhos eletroeletronicos para uso domes- } \\
\text { tico, exceto informatica e comunicacao }\end{array}$ \\
\hline 475 & 47512 & 1 & 1 & 0 & $\begin{array}{l}\text { Comercio varejista especializado de equipamentos e } \\
\text { suprimentos de informatica }\end{array}$ \\
\hline 475 & 47521 & 1 & 1 & 0 & $\begin{array}{l}\text { Comercio varejista especializado de equipamentos de } \\
\text { telefonia e comunicacao }\end{array}$ \\
\hline 475 & 47539 & 1 & 1 & 0 & $\begin{array}{l}\text { Comercio varejista especializado de eletrodomesticos } \\
\text { e equipamentos de audio e video }\end{array}$ \\
\hline 475 & 47547 & 1 & 1 & 0 & $\begin{array}{l}\text { Comercio varejista especializado de moveis, colchoa- } \\
\text { ria e artigos de iluminacao }\end{array}$ \\
\hline 475 & 47555 & 1 & 1 & 0 & $\begin{array}{l}\text { Comercio varejista especializado de tecidos e artigos } \\
\text { de cama, mesa e banho }\end{array}$ \\
\hline 475 & 47598 & 1 & 1 & 0 & $\begin{array}{l}\text { Comercio varejista de artigos de uso domestico nao } \\
\text { especificados anteriormente }\end{array}$ \\
\hline 477 & 47717 & 0 & 0 & 0 & $\begin{array}{l}\text { Comercio varejista de produtos farmaceuticos para } \\
\text { uso humano e veterinario }\end{array}$ \\
\hline 477 & 47733 & 0 & 0 & 0 & Comercio varejista de artigos medicos e ortopedicos \\
\hline 477 & 47741 & 0 & 0 & 0 & Comercio varejista de artigos de optica \\
\hline 477 & 47725 & 1 & 1 & 0 & $\begin{array}{l}\text { Comercio varejista de cosmeticos, produtos de per- } \\
\text { fumaria e de higiene pessoal }\end{array}$ \\
\hline 478 & 47831 & 0 & 0 & 0 & Comercio varejista de joias e relogios \\
\hline 478 & 47849 & 0 & 0 & 0 & $\begin{array}{l}\text { Comercio varejista de gas liqüefeito de petroleo } \\
(\mathrm{GLP})\end{array}$ \\
\hline 478 & 47857 & 0 & 0 & 0 & Comercio varejista de artigos usados \\
\hline 478 & 47814 & 1 & 1 & 0 & $\begin{array}{l}\text { Comercio varejista de artigos do vestuario e acesso- } \\
\text { rios }\end{array}$ \\
\hline 478 & 47822 & 1 & 1 & 0 & Comercio varejista de calcados e artigos de viagem \\
\hline
\end{tabular}

Nota: Tabela de classes da CNAE onde existem tanto tratados quanto controles dentro de um mesmo grupo (3 dígitos). Para a desoneração, "NCM" e "CNAE" indicam o modo pelo qual o setor foi desonerado (pelo NCM de seus produtos ou por sua área de atividade), enquanto "Desonerado" indica desoneração, independente do modo. "1" indica que houve desoneração pelo critério definido, enquanto " 0 " indica que não houve tratamento 


\begin{tabular}{|c|c|c|c|c|c|}
\hline \multirow[t]{2}{*}{ Grupo } & \multirow[t]{2}{*}{ CNAE } & \multicolumn{3}{|c|}{ Desoneração } & \multirow[t]{2}{*}{ Descrição } \\
\hline & & Desonerado & CNAE & $\mathrm{NCM}$ & \\
\hline 478 & 47890 & 1 & 1 & 0 & $\begin{array}{l}\text { Comercio varejista de outros produtos novos nao es- } \\
\text { pecificados anteriormente }\end{array}$ \\
\hline 492 & 49230 & 0 & 0 & 0 & Transporte rodoviario de taxi \\
\hline 492 & 49248 & 0 & 0 & 0 & Transporte escolar \\
\hline 492 & 49299 & 0 & 0 & 0 & $\begin{array}{l}\text { Transporte rodoviario coletivo de passageiros, sob re- } \\
\text { gime de fretamento, e outros transportes rodoviarios } \\
\text { nao especificados anteriormente }\end{array}$ \\
\hline 492 & 49213 & 1 & 1 & 0 & $\begin{array}{l}\text { Transporte rodoviario coletivo de passageiros, com } \\
\text { itinerario fixo, municipal e em regiao metropolitana }\end{array}$ \\
\hline 492 & 49221 & 1 & 1 & 0 & $\begin{array}{l}\text { Transporte rodoviario coletivo de passageiros, com } \\
\text { itinerario fixo, intermunicipal, interestadual e inter- } \\
\text { nacional }\end{array}$ \\
\hline 521 & 52117 & 0 & 0 & 0 & Armazenamento \\
\hline 521 & 52125 & 1 & 1 & 0 & Carga e descarga \\
\hline 523 & 52320 & 0 & 0 & 0 & Atividades de agenciamento maritimo \\
\hline 523 & 52397 & 0 & 0 & 0 & $\begin{array}{l}\text { Atividades auxiliares dos transportes aquaviarios } \\
\text { nao especificadas anteriormente }\end{array}$ \\
\hline 523 & 52311 & 1 & 1 & 0 & Gestao de portos e terminais \\
\hline 581 & 58191 & 0 & 0 & 0 & $\begin{array}{l}\text { Edicao de cadastros, listas e de outros produtos gra- } \\
\text { ficos }\end{array}$ \\
\hline 581 & 58115 & 1 & 1 & 0 & Edicao de livros \\
\hline 581 & 58123 & 1 & 1 & 0 & Edicao de jornais \\
\hline 581 & 58131 & 1 & 1 & 0 & Edicao de revistas \\
\hline 582 & 58212 & 0 & 0 & 0 & Edicao integrada a impressao de livros \\
\hline 582 & 58298 & 0 & 0 & 0 & $\begin{array}{l}\text { Edicao integrada a impressao de cadastros, listas e } \\
\text { de outros produtos graficos }\end{array}$ \\
\hline 582 & 58221 & 1 & 1 & 0 & Edicao integrada a impressao de jornais \\
\hline 582 & 58239 & 1 & 1 & 0 & Edicao integrada a impressao de revistas \\
\hline 602 & 60225 & 0 & 0 & 0 & $\begin{array}{l}\text { Programadoras e atividades relacionadas a televisao } \\
\text { por assinatura }\end{array}$ \\
\hline 602 & 60217 & 1 & 1 & 0 & Atividades de televisao aberta \\
\hline
\end{tabular}

Nota: Tabela de classes da CNAE onde existem tanto tratados quanto controles dentro de um mesmo grupo (3 dígitos). Para a desoneração, "NCM" e "CNAE" indicam o modo pelo qual o setor foi desonerado (pelo NCM de seus produtos ou por sua área de atividade), enquanto "Desonerado" indica desoneração, independente do modo. "1" indica que houve desoneração pelo critério definido, enquanto "0" indica que não houve tratamento 


\section{ANEXO B - Comparação das Contribuições na CPP e na CPRB}

\begin{tabular}{|c|c|c|c|c|c|}
\hline \multirow[b]{2}{*}{ Descrição } & \multirow[b]{2}{*}{ CNAE } & \multirow[b]{2}{*}{ Alíq. CPRB } & \multicolumn{2}{|c|}{ Contribuição* } & \multirow[b]{2}{*}{$\frac{C P R B}{C P P}$} \\
\hline & & & CPP & $\mathrm{CPRB}$ & \\
\hline $\begin{array}{l}\text { Cultivo de plantas de lavoura } \\
\text { temporaria nao especificadas an- } \\
\text { teriormente }\end{array}$ & 119 & $1 \%$ & 28,2 & 5,1 & $18,3 \%$ \\
\hline Horticultura & 121 & $1 \%$ & 12,4 & 4,4 & $36,0 \%$ \\
\hline Criacao de bovinos & 151 & $1 \%$ & 121,6 & 41,9 & $34,5 \%$ \\
\hline $\begin{array}{l}\text { Criacao de outros animais de } \\
\text { grande porte }\end{array}$ & 152 & $1 \%$ & 5,9 & 0,6 & $11,5 \%$ \\
\hline Criacao de caprinos e ovinos & 153 & $1 \%$ & 1,0 & 0,2 & $24,2 \%$ \\
\hline Criacao de suinos & 154 & $1 \%$ & 9,9 & 9,7 & $98,3 \%$ \\
\hline Criacao de aves & 155 & $1 \%$ & 153,9 & 70,9 & $46,1 \%$ \\
\hline $\begin{array}{l}\text { Criacao de animais nao especifi- } \\
\text { cados anteriormente }\end{array}$ & 159 & $1 \%$ & 3,5 & 0,9 & $25,2 \%$ \\
\hline $\begin{array}{l}\text { Producao florestal florestas plan- } \\
\text { tadas }\end{array}$ & 210 & $1 \%$ & 113,1 & 27,0 & $23,9 \%$ \\
\hline $\begin{array}{l}\text { Producao florestal florestas nati- } \\
\text { vas }\end{array}$ & 220 & $1 \%$ & 8,4 & 2,1 & $25,6 \%$ \\
\hline Pesca em agua salgada & 311 & $1 \%$ & 7,5 & 1,9 & $25,2 \%$ \\
\hline Pesca em agua doce & 312 & $1 \%$ & 0,0 & 0,0 & $0,1 \%$ \\
\hline $\begin{array}{l}\text { Aqüicultura em agua salgada e } \\
\text { salobra }\end{array}$ & 321 & $1 \%$ & 10,8 & 3,3 & $30,7 \%$ \\
\hline Aqüicultura em agua doce & 322 & $1 \%$ & 13,6 & 1,9 & $13,9 \%$ \\
\hline Extracao de pedra, areia e argila & 810 & $1 \%$ & 232,6 & 96,4 & $41,4 \%$ \\
\hline $\begin{array}{l}\text { Extracao e refino de sal marinho } \\
\text { e salgema }\end{array}$ & 892 & $1 \%$ & 21,4 & 9,1 & $42,6 \%$ \\
\hline Abate de reses, exceto suinos & 1011 & $1 \%$ & 390,9 & 350,2 & $89,6 \%$ \\
\hline $\begin{array}{l}\text { Abate de suinos, aves e outros } \\
\text { pequenos animais }\end{array}$ & 1012 & $1 \%$ & 884,4 & 408,8 & $46,2 \%$ \\
\hline Fabricacao de produtos de carne & 1013 & $1 \%$ & 239,1 & 151,9 & $63,6 \%$ \\
\hline $\begin{array}{l}\text { Preservacao do pescado e fabri- } \\
\text { cacao de produtos do pescado }\end{array}$ & 1020 & $1 \%$ & 47,1 & 35,4 & $75,3 \%$ \\
\hline $\begin{array}{l}\text { Fabricacao de sucos de frutas, } \\
\text { hortalicas e legumes }\end{array}$ & 1033 & $1 \%$ & 188,8 & 41,2 & $21,9 \%$ \\
\hline Fabricacao de laticinios & 1052 & $1 \%$ & 301,6 & 333,1 & $110,4 \%$ \\
\hline $\begin{array}{l}\text { Beneficiamento de arroz e fabri- } \\
\text { cacao de produtos do arroz }\end{array}$ & 1061 & $1 \%$ & 111,4 & 144,8 & $130,0 \%$ \\
\hline
\end{tabular}

Nota: *Contribuição em milhões de reais. Tabela de comparação das contribuições dos setores desonerados em cada um dos possíveis regimes. Alíq. CPRB aponta a alíquota dos setores no novo regime. $\frac{C P R B}{C P P}$ compara as contribuições no novo regime com aquelas no regime antigo. 


\begin{tabular}{|c|c|c|c|c|c|}
\hline \multirow[b]{2}{*}{ Descrição } & \multirow[b]{2}{*}{ CNAE } & \multirow[b]{2}{*}{ Alíq. CPRB } & \multicolumn{2}{|c|}{ Contribuição* } & \multirow[b]{2}{*}{$\frac{C P R B}{C P P}$} \\
\hline & & & $\mathrm{CPP}$ & CPRB & \\
\hline $\begin{array}{l}\text { Moagem de trigo e fabricacao de } \\
\text { derivados }\end{array}$ & 1062 & $1 \%$ & 120,2 & 123,2 & $102,5 \%$ \\
\hline $\begin{array}{l}\text { Fabricacao de farinha de milho e } \\
\text { derivados, exceto oleos de milho }\end{array}$ & 1064 & $1 \%$ & 20,2 & 12,3 & $61,3 \%$ \\
\hline $\begin{array}{l}\text { Fabricacao de amidos e feculas de } \\
\text { vegetais e de oleos de milho }\end{array}$ & 1065 & $1 \%$ & 31,3 & 30,0 & $96,0 \%$ \\
\hline $\begin{array}{l}\text { Moagem e fabricacao de produ- } \\
\text { tos de origem vegetal nao especi- } \\
\text { ficados anteriormente }\end{array}$ & 1069 & $1 \%$ & 83,3 & 111,4 & $133,7 \%$ \\
\hline $\begin{array}{l}\text { Fabricacao de produtos de pani- } \\
\text { ficacao }\end{array}$ & 1091 & $1 \%$ & 219,4 & 85,9 & $39,2 \%$ \\
\hline $\begin{array}{l}\text { Fabricacao de biscoitos e bola- } \\
\text { chas }\end{array}$ & 1092 & $1 \%$ & 113,8 & 58,8 & $51,7 \%$ \\
\hline $\begin{array}{l}\text { Fabricacao de massas alimenti- } \\
\text { cias }\end{array}$ & 1094 & $1 \%$ & 170,4 & 90,1 & $52,9 \%$ \\
\hline $\begin{array}{l}\text { Fabricacao de alimentos e pratos } \\
\text { prontos }\end{array}$ & 1096 & $1 \%$ & 10,1 & 3,0 & $29,6 \%$ \\
\hline $\begin{array}{l}\text { Fabricacao de produtos alimen- } \\
\text { ticios nao especificados anterior- } \\
\text { mente }\end{array}$ & 1099 & $1 \%$ & 543,3 & 388,0 & $71,4 \%$ \\
\hline $\begin{array}{l}\text { Fabricacao de refrigerantes e de } \\
\text { outras bebidas naoalcoolicas }\end{array}$ & 1122 & $1 \%$ & 313,1 & 268,8 & $85,8 \%$ \\
\hline Fabricacao de produtos do fumo & 1220 & $1 \%$ & 95,4 & 105,8 & $110,9 \%$ \\
\hline $\begin{array}{l}\text { Preparacao e fiacao de fibras de } \\
\text { algodao }\end{array}$ & 1311 & $1 \%$ & 164,8 & 81,3 & $49,4 \%$ \\
\hline $\begin{array}{l}\text { Preparacao e fiacao de fibras tex- } \\
\text { teis naturais, exceto algodao }\end{array}$ & 1312 & $1 \%$ & 18,8 & 3,3 & $18,0 \%$ \\
\hline $\begin{array}{l}\text { Fiacao de fibras artificiais e sin- } \\
\text { teticas }\end{array}$ & 1313 & $1 \%$ & 64,5 & 29,4 & $45,6 \%$ \\
\hline $\begin{array}{l}\text { Fabricacao de linhas para costu- } \\
\text { rar e bordar }\end{array}$ & 1314 & $1 \%$ & 24,5 & 10,4 & $42,6 \%$ \\
\hline Tecelagem de fios de algodao & 1321 & $1 \%$ & 99,7 & 44,4 & $44,6 \%$ \\
\hline $\begin{array}{l}\text { Tecelagem de fios de fibras tex- } \\
\text { teis naturais, exceto algodao }\end{array}$ & 1322 & $1 \%$ & 8,2 & 3,9 & $48,2 \%$ \\
\hline $\begin{array}{l}\text { Tecelagem de fios de fibras arti- } \\
\text { ficiais e sinteticas }\end{array}$ & 1323 & $1 \%$ & 80,9 & 37,5 & $46,5 \%$ \\
\hline Fabricacao de tecidos de malha & 1330 & $1 \%$ & 100,6 & 62,6 & $62,3 \%$ \\
\hline $\begin{array}{l}\text { Fabricacao de artefatos texteis } \\
\text { para uso domestico }\end{array}$ & 1351 & $1 \%$ & 159,4 & 64,2 & $40,3 \%$ \\
\hline $\begin{array}{l}\text { Fabricacao de artefatos de tape- } \\
\text { caria }\end{array}$ & 1352 & $1 \%$ & 18,8 & 7,5 & $40,3 \%$ \\
\hline
\end{tabular}

Nota: *Contribuição em milhões de reais. Tabela de comparação das contribuições dos setores desonerados em cada um dos possíveis regimes. Alíq. CPRB aponta a alíquota dos setores no novo regime. $\frac{C P R B}{C P P}$ compara as contribuições no novo regime com aquelas no regime antigo. 


\begin{tabular}{|c|c|c|c|c|c|}
\hline \multirow[b]{2}{*}{ Descrição } & \multirow[b]{2}{*}{ CNAE } & \multirow[b]{2}{*}{ Alíq. CPRB } & \multicolumn{2}{|c|}{ Contribuição* } & \multirow[b]{2}{*}{$\frac{C P R B}{C P P}$} \\
\hline & & & $\mathrm{CPP}$ & CPRB & \\
\hline $\begin{array}{l}\text { Fabricacao de artefatos de cordo- } \\
\text { aria }\end{array}$ & 1353 & $1 \%$ & 6,5 & 3,1 & $48,2 \%$ \\
\hline $\begin{array}{l}\text { Fabricacao de tecidos especiais, } \\
\text { inclusive artefatos }\end{array}$ & 1354 & $1 \%$ & 88,5 & 38,8 & $43,8 \%$ \\
\hline $\begin{array}{l}\text { Fabricacao de outros produtos } \\
\text { texteis nao especificados anteri- } \\
\text { ormente }\end{array}$ & 1359 & $1 \%$ & 137,5 & 65,4 & $47,6 \%$ \\
\hline Confeccao de roupas intimas & 1411 & $1 \%$ & 109,6 & 34,4 & $31,4 \%$ \\
\hline $\begin{array}{l}\text { Confeccao de pecas do vestuario, } \\
\text { exceto roupas intimas }\end{array}$ & 1412 & $1 \%$ & 797,6 & 342,4 & $42,9 \%$ \\
\hline $\begin{array}{l}\text { Confeccao de roupas profissio- } \\
\text { nais }\end{array}$ & 1413 & $1 \%$ & 24,8 & 10,5 & $42,5 \%$ \\
\hline $\begin{array}{l}\text { Fabricacao de acessorios do ves- } \\
\text { tuario, exceto para seguranca e } \\
\text { protecao }\end{array}$ & 1414 & $1 \%$ & 22,3 & 8,5 & $38,2 \%$ \\
\hline Fabricacao de meias & 1421 & $1 \%$ & 49,5 & 15,2 & $30,8 \%$ \\
\hline $\begin{array}{l}\text { Fabricacao de artigos do vestu- } \\
\text { ario, produzidos em malharias e } \\
\text { tricotagens, exceto meias }\end{array}$ & 1422 & $1 \%$ & 58,3 & 28,9 & $49,6 \%$ \\
\hline $\begin{array}{l}\text { Curtimento e outras preparacoes } \\
\text { de couro }\end{array}$ & 1510 & $1 \%$ & 105,5 & 37,7 & $35,8 \%$ \\
\hline $\begin{array}{l}\text { Fabricacao de artigos para vi- } \\
\text { agem, bolsas e semelhantes de } \\
\text { qualquer material }\end{array}$ & 1521 & $1 \%$ & 16,8 & 8,1 & $48,3 \%$ \\
\hline $\begin{array}{l}\text { Fabricacao de artefatos de couro } \\
\text { nao especificados anteriormente }\end{array}$ & 1529 & $1 \%$ & 19,7 & 7,1 & $36,3 \%$ \\
\hline Fabricacao de calcados de couro & 1531 & $1 \%$ & 411,0 & 122,2 & $29,7 \%$ \\
\hline $\begin{array}{l}\text { Fabricacao de tenis de qualquer } \\
\text { material }\end{array}$ & 1532 & $1 \%$ & 45,8 & 13,2 & $28,9 \%$ \\
\hline $\begin{array}{l}\text { Fabricacao de calcados de mate- } \\
\text { rial sintetico }\end{array}$ & 1533 & $1 \%$ & 181,9 & 62,4 & $34,3 \%$ \\
\hline $\begin{array}{l}\text { Fabricacao de calcados de mate- } \\
\text { riais nao especificados anterior- } \\
\text { mente }\end{array}$ & 1539 & $1 \%$ & 42,7 & 16,3 & $38,2 \%$ \\
\hline $\begin{array}{l}\text { Fabricacao de partes para calca- } \\
\text { dos, de qualquer material }\end{array}$ & 1540 & $1 \%$ & 35,5 & 12,0 & $34,0 \%$ \\
\hline $\begin{array}{l}\text { Fabricacao de estruturas de ma- } \\
\text { deira e de artigos de carpintaria } \\
\text { para construcao }\end{array}$ & 1622 & $1 \%$ & 37,7 & 8,5 & $22,8 \%$ \\
\hline $\begin{array}{l}\text { Fabricacao de artefatos de tano- } \\
\text { aria e de embalagens de madeira }\end{array}$ & 1623 & $1 \%$ & 33,3 & 18,4 & $55,3 \%$ \\
\hline
\end{tabular}

Nota: *Contribuição em milhões de reais. Tabela de comparação das contribuições dos setores desonerados em cada um dos possíveis regimes. Alíq. CPRB aponta a alíquota dos setores no novo regime. $\frac{C P R B}{C P P}$ compara as contribuições no novo regime com aquelas no regime antigo. 


\begin{tabular}{|c|c|c|c|c|c|}
\hline \multirow[b]{2}{*}{ Descrição } & \multirow[b]{2}{*}{ CNAE } & \multirow[b]{2}{*}{ Alíq. CPRB } & \multicolumn{2}{|c|}{ Contribuição* } & \multirow[b]{2}{*}{$\frac{C P R B}{C P P}$} \\
\hline & & & $\mathrm{CPP}$ & $\mathrm{CPRB}$ & \\
\hline $\begin{array}{l}\text { Fabricacao de artefatos de ma- } \\
\text { deira, palha, cortica, vime e ma- } \\
\text { terial trancado nao especificados } \\
\text { anteriormente, exceto moveis }\end{array}$ & 1629 & $1 \%$ & 29,6 & 9,6 & $32,5 \%$ \\
\hline $\begin{array}{l}\text { Fabricacao de celulose e outras } \\
\text { pastas para a fabricacao de pa- } \\
\text { pel }\end{array}$ & 1710 & $1 \%$ & 305,6 & 109,2 & $35,8 \%$ \\
\hline Fabricacao de papel & 1721 & $1 \%$ & 218,2 & 136,3 & $62,4 \%$ \\
\hline $\begin{array}{l}\text { Fabricacao de cartolina e papel- } \\
\text { cartao }\end{array}$ & 1722 & $1 \%$ & 20,2 & 8,6 & $42,9 \%$ \\
\hline $\begin{array}{l}\text { Fabricacao de embalagens de pa- } \\
\text { pel }\end{array}$ & 1731 & $1 \%$ & 87,7 & 68,3 & $77,9 \%$ \\
\hline $\begin{array}{l}\text { Fabricacao de embalagens de car- } \\
\text { tolina e papelcartao }\end{array}$ & 1732 & $1 \%$ & 48,5 & 22,4 & $46,3 \%$ \\
\hline $\begin{array}{l}\text { Fabricacao de chapas e de emba- } \\
\text { lagens de papelao ondulado }\end{array}$ & 1733 & $1 \%$ & 181,5 & 92,2 & $50,8 \%$ \\
\hline $\begin{array}{l}\text { Fabricacao de produtos de papel, } \\
\text { cartolina, papelcartao e papelao } \\
\text { ondulado para uso industrial, co- } \\
\text { mercial e de escritorio }\end{array}$ & 1741 & $1 \%$ & 61,9 & 37,8 & $61,1 \%$ \\
\hline $\begin{array}{l}\text { Fabricacao de produtos de papel } \\
\text { para usos domestico e higienico- } \\
\text { sanitario }\end{array}$ & 1742 & $1 \%$ & 73,1 & 54,1 & $74,0 \%$ \\
\hline $\begin{array}{l}\text { Fabricacao de produtos de pas- } \\
\text { tas celulosicas, papel, cartolina, } \\
\text { papelcartao e papelao ondulado } \\
\text { nao especificados anteriormente }\end{array}$ & 1749 & $1 \%$ & 51,2 & 28,4 & $55,5 \%$ \\
\hline $\begin{array}{l}\text { Impressao de jornais, livros, re- } \\
\text { vistas e outras publicacoes peri- } \\
\text { odicas }\end{array}$ & 1811 & $1 \%$ & 93,1 & 31,4 & $33,8 \%$ \\
\hline Servicos de preimpressao & 1821 & $1 \%$ & 28,7 & 10,9 & $38,1 \%$ \\
\hline $\begin{array}{l}\text { Fabricacao de produtos quimicos } \\
\text { organicos nao especificados ante- } \\
\text { riormente }\end{array}$ & 2029 & $1 \%$ & 170,7 & 137,2 & $80,4 \%$ \\
\hline $\begin{array}{l}\text { Fabricacao de fibras artificiais e } \\
\text { sinteticas }\end{array}$ & 2040 & $1 \%$ & 17,1 & 10,2 & $59,8 \%$ \\
\hline $\begin{array}{l}\text { Fabricacao de defensivos agrico- } \\
\text { las }\end{array}$ & 2051 & $1 \%$ & 119,0 & 140,2 & $117,8 \%$ \\
\hline $\begin{array}{l}\text { Fabricacao de desinfestantes do- } \\
\text { missanitarios }\end{array}$ & 2052 & $1 \%$ & 4,8 & 3,5 & $73,2 \%$ \\
\hline $\begin{array}{l}\text { Fabricacao de saboes e detergen- } \\
\text { tes sinteticos }\end{array}$ & 2061 & $1 \%$ & 104,0 & 75,3 & $72,5 \%$ \\
\hline
\end{tabular}

Nota: *Contribuição em milhões de reais. Tabela de comparação das contribuições dos setores desonerados em cada um dos possíveis regimes. Alíq. CPRB aponta a alíquota dos setores no novo regime. $\frac{C P R B}{C P P}$ compara as contribuições no novo regime com aquelas no regime antigo. 


\begin{tabular}{|c|c|c|c|c|c|}
\hline \multirow[b]{2}{*}{ Descrição } & \multirow[b]{2}{*}{ CNAE } & \multirow[b]{2}{*}{ Alíq. CPRB } & \multicolumn{2}{|c|}{ Contribuição* } & \multirow[b]{2}{*}{$\frac{C P R B}{C P P}$} \\
\hline & & & $\mathrm{CPP}$ & CPRB & \\
\hline $\begin{array}{l}\text { Fabricacao de produtos de lim- } \\
\text { peza e polimento }\end{array}$ & 2062 & $1 \%$ & 89,6 & 73,8 & $82,4 \%$ \\
\hline $\begin{array}{l}\text { Fabricacao de cosmeticos, produ- } \\
\text { tos de perfumaria e de higiene } \\
\text { pessoal }\end{array}$ & 2063 & $1 \%$ & 255,9 & 231,0 & $90,3 \%$ \\
\hline $\begin{array}{l}\text { Fabricacao de tintas, vernizes, } \\
\text { esmaltes e lacas }\end{array}$ & 2071 & $1 \%$ & 219,3 & 153,7 & $70,1 \%$ \\
\hline $\begin{array}{l}\text { Fabricacao de impermeabilizan- } \\
\text { tes, solventes e produtos afins }\end{array}$ & 2073 & $1 \%$ & 24,6 & 17,6 & $71,7 \%$ \\
\hline Fabricacao de catalisadores & 2094 & $1 \%$ & 4,5 & 4,3 & $95,0 \%$ \\
\hline $\begin{array}{l}\text { Fabricacao de produtos quimicos } \\
\text { nao especificados anteriormente }\end{array}$ & 2099 & $1 \%$ & 570,8 & 419,0 & $73,4 \%$ \\
\hline $\begin{array}{l}\text { Fabricacao de produtos farmo- } \\
\text { quimicos }\end{array}$ & 2110 & $1 \%$ & 56,1 & 33,7 & $60,1 \%$ \\
\hline $\begin{array}{l}\text { Fabricacao de medicamentos } \\
\text { para uso humano }\end{array}$ & 2121 & $1 \%$ & 1097,5 & 421,0 & $38,4 \%$ \\
\hline $\begin{array}{l}\text { Fabricacao de medicamentos } \\
\text { para uso veterinario }\end{array}$ & 2122 & $1 \%$ & 89,9 & 41,1 & $45,7 \%$ \\
\hline $\begin{array}{l}\text { Fabricacao de preparacoes far- } \\
\text { maceuticas }\end{array}$ & 2123 & $1 \%$ & 10,1 & 3,7 & $37,1 \%$ \\
\hline $\begin{array}{l}\text { Fabricacao de pneumaticos e de } \\
\text { camarasdear }\end{array}$ & 2211 & $1 \%$ & 206,1 & 115,2 & $55,9 \%$ \\
\hline $\begin{array}{l}\text { Fabricacao de artefatos de bor- } \\
\text { racha nao especificados anterior- } \\
\text { mente }\end{array}$ & 2219 & $1 \%$ & 243,0 & 104,8 & $43,1 \%$ \\
\hline $\begin{array}{l}\text { Fabricacao de laminados planos } \\
\text { e tubulares de material plastico }\end{array}$ & 2221 & $1 \%$ & 90,0 & 57,8 & $64,2 \%$ \\
\hline $\begin{array}{l}\text { Fabricacao de embalagens de ma- } \\
\text { terial plastico }\end{array}$ & 2222 & $1 \%$ & 450,7 & 266,4 & $59,1 \%$ \\
\hline $\begin{array}{l}\text { Fabricacao de tubos e acessorios } \\
\text { de material plastico para uso na } \\
\text { construcao }\end{array}$ & 2223 & $1 \%$ & 89,1 & 59,2 & $66,5 \%$ \\
\hline $\begin{array}{l}\text { Fabricacao de artefatos de mate- } \\
\text { rial plastico nao especificados an- } \\
\text { teriormente }\end{array}$ & 2229 & $1 \%$ & 814,6 & 389,8 & $47,9 \%$ \\
\hline $\begin{array}{l}\text { Fabricacao de vidro plano e de } \\
\text { seguranca }\end{array}$ & 2311 & $1 \%$ & 100,3 & 53,3 & $53,1 \%$ \\
\hline $\begin{array}{l}\text { Fabricacao de embalagens de vi- } \\
\text { dro }\end{array}$ & 2312 & $1 \%$ & 47,7 & 24,2 & $50,7 \%$ \\
\hline Fabricacao de artigos de vidro & 2319 & $1 \%$ & 69,3 & 27,2 & $39,3 \%$ \\
\hline
\end{tabular}

Nota: *Contribuição em milhões de reais. Tabela de comparação das contribuições dos setores desonerados em cada um dos possíveis regimes. Alíq. CPRB aponta a alíquota dos setores no novo regime. $\frac{C P R B}{C P P}$ compara as contribuições no novo regime com aquelas no regime antigo. 


\begin{tabular}{|c|c|c|c|c|c|}
\hline \multirow[b]{2}{*}{ Descrição } & \multirow[b]{2}{*}{ CNAE } & \multirow[b]{2}{*}{ Alíq. CPRB } & \multicolumn{2}{|c|}{ Contribuição* } & \multirow[b]{2}{*}{$\frac{C P R B}{C P P}$} \\
\hline & & & $\mathrm{CPP}$ & CPRB & \\
\hline $\begin{array}{l}\text { Fabricacao de artefatos de con- } \\
\text { creto, cimento, fibrocimento, } \\
\text { gesso e materiais semelhantes }\end{array}$ & 2330 & $1 \%$ & 274,5 & 130,1 & $47,4 \%$ \\
\hline $\begin{array}{l}\text { Fabricacao de produtos cerami- } \\
\text { cos refratarios }\end{array}$ & 2341 & $1 \%$ & 60,6 & 21,5 & $35,5 \%$ \\
\hline $\begin{array}{l}\text { Fabricacao de produtos cerami- } \\
\text { cos naorefratarios para uso estru- } \\
\text { tural na construcao }\end{array}$ & 2342 & $1 \%$ & 224,8 & 94,5 & $42,0 \%$ \\
\hline $\begin{array}{l}\text { Fabricacao de produtos cerami- } \\
\text { cos naorefratarios nao especifica- } \\
\text { dos anteriormente }\end{array}$ & 2349 & $1 \%$ & 57,6 & 18,1 & $31,5 \%$ \\
\hline $\begin{array}{l}\text { Aparelhamento e outros traba- } \\
\text { lhos em pedras }\end{array}$ & 2391 & $1 \%$ & 56,1 & 11,4 & $20,3 \%$ \\
\hline Fabricacao de cal e gesso & 2392 & $1 \%$ & 35,7 & 19,2 & $53,9 \%$ \\
\hline $\begin{array}{l}\text { Fabricacao de produtos de mine- } \\
\text { rais naometalicos nao especifica- } \\
\text { dos anteriormente }\end{array}$ & 2399 & $1 \%$ & 91,0 & 51,5 & $56,6 \%$ \\
\hline Producao de ferrogusa & 2411 & $1 \%$ & 60,0 & 22,2 & $37,1 \%$ \\
\hline $\begin{array}{l}\text { Producao de semiacabados de } \\
\text { aco }\end{array}$ & 2421 & $1 \%$ & 42,4 & 15,8 & $37,4 \%$ \\
\hline $\begin{array}{l}\text { Producao de laminados planos de } \\
\text { aco }\end{array}$ & 2422 & $1 \%$ & 329,4 & 314,6 & $95,5 \%$ \\
\hline $\begin{array}{l}\text { Producao de laminados longos de } \\
\text { aco }\end{array}$ & 2423 & $1 \%$ & 525,8 & 429,9 & $81,8 \%$ \\
\hline $\begin{array}{l}\text { Producao de relaminados, trefi- } \\
\text { lados e perfilados de aco }\end{array}$ & 2424 & $1 \%$ & 101,4 & 79,2 & $78,1 \%$ \\
\hline $\begin{array}{l}\text { Producao de tubos de aco com } \\
\text { costura }\end{array}$ & 2431 & $1 \%$ & 122,4 & 94,2 & $76,9 \%$ \\
\hline $\begin{array}{l}\text { Producao de outros tubos de } \\
\text { ferro e aco }\end{array}$ & 2439 & $1 \%$ & 21,2 & 14,1 & $66,7 \%$ \\
\hline Fundicao de ferro e aco & 2451 & $1 \%$ & 254,9 & 65,3 & $25,6 \%$ \\
\hline $\begin{array}{l}\text { Fabricacao de estruturas metali- } \\
\text { cas }\end{array}$ & 2511 & $1 \%$ & 253,6 & 95,0 & $37,5 \%$ \\
\hline $\begin{array}{l}\text { Fabricacao de esquadrias de me- } \\
\text { tal }\end{array}$ & 2512 & $1 \%$ & 69,6 & 25,5 & $36,7 \%$ \\
\hline $\begin{array}{l}\text { Fabricacao de obras de caldeira- } \\
\text { ria pesada }\end{array}$ & 2513 & $1 \%$ & 102,5 & 19,9 & $19,5 \%$ \\
\hline $\begin{array}{l}\text { Fabricacao de tanques, reserva- } \\
\text { torios metalicos e caldeiras para } \\
\text { aquecimento central }\end{array}$ & 2521 & $1 \%$ & 35,6 & 13,6 & $38,3 \%$ \\
\hline
\end{tabular}

Nota: *Contribuição em milhões de reais. Tabela de comparação das contribuições dos setores desonerados em cada um dos possíveis regimes. Alíq. CPRB aponta a alíquota dos setores no novo regime. $\frac{C P R B}{C P P}$ compara as contribuições no novo regime com aquelas no regime antigo. 


\begin{tabular}{|c|c|c|c|c|c|}
\hline \multirow[b]{2}{*}{ Descrição } & \multirow[b]{2}{*}{ CNAE } & \multirow[b]{2}{*}{ Alíq. CPRB } & \multicolumn{2}{|c|}{ Contribuição* } & \multirow[b]{2}{*}{$\frac{C P R B}{C P P}$} \\
\hline & & & $\mathrm{CPP}$ & CPRB & \\
\hline $\begin{array}{l}\text { Fabricacao de caldeiras gerado- } \\
\text { ras de vapor, exceto para aque- } \\
\text { cimento central e para veiculos }\end{array}$ & 2522 & $1 \%$ & 33,4 & 13,0 & $38,9 \%$ \\
\hline $\begin{array}{l}\text { Producao de forjados de aco e de } \\
\text { metais naoferrosos e suas ligas }\end{array}$ & 2531 & $1 \%$ & 35,4 & 12,0 & $33,9 \%$ \\
\hline $\begin{array}{l}\text { Producao de artefatos estampa- } \\
\text { dos de metal e metalurgia do po }\end{array}$ & 2532 & $1 \%$ & 145,7 & 71,8 & $49,3 \%$ \\
\hline $\begin{array}{l}\text { Fabricacao de artigos de cutela- } \\
\text { ria }\end{array}$ & 2541 & $1 \%$ & 70,2 & 52,7 & $75,1 \%$ \\
\hline $\begin{array}{l}\text { Fabricacao de artigos de serra- } \\
\text { lheria, exceto esquadrias }\end{array}$ & 2542 & $1 \%$ & 72,9 & 29,5 & $40,5 \%$ \\
\hline Fabricacao de ferramentas & 2543 & $1 \%$ & 111,5 & 38,3 & $34,4 \%$ \\
\hline $\begin{array}{l}\text { Fabricacao de embalagens meta- } \\
\text { licas }\end{array}$ & 2591 & $1 \%$ & 142,5 & 126,0 & $88,4 \%$ \\
\hline $\begin{array}{l}\text { Fabricacao de produtos de trefi- } \\
\text { lados de metal }\end{array}$ & 2592 & $1 \%$ & 111,0 & 51,3 & $46,2 \%$ \\
\hline $\begin{array}{l}\text { Fabricacao de artigos de metal } \\
\text { para uso domestico e pessoal }\end{array}$ & 2593 & $1 \%$ & 53,2 & 27,0 & $50,8 \%$ \\
\hline $\begin{array}{l}\text { Fabricacao de produtos de metal } \\
\text { nao especificados anteriormente }\end{array}$ & 2599 & $1 \%$ & 385,0 & 191,1 & $49,6 \%$ \\
\hline $\begin{array}{l}\text { Fabricacao de componentes ele- } \\
\text { tronicos }\end{array}$ & 2610 & $1 \%$ & 163,9 & 100,1 & $61,1 \%$ \\
\hline $\begin{array}{l}\text { Fabricacao de equipamentos de } \\
\text { informatica }\end{array}$ & 2621 & $1 \%$ & 189,5 & 176,0 & $92,8 \%$ \\
\hline $\begin{array}{l}\text { Fabricacao de perifericos para } \\
\text { equipamentos de informatica }\end{array}$ & 2622 & $1 \%$ & 182,7 & 172,8 & $94,6 \%$ \\
\hline $\begin{array}{l}\text { Fabricacao de equipamentos } \\
\text { transmissores de comunicacao }\end{array}$ & 2631 & $1 \%$ & 96,4 & 44,8 & $46,5 \%$ \\
\hline $\begin{array}{l}\text { Fabricacao de aparelhos telefoni- } \\
\text { cos e de outros equipamentos de } \\
\text { comunicacao }\end{array}$ & 2632 & $1 \%$ & 58,5 & 42,7 & $73,1 \%$ \\
\hline $\begin{array}{l}\text { Fabricacao de aparelhos de re- } \\
\text { cepcao, reproducao, gravacao e } \\
\text { amplificacao de audio e video }\end{array}$ & 2640 & $1 \%$ & 217,8 & 281,9 & $129,4 \%$ \\
\hline $\begin{array}{l}\text { Fabricacao de aparelhos e equi- } \\
\text { pamentos de medida, teste e con- } \\
\text { trole }\end{array}$ & 2651 & $1 \%$ & 185,4 & 58,6 & $31,6 \%$ \\
\hline $\begin{array}{l}\text { Fabricacao de cronometros e re- } \\
\text { logios }\end{array}$ & 2652 & $1 \%$ & 26,0 & 11,8 & $45,7 \%$ \\
\hline $\begin{array}{l}\text { Fabricacao de aparelhos eletro- } \\
\text { medicos e eletroterapeuticos e } \\
\text { equipamentos de irradiacao }\end{array}$ & 2660 & $1 \%$ & 32,3 & 11,3 & $35,1 \%$ \\
\hline
\end{tabular}

Nota: ${ }^{*}$ Contribuição em milhões de reais. Tabela de comparação das contribuições dos setores desonerados em cada um dos possíveis regimes. Alíq. CPRB aponta a alíquota dos setores no novo regime. $\frac{C P R B}{C P P}$ compara as contribuições no novo regime com aquelas no regime antigo. 


\begin{tabular}{|c|c|c|c|c|c|}
\hline \multirow[b]{2}{*}{ Descrição } & \multirow[b]{2}{*}{ CNAE } & \multirow[b]{2}{*}{ Alíq. CPRB } & \multicolumn{2}{|c|}{ Contribuição* } & \multirow[b]{2}{*}{$\frac{C P R B}{C P P}$} \\
\hline & & & $\mathrm{CPP}$ & $\mathrm{CPRB}$ & \\
\hline $\begin{array}{l}\text { Fabricacao de equipamentos e } \\
\text { instrumentos opticos, fotografi- } \\
\text { cos e cinematograficos }\end{array}$ & 2670 & $1 \%$ & 15,4 & 5,7 & $37,3 \%$ \\
\hline $\begin{array}{l}\text { Fabricacao de geradores, trans- } \\
\text { formadores e motores eletricos }\end{array}$ & 2710 & $1 \%$ & 241,3 & 81,1 & $33,6 \%$ \\
\hline $\begin{array}{l}\text { Fabricacao de pilhas, baterias } \\
\text { e acumuladores eletricos, exceto } \\
\text { para veiculos automotores }\end{array}$ & 2721 & $1 \%$ & 10,4 & 7,1 & $67,9 \%$ \\
\hline $\begin{array}{l}\text { Fabricacao de baterias e acumu- } \\
\text { ladores para veiculos automoto- } \\
\text { res }\end{array}$ & 2722 & $1 \%$ & 45,0 & 21,7 & $48,2 \%$ \\
\hline $\begin{array}{l}\text { Fabricacao de aparelhos e equi- } \\
\text { pamentos para distribuicao e } \\
\text { controle de energia eletrica }\end{array}$ & 2731 & $1 \%$ & 263,4 & 103,4 & $39,3 \%$ \\
\hline $\begin{array}{l}\text { Fabricacao de material eletrico } \\
\text { para instalacoes em circuito de } \\
\text { consumo }\end{array}$ & 2732 & $1 \%$ & 58,1 & 26,3 & $45,4 \%$ \\
\hline $\begin{array}{l}\text { Fabricacao de fios, cabos e con- } \\
\text { dutores eletricos isolados }\end{array}$ & 2733 & $1 \%$ & 164,2 & 167,8 & $102,2 \%$ \\
\hline $\begin{array}{l}\text { Fabricacao de lampadas e outros } \\
\text { equipamentos de iluminacao }\end{array}$ & 2740 & $1 \%$ & 45,8 & 25,0 & $54,6 \%$ \\
\hline $\begin{array}{l}\text { Fabricacao de fogoes, refrigera- } \\
\text { dores e maquinas de lavar e secar } \\
\text { para uso domestico }\end{array}$ & 2751 & $1 \%$ & 289,4 & 151,7 & $52,4 \%$ \\
\hline $\begin{array}{l}\text { Fabricacao de aparelhos eletro- } \\
\text { domesticos nao especificados an- } \\
\text { teriormente }\end{array}$ & 2759 & $1 \%$ & 98,5 & 65,6 & $66,6 \%$ \\
\hline $\begin{array}{l}\text { Fabricacao de equipamentos e } \\
\text { aparelhos eletricos nao especifi- } \\
\text { cados anteriormente }\end{array}$ & 2790 & $1 \%$ & 187,8 & 80,4 & $42,8 \%$ \\
\hline $\begin{array}{l}\text { Fabricacao de motores e turbi- } \\
\text { nas, exceto para avioes e veiculos } \\
\text { rodoviarios }\end{array}$ & 2811 & $1 \%$ & 75,6 & 26,5 & $35,2 \%$ \\
\hline $\begin{array}{l}\text { Fabricacao de equipamentos hi- } \\
\text { draulicos e pneumaticos, exceto } \\
\text { valvulas }\end{array}$ & 2812 & $1 \%$ & 102,0 & 36,3 & $35,7 \%$ \\
\hline $\begin{array}{l}\text { Fabricacao de valvulas, registros } \\
\text { e dispositivos semelhantes }\end{array}$ & 2813 & $1 \%$ & 87,9 & 28,6 & $32,6 \%$ \\
\hline Fabricacao de compressores & 2814 & $1 \%$ & 80,3 & 32,6 & $40,7 \%$ \\
\hline $\begin{array}{l}\text { Fabricacao de equipamentos de } \\
\text { transmissao para fins industriais }\end{array}$ & 2815 & $1 \%$ & 86,6 & 28,9 & $33,5 \%$ \\
\hline
\end{tabular}

Nota: ${ }^{*}$ Contribuição em milhões de reais. Tabela de comparação das contribuições dos setores desonerados em cada um dos possíveis regimes. Alíq. CPRB aponta a alíquota dos setores no novo regime. $\frac{C P R B}{C P P}$ compara as contribuições no novo regime com aquelas no regime antigo. 


\begin{tabular}{|c|c|c|c|c|c|}
\hline \multirow[b]{2}{*}{ Descrição } & \multirow[b]{2}{*}{ CNAE } & \multirow[b]{2}{*}{ Alíq. CPRB } & \multicolumn{2}{|c|}{ Contribuição* } & \multirow[b]{2}{*}{$\frac{C P R B}{C P P}$} \\
\hline & & & $\mathrm{CPP}$ & CPRB & \\
\hline $\begin{array}{l}\text { Fabricacao de aparelhos e equi- } \\
\text { pamentos para instalacoes termi- } \\
\text { cas }\end{array}$ & 2821 & $1 \%$ & 32,6 & 12,6 & $38,9 \%$ \\
\hline $\begin{array}{l}\text { Fabricacao de maquinas, equipa- } \\
\text { mentos e aparelhos para trans- } \\
\text { porte e elevacao de cargas e pes- } \\
\text { soas }\end{array}$ & 2822 & $1 \%$ & 207,1 & 85,3 & $41,2 \%$ \\
\hline $\begin{array}{l}\text { Fabricacao de maquinas e apare- } \\
\text { lhos de refrigeracao e ventilacao } \\
\text { para uso industrial e comercial }\end{array}$ & 2823 & $1 \%$ & 97,2 & 51,3 & $52,8 \%$ \\
\hline $\begin{array}{l}\text { Fabricacao de aparelhos e equi- } \\
\text { pamentos de ar condicionado }\end{array}$ & 2824 & $1 \%$ & 52,8 & 56,4 & $106,9 \%$ \\
\hline $\begin{array}{l}\text { Fabricacao de maquinas e equi- } \\
\text { pamentos para saneamento ba- } \\
\text { sico e ambiental }\end{array}$ & 2825 & $1 \%$ & 21,4 & 7,5 & $35,2 \%$ \\
\hline $\begin{array}{l}\text { Fabricacao de maquinas e equi- } \\
\text { pamentos de uso geral nao espe- } \\
\text { cificados anteriormente }\end{array}$ & 2829 & $1 \%$ & 384,5 & 139,1 & $36,2 \%$ \\
\hline Fabricacao de tratores agricolas & 2831 & $1 \%$ & 71,3 & 61,3 & $86,1 \%$ \\
\hline $\begin{array}{l}\text { Fabricacao de equipamentos } \\
\text { para irrigacao agricola }\end{array}$ & 2832 & $1 \%$ & 12,5 & 11,5 & $91,8 \%$ \\
\hline $\begin{array}{l}\text { Fabricacao de maquinas e equi- } \\
\text { pamentos para a agricultura e } \\
\text { pecuaria, exceto para irrigacao }\end{array}$ & 2833 & $1 \%$ & 435,5 & 229,7 & $52,7 \%$ \\
\hline $\begin{array}{l}\text { Fabricacao de maquinasferra- } \\
\text { menta }\end{array}$ & 2840 & $1 \%$ & 139,3 & 40,8 & $29,3 \%$ \\
\hline $\begin{array}{l}\text { Fabricacao de maquinas e equi- } \\
\text { pamentos para a prospeccao e ex- } \\
\text { tracao de petroleo }\end{array}$ & 2851 & $1 \%$ & 116,0 & 39,9 & $34,4 \%$ \\
\hline $\begin{array}{l}\text { Fabricacao de outras maquinas e } \\
\text { equipamentos para uso na extra- } \\
\text { cao mineral, exceto na extracao } \\
\text { de petroleo }\end{array}$ & 2852 & $1 \%$ & 61,6 & 24,4 & $39,7 \%$ \\
\hline $\begin{array}{l}\text { Fabricacao de tratores, exceto } \\
\text { agricolas }\end{array}$ & 2853 & $1 \%$ & 85,1 & 43,3 & $50,9 \%$ \\
\hline $\begin{array}{l}\text { Fabricacao de maquinas e equi- } \\
\text { pamentos para terraplenagem, } \\
\text { pavimentacao e construcao, ex- } \\
\text { ceto tratores }\end{array}$ & 2854 & $1 \%$ & 120,2 & 106,7 & $88,7 \%$ \\
\hline $\begin{array}{l}\text { Fabricacao de maquinas para } \\
\text { a industria metalurgica, exceto } \\
\text { maquinasferramenta }\end{array}$ & 2861 & $1 \%$ & 28,6 & 10,9 & $38,1 \%$ \\
\hline
\end{tabular}

Nota: *Contribuição em milhões de reais. Tabela de comparação das contribuições dos setores desonerados em cada um dos possíveis regimes. Alíq. CPRB aponta a alíquota dos setores no novo regime. $\frac{C P R B}{C P P}$ compara as contribuições no novo regime com aquelas no regime antigo. 


\begin{tabular}{|c|c|c|c|c|c|}
\hline \multirow[b]{2}{*}{ Descrição } & \multirow[b]{2}{*}{ CNAE } & \multirow[b]{2}{*}{ Alíq. CPRB } & \multicolumn{2}{|c|}{ Contribuição* } & \multirow[b]{2}{*}{$\frac{C P R B}{C P P}$} \\
\hline & & & $\mathrm{CPP}$ & CPRB & \\
\hline $\begin{array}{l}\text { Fabricacao de maquinas e equi- } \\
\text { pamentos para as industrias de } \\
\text { alimentos, bebidas e fumo }\end{array}$ & 2862 & $1 \%$ & 124,7 & 45,7 & $36,7 \%$ \\
\hline $\begin{array}{l}\text { Fabricacao de maquinas e equi- } \\
\text { pamentos para a industria textil }\end{array}$ & 2863 & $1 \%$ & 14,2 & 4,2 & $29,8 \%$ \\
\hline $\begin{array}{l}\text { Fabricacao de maquinas e equi- } \\
\text { pamentos para as industrias do } \\
\text { vestuario, do couro e de calcados }\end{array}$ & 2864 & $1 \%$ & 15,6 & 6,0 & $39,1 \%$ \\
\hline $\begin{array}{l}\text { Fabricacao de maquinas e equi- } \\
\text { pamentos para as industrias de } \\
\text { celulose, papel e papelao e arte- } \\
\text { fatos }\end{array}$ & 2865 & $1 \%$ & 43,0 & 17,7 & $41,3 \%$ \\
\hline $\begin{array}{l}\text { Fabricacao de maquinas e equi- } \\
\text { pamentos para a industria do } \\
\text { plastico }\end{array}$ & 2866 & $1 \%$ & 11,3 & 3,7 & $33,3 \%$ \\
\hline $\begin{array}{l}\text { Fabricacao de maquinas e equi- } \\
\text { pamentos para uso industrial es- } \\
\text { pecifico nao especificados anteri- } \\
\text { ormente }\end{array}$ & 2869 & $1 \%$ & 370,9 & 115,1 & $31,0 \%$ \\
\hline $\begin{array}{l}\text { Fabricacao de automoveis, cami- } \\
\text { onetas e utilitarios }\end{array}$ & 2910 & $1 \%$ & 1390,7 & 1445,1 & $103,9 \%$ \\
\hline $\begin{array}{l}\text { Fabricacao de caminhoes e oni- } \\
\text { bus }\end{array}$ & 2920 & $1 \%$ & 501,8 & 414,4 & $82,6 \%$ \\
\hline $\begin{array}{l}\text { Fabricacao de cabines, carroce- } \\
\text { rias e reboques para veiculos au- } \\
\text { tomotores }\end{array}$ & 2930 & $1 \%$ & 352,7 & 161,9 & $45,9 \%$ \\
\hline $\begin{array}{l}\text { Fabricacao de pecas e acessorios } \\
\text { para o sistema motor de veiculos } \\
\text { automotores }\end{array}$ & 2941 & $1 \%$ & 407,4 & 142,2 & $34,9 \%$ \\
\hline $\begin{array}{l}\text { Fabricacao de pecas e acessorios } \\
\text { para os sistemas de marcha e } \\
\text { transmissao de veiculos automo- } \\
\text { tores }\end{array}$ & 2942 & $1 \%$ & 93,6 & 35,9 & $38,3 \%$ \\
\hline $\begin{array}{l}\text { Fabricacao de pecas e acessorios } \\
\text { para o sistema de freios de veicu- } \\
\text { los automotores }\end{array}$ & 2943 & $1 \%$ & 139,7 & 64,0 & $45,8 \%$ \\
\hline $\begin{array}{l}\text { Fabricacao de pecas e acessorios } \\
\text { para o sistema de direcao e sus- } \\
\text { pensao de veiculos automotores }\end{array}$ & 2944 & $1 \%$ & 111,9 & 59,6 & $53,3 \%$ \\
\hline $\begin{array}{l}\text { Fabricacao de material eletrico e } \\
\text { eletronico para veiculos automo- } \\
\text { tores, exceto baterias }\end{array}$ & 2945 & $1 \%$ & 179,7 & 70,2 & $39,1 \%$ \\
\hline
\end{tabular}

Nota: *Contribuição em milhões de reais. Tabela de comparação das contribuições dos setores desonerados em cada um dos possíveis regimes. Alíq. CPRB aponta a alíquota dos setores no novo regime. $\frac{C P R B}{C P P}$ compara as contribuições no novo regime com aquelas no regime antigo. 


\begin{tabular}{|c|c|c|c|c|c|}
\hline \multirow[b]{2}{*}{ Descrição } & \multirow[b]{2}{*}{ CNAE } & \multirow[b]{2}{*}{ Alíq. CPRB } & \multicolumn{2}{|c|}{ Contribuição* } & \multirow[b]{2}{*}{$\frac{C P R B}{C P P}$} \\
\hline & & & $\mathrm{CPP}$ & CPRB & \\
\hline $\begin{array}{l}\text { Fabricacao de pecas e acessorios } \\
\text { para veiculos automotores nao } \\
\text { especificados anteriormente }\end{array}$ & 2949 & $1 \%$ & 1443,5 & 733,3 & $50,8 \%$ \\
\hline $\begin{array}{l}\text { Construcao de embarcacoes e es- } \\
\text { truturas flutuantes }\end{array}$ & 3011 & $1 \%$ & 505,4 & 118,9 & $23,5 \%$ \\
\hline $\begin{array}{l}\text { Construcao de embarcacoes para } \\
\text { esporte e lazer }\end{array}$ & 3012 & $1 \%$ & 18,1 & 5,5 & $30,8 \%$ \\
\hline $\begin{array}{l}\text { Fabricacao de locomotivas, va- } \\
\text { goes e outros materiais rodantes }\end{array}$ & 3031 & $1 \%$ & 32,2 & 16,1 & $50,2 \%$ \\
\hline $\begin{array}{l}\text { Fabricacao de pecas e acessorios } \\
\text { para veiculos ferroviarios }\end{array}$ & 3032 & $1 \%$ & 14,4 & 5,4 & $37,5 \%$ \\
\hline Fabricacao de aeronaves & 3041 & $1 \%$ & 340,7 & 105,7 & $31,0 \%$ \\
\hline $\begin{array}{l}\text { Fabricacao de turbinas, motores } \\
\text { e outros componentes e pecas } \\
\text { para aeronaves }\end{array}$ & 3042 & $1 \%$ & 25,0 & 2,6 & $10,6 \%$ \\
\hline Fabricacao de motocicletas & 3091 & $1 \%$ & 146,0 & 128,5 & $88,0 \%$ \\
\hline $\begin{array}{l}\text { Fabricacao de bicicletas e trici- } \\
\text { clos naomotorizados }\end{array}$ & 3092 & $1 \%$ & 28,2 & 15,3 & $54,2 \%$ \\
\hline $\begin{array}{l}\text { Fabricacao de equipamentos de } \\
\text { transporte nao especificados an- } \\
\text { teriormente }\end{array}$ & 3099 & $1 \%$ & 27,8 & 14,9 & $53,7 \%$ \\
\hline $\begin{array}{l}\text { Fabricacao de moveis com predo- } \\
\text { minancia de madeira }\end{array}$ & 3101 & $1 \%$ & 420,1 & 179,0 & $42,6 \%$ \\
\hline $\begin{array}{l}\text { Fabricacao de moveis com predo- } \\
\text { minancia de metal }\end{array}$ & 3102 & $1 \%$ & 109,1 & 53,2 & $48,8 \%$ \\
\hline $\begin{array}{l}\text { Fabricacao de moveis de outros } \\
\text { materiais, exceto madeira e me- } \\
\text { tal }\end{array}$ & 3103 & $1 \%$ & 12,0 & 3,9 & $32,7 \%$ \\
\hline Fabricacao de colchoes & 3104 & $1 \%$ & 108,1 & 53,2 & $49,2 \%$ \\
\hline $\begin{array}{l}\text { Fabricacao de artefatos para } \\
\text { pesca e esporte }\end{array}$ & 3230 & $1 \%$ & 7,0 & 3,9 & $56,1 \%$ \\
\hline $\begin{array}{l}\text { Fabricacao de brinquedos e jogos } \\
\text { recreativos }\end{array}$ & 3240 & $1 \%$ & 45,5 & 23,4 & $51,5 \%$ \\
\hline $\begin{array}{l}\text { Fabricacao de instrumentos e } \\
\text { materiais para uso medico e } \\
\text { odontologico e de artigos opticos }\end{array}$ & 3250 & $1 \%$ & 248,5 & 96,4 & $38,8 \%$ \\
\hline $\begin{array}{l}\text { Fabricacao de escovas, pinceis e } \\
\text { vassouras }\end{array}$ & 3291 & $1 \%$ & 28,2 & 13,8 & $49,1 \%$ \\
\hline $\begin{array}{l}\text { Fabricacao de equipamentos e } \\
\text { acessorios para seguranca e pro- } \\
\text { tecao pessoal e profissional }\end{array}$ & 3292 & $1 \%$ & 43,3 & 23,2 & $53,7 \%$ \\
\hline
\end{tabular}

Nota: *Contribuição em milhões de reais. Tabela de comparação das contribuições dos setores desonerados em cada um dos possíveis regimes. Alíq. CPRB aponta a alíquota dos setores no novo regime. $\frac{C P R B}{C P P}$ compara as contribuições no novo regime com aquelas no regime antigo. 


\begin{tabular}{|c|c|c|c|c|c|}
\hline \multirow[b]{2}{*}{ Descrição } & \multirow[b]{2}{*}{ CNAE } & \multirow[b]{2}{*}{ Alíq. CPRB } & \multicolumn{2}{|c|}{ Contribuição* } & \multirow[b]{2}{*}{$\frac{C P R B}{C P P}$} \\
\hline & & & $\mathrm{CPP}$ & CPRB & \\
\hline $\begin{array}{l}\text { Fabricacao de produtos diversos } \\
\text { nao especificados anteriormente }\end{array}$ & 3299 & $1 \%$ & 91,5 & 32,1 & $35,1 \%$ \\
\hline $\begin{array}{l}\text { Manutencao e reparacao de aero- } \\
\text { naves }\end{array}$ & 3316 & $1 \%$ & 83,8 & 18,2 & $21,7 \%$ \\
\hline $\begin{array}{l}\text { Recuperacao de materiais meta- } \\
\text { licos }\end{array}$ & 3831 & $1 \%$ & 32,2 & 17,9 & $55,8 \%$ \\
\hline Construcao de edificios & 4120 & $2 \%$ & 3583,9 & 1886,3 & $52,6 \%$ \\
\hline Instalacoes eletricas & 4321 & $2 \%$ & 469,4 & 176,3 & $37,5 \%$ \\
\hline $\begin{array}{l}\text { Instalacoes hidraulicas, de siste- } \\
\text { mas de ventilacao e refrigeracao }\end{array}$ & 4322 & $2 \%$ & 170,7 & 88,2 & $51,7 \%$ \\
\hline $\begin{array}{l}\text { Obras de instalacoes em constru- } \\
\text { coes nao especificadas anterior- } \\
\text { mente }\end{array}$ & 4329 & $2 \%$ & 284,0 & 136,0 & $47,9 \%$ \\
\hline Obras de acabamento & 4330 & $2 \%$ & 215,2 & 95,6 & $44,4 \%$ \\
\hline Obras de fundacoes & 4391 & $2 \%$ & 118,8 & 57,9 & $48,7 \%$ \\
\hline $\begin{array}{l}\text { Servicos especializados para } \\
\text { construcao nao especificados } \\
\text { anteriormente }\end{array}$ & 4399 & $2 \%$ & 377,5 & 169,9 & $45,0 \%$ \\
\hline $\begin{array}{l}\text { Comercio varejista de mercado- } \\
\text { rias em geral, sem predominancia } \\
\text { de produtos alimenticios }\end{array}$ & 4713 & $1 \%$ & 504,9 & 352,3 & $69,8 \%$ \\
\hline $\begin{array}{l}\text { Comercio varejista de ferragens, } \\
\text { madeira e materiais de constru- } \\
\text { cao }\end{array}$ & 4744 & $1 \%$ & 1173,3 & 815,2 & $69,5 \%$ \\
\hline $\begin{array}{l}\text { Comercio varejista especializado } \\
\text { de equipamentos e suprimentos } \\
\text { de informatica }\end{array}$ & 4751 & $1 \%$ & 208,9 & 109,8 & $52,6 \%$ \\
\hline $\begin{array}{l}\text { Comercio varejista especializado } \\
\text { de equipamentos de telefonia e } \\
\text { comunicacao }\end{array}$ & 4752 & $1 \%$ & 83,8 & 38,7 & $46,2 \%$ \\
\hline $\begin{array}{l}\text { Comercio varejista especializado } \\
\text { de eletrodomesticos e equipa- } \\
\text { mentos de audio e video }\end{array}$ & 4753 & $1 \%$ & 839,2 & 602,0 & $71,7 \%$ \\
\hline $\begin{array}{l}\text { Comercio varejista especializado } \\
\text { de moveis, colchoaria e artigos de } \\
\text { iluminacao }\end{array}$ & 4754 & $1 \%$ & 340,4 & 182,9 & $53,7 \%$ \\
\hline $\begin{array}{l}\text { Comercio varejista especializado } \\
\text { de tecidos e artigos de cama, } \\
\text { mesa e banho }\end{array}$ & 4755 & $1 \%$ & 73,5 & 42,4 & $57,6 \%$ \\
\hline $\begin{array}{l}\text { Comercio varejista de artigos de } \\
\text { uso domestico nao especificados } \\
\text { anteriormente }\end{array}$ & 4759 & $1 \%$ & 61,5 & 43,5 & $70,6 \%$ \\
\hline
\end{tabular}

Nota: *Contribuição em milhões de reais. Tabela de comparação das contribuições dos setores desonerados em cada um dos possíveis regimes. Alíq. CPRB aponta a alíquota dos setores no novo regime. $\frac{C P R B}{C P P}$ compara as contribuições no novo regime com aquelas no regime antigo. 


\begin{tabular}{|c|c|c|c|c|c|}
\hline \multirow[b]{2}{*}{ Descrição } & \multirow[b]{2}{*}{ CNAE } & \multirow[b]{2}{*}{ Alíq. CPRB } & \multicolumn{2}{|c|}{ Contribuição* } & \multirow[b]{2}{*}{$\frac{C P R B}{C P P}$} \\
\hline & & & $\mathrm{CPP}$ & CPRB & \\
\hline $\begin{array}{l}\text { Comercio varejista de livros, jor- } \\
\text { nais, revistas e papelaria }\end{array}$ & 4761 & $1 \%$ & 130,2 & 74,4 & $57,2 \%$ \\
\hline $\begin{array}{l}\text { Comercio varejista de discos, } \\
\text { CDs, DVDs e fitas }\end{array}$ & 4762 & $1 \%$ & 5,1 & 5,3 & $102,0 \%$ \\
\hline $\begin{array}{l}\text { Comercio varejista de artigos re- } \\
\text { creativos e esportivos }\end{array}$ & 4763 & $1 \%$ & 244,3 & 179,2 & $73,3 \%$ \\
\hline $\begin{array}{l}\text { Comercio varejista de produtos } \\
\text { farmaceuticos para uso humano } \\
\text { e veterinario }\end{array}$ & 4771 & $1 \%$ & 642,3 & 361,1 & $56,2 \%$ \\
\hline $\begin{array}{l}\text { Comercio varejista de cosmeti- } \\
\text { cos, produtos de perfumaria e de } \\
\text { higiene pessoal }\end{array}$ & 4772 & $1 \%$ & 140,7 & 93,9 & $66,7 \%$ \\
\hline $\begin{array}{l}\text { Comercio varejista de artigos do } \\
\text { vestuario e acessorios }\end{array}$ & 4781 & $1 \%$ & 719,4 & 376,6 & $52,4 \%$ \\
\hline $\begin{array}{l}\text { Comercio varejista de calcados e } \\
\text { artigos de viagem }\end{array}$ & 4782 & $1 \%$ & 250,2 & 116,5 & $46,6 \%$ \\
\hline $\begin{array}{l}\text { Comercio varejista de outros pro- } \\
\text { dutos novos nao especificados an- } \\
\text { teriormente }\end{array}$ & 4789 & $1 \%$ & 43,9 & 40,4 & $92,0 \%$ \\
\hline Transporte ferroviario de carga & 4911 & $1 \%$ & 168,6 & 117,4 & $69,6 \%$ \\
\hline $\begin{array}{l}\text { Transporte metroferroviario de } \\
\text { passageiros }\end{array}$ & 4912 & $2 \%$ & 418,8 & 96,8 & $23,1 \%$ \\
\hline $\begin{array}{l}\text { Transporte rodoviario coletivo de } \\
\text { passageiros, com itinerario fixo, } \\
\text { municipal e em regiao metropo- } \\
\text { litana }\end{array}$ & 4921 & $2 \%$ & 1857,7 & 640,2 & $34,5 \%$ \\
\hline $\begin{array}{l}\text { Transporte rodoviario coletivo de } \\
\text { passageiros, com itinerario fixo, } \\
\text { intermunicipal, interestadual e } \\
\text { internacional }\end{array}$ & 4922 & $2 \%$ & 553,9 & 263,1 & $47,5 \%$ \\
\hline Transporte rodoviario de carga & 4930 & $1 \%$ & 2971,0 & 1390,2 & $46,8 \%$ \\
\hline $\begin{array}{l}\text { Transporte maritimo de cabota- } \\
\text { gem }\end{array}$ & 5011 & $1 \%$ & 149,1 & 103,1 & $69,2 \%$ \\
\hline $\begin{array}{l}\text { Transporte maritimo de longo } \\
\text { curso }\end{array}$ & 5012 & $1 \%$ & 43,0 & 16,0 & $37,2 \%$ \\
\hline $\begin{array}{l}\text { Transporte por navegacao inte- } \\
\text { rior de carga }\end{array}$ & 5021 & $1 \%$ & 64,1 & 23,6 & $36,9 \%$ \\
\hline $\begin{array}{l}\text { Transporte por navegacao inte- } \\
\text { rior de passageiros em linhas re- } \\
\text { gulares }\end{array}$ & 5022 & $1 \%$ & 3,5 & 0,5 & $16,1 \%$ \\
\hline Navegacao de apoio & 5030 & $1 \%$ & 580,1 & 118,1 & $20,4 \%$ \\
\hline
\end{tabular}

Nota: *Contribuição em milhões de reais. Tabela de comparação das contribuições dos setores desonerados em cada um dos possíveis regimes. Alíq. CPRB aponta a alíquota dos setores no novo regime. $\frac{C P R B}{C P P}$ compara as contribuições no novo regime com aquelas no regime antigo. 


\begin{tabular}{|c|c|c|c|c|c|}
\hline \multirow[b]{2}{*}{ Descrição } & \multirow[b]{2}{*}{ CNAE } & \multirow[b]{2}{*}{ Alíq. CPRB } & \multicolumn{2}{|c|}{ Contribuição* } & \multirow[b]{2}{*}{$\frac{C P R B}{C P P}$} \\
\hline & & & $\mathrm{CPP}$ & CPRB & \\
\hline $\begin{array}{l}\text { Transporte aereo de passageiros } \\
\text { regular }\end{array}$ & 5111 & $1 \%$ & 703,4 & 286,5 & $40,7 \%$ \\
\hline Transporte aereo de carga & 5120 & $1 \%$ & 28,8 & 18,3 & $63,6 \%$ \\
\hline Carga e descarga & 5212 & $1 \%$ & 110,8 & 35,6 & $32,2 \%$ \\
\hline Gestao de portos e terminais & 5231 & $1 \%$ & 307,7 & 127,3 & $41,4 \%$ \\
\hline Edicao de livros & 5811 & $1 \%$ & 141,4 & 54,0 & $38,2 \%$ \\
\hline Edicao de jornais & 5812 & $1 \%$ & 84,5 & 19,6 & $23,2 \%$ \\
\hline Edicao de revistas & 5813 & $1 \%$ & 28,5 & 12,1 & $42,7 \%$ \\
\hline $\begin{array}{l}\text { Edicao integrada a impressao de } \\
\text { jornais }\end{array}$ & 5822 & $1 \%$ & 224,2 & 44,6 & $19,9 \%$ \\
\hline $\begin{array}{l}\text { Edicao integrada a impressao de } \\
\text { revistas }\end{array}$ & 5823 & $1 \%$ & 90,4 & 24,6 & $27,2 \%$ \\
\hline Atividades de radio & 6010 & $1 \%$ & 96,6 & 22,5 & $23,3 \%$ \\
\hline Atividades de televisao aberta & 6021 & $1 \%$ & 719,2 & 215,1 & $29,9 \%$ \\
\hline $\begin{array}{l}\text { Desenvolvimento de programas } \\
\text { de computador sob encomenda }\end{array}$ & 6201 & $2 \%$ & 1000,8 & 377,7 & $37,7 \%$ \\
\hline $\begin{array}{l}\text { Desenvolvimento e licenciamento } \\
\text { de programas de computador } \\
\text { customizaveis }\end{array}$ & 6202 & $2 \%$ & 244,1 & 101,1 & $41,4 \%$ \\
\hline $\begin{array}{l}\text { Desenvolvimento e licenciamento } \\
\text { de programas de computador na- } \\
\text { ocustomizaveis }\end{array}$ & 6203 & $2 \%$ & 382,0 & 154,6 & $40,5 \%$ \\
\hline $\begin{array}{l}\text { Consultoria em tecnologia da in- } \\
\text { formacao }\end{array}$ & 6204 & $2 \%$ & 864,0 & 364,8 & $42,2 \%$ \\
\hline $\begin{array}{l}\text { Suporte tecnico, manutencao e } \\
\text { outros servicos em tecnologia da } \\
\text { informacao }\end{array}$ & 6209 & $2 \%$ & 511,4 & 279,8 & $54,7 \%$ \\
\hline $\begin{array}{l}\text { Tratamento de dados, provedores } \\
\text { de servicos de aplicacao e servi- } \\
\text { cos de hospedagem na internet }\end{array}$ & 6311 & $2 \%$ & 414,7 & 174,5 & $42,1 \%$ \\
\hline $\begin{array}{l}\text { Portais, provedores de conteudo } \\
\text { e outros servicos de informacao } \\
\text { na internet }\end{array}$ & 6319 & $1 \%$ & 130,6 & 61,5 & $47,1 \%$ \\
\hline Atividades de teleatendimento & 8220 & $2 \%$ & 1104,5 & 290,9 & $26,3 \%$ \\
\hline $\begin{array}{l}\text { Manutencao e reparacao de em- } \\
\text { barcacoes }\end{array}$ & 3317 & $1 \%$ & 17,9 & 2,8 & $15,7 \%$ \\
\hline
\end{tabular}

Nota: *Contribuição em milhões de reais. Tabela de comparação das contribuições dos setores desonerados em cada um dos possíveis regimes. Alíq. CPRB aponta a alíquota dos setores no novo regime. $\frac{C P R B}{C P P}$ compara as contribuições no novo regime com aquelas no regime antigo. 


\section{ANEXO C - Lista de Setores Analisáveis Mantidos pela MP 774}

Tabela 28 - Lista de Setores Mantidos pela MP 774 e "Analisáveis"

\begin{tabular}{|c|c|c|}
\hline Grupo & Classe & Descrição \\
\hline 41 & 41204 & Construcao de edificios \\
\hline 49 & 49124 & Transporte metroferroviario de passageiros \\
\hline 49 & 49213 & $\begin{array}{l}\text { Transporte rodoviario coletivo de passageiros, } \\
\text { com itinerario fixo, municipal e em regiao metro- } \\
\text { politana }\end{array}$ \\
\hline 49 & 49221 & $\begin{array}{l}\text { Transporte rodoviario coletivo de passageiros, } \\
\text { com itinerario fixo, intermunicipal, interestadual } \\
\text { e internacional }\end{array}$ \\
\hline 18 & 18113 & $\begin{array}{l}\text { Impressao de jornais, livros, revistas e outras pu- } \\
\text { blicacoes periodicas }\end{array}$ \\
\hline 58 & 58115 & Edicao de livros \\
\hline 58 & 58123 & Edicao de jornais \\
\hline 58 & 58131 & Edicao de revistas \\
\hline 58 & 58221 & Edicao integrada a impressao de jornais \\
\hline 58 & 58239 & Edicao integrada a impressao de revistas \\
\hline 60 & 60225 & $\begin{array}{l}\text { Programadoras e atividades relacionadas a televi- } \\
\text { sao por assinatura }\end{array}$ \\
\hline 60 & 60101 & Atividades de radio \\
\hline 60 & 60217 & Atividades de televisao aberta \\
\hline 63 & 63194 & $\begin{array}{l}\text { Portais, provedores de conteudo e outros servicos } \\
\text { de informacao na internet }\end{array}$ \\
\hline
\end{tabular}

Nota: Lista de setores que são "analisáveis" (possuem tanto desonerados quanto controles dentro de um mesmo grupo) e que foram mantidos pela MP 774 . 